\title{
DOE Hydropower Program Biennial Report for FY 2005-2006
}

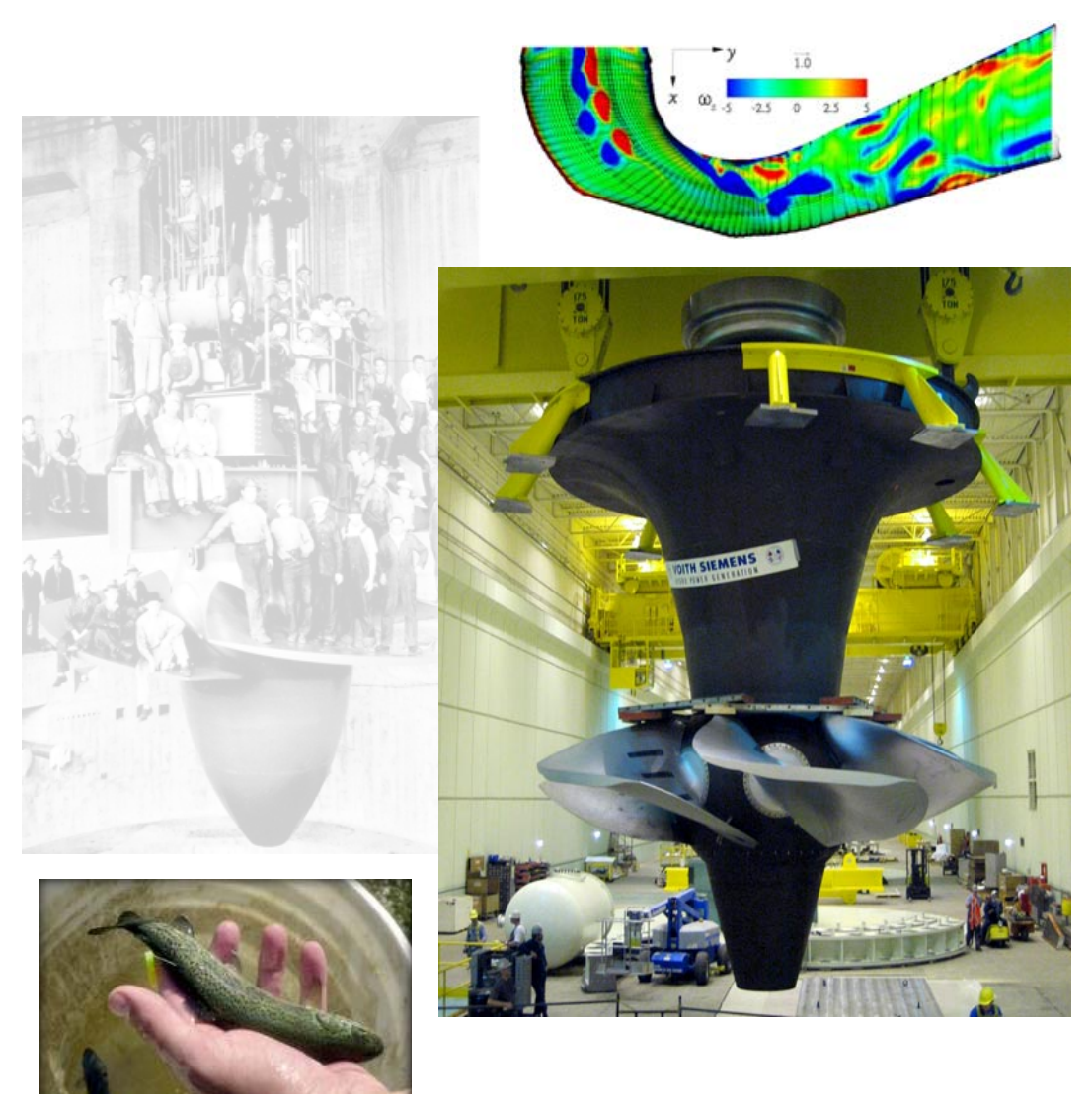

\section{U.S. Department of Energy \\ Energy Efficiency and Renewable Energy \\ Wind and Hydropower Technologies}

Bringing you a prosperous future where energy is clean, abundant, reliable, and affordable. 


\section{DOCUMENT AVAILABILITY}

Reports produced after January 1, 1996, are generally available free via the U.S. Department of Energy (DOE) Information Bridge.

Web site http://www.osti.gov/bridge

Reports produced before January 1, 1996, may be purchased by members of the public from the following source.

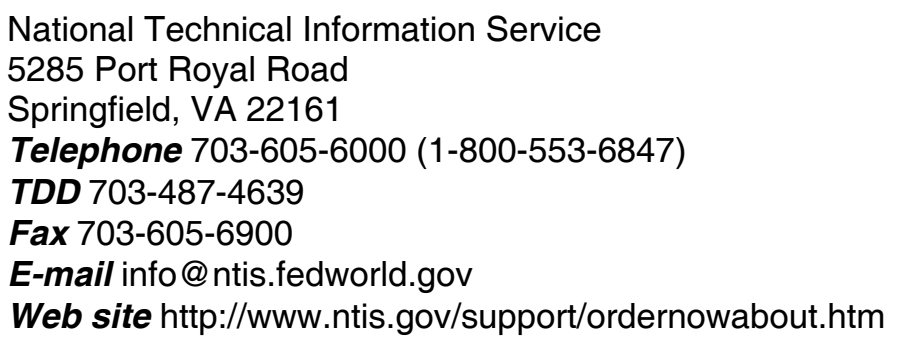

Reports are available to DOE employees, DOE contractors, Energy Technology Data Exchange (ETDE) representatives, and International Nuclear Information System (INIS) representatives from the following source.

Office of Scientific and Technical Information

P.O. Box 62

Oak Ridge, TN 37831

Telephone 865-576-8401

Fax 865-576-5728

E-mail reports@adonis.osti.gov

Web site http://www.osti.gov/contact.html

This report was prepared as an account of work sponsored by an agency of the United States Government. Neither the United States Government nor any agency thereof, nor any of their employees, makes any warranty, express or implied, or assumes any legal liability or responsibility for the accuracy, completeness, or usefulness of any information, apparatus, product, or process disclosed, or represents that its use would not infringe privately owned rights. Reference herein to any specific commercial product, process, or service by trade name, trademark, manufacturer, or otherwise, does not necessarily constitute or imply its endorsement, recommendation, or favoring by the United States Government or any agency thereof. The views and opinions of authors expressed herein do not necessarily state or reflect those of the United States Government or any agency thereof. 


\title{
DOE Hydropower Program Biennial Report for FY 2005-2006
}

\author{
Michael J. Sale ${ }^{1}$ \\ Glenn F. Cada ${ }^{1}$ \\ Thomas L. Acker ${ }^{2}$ \\ Thomas Carlson ${ }^{3}$ \\ Dennis D. Dauble ${ }^{3}$ \\ Douglas G. Hall ${ }^{4}$
}

Date Published: July 2006

\begin{abstract}
Prepared for
U.S. Department of Energy

Office of Energy Efficiency and Renewable Energy

Wind and Hydropower Technologies
\end{abstract}

\footnotetext{
${ }^{1}$ Oak Ridge National Laboratory

${ }^{2}$ Northern Arizona State University and National Renewable Energy Laboratory

${ }^{3}$ Pacific Northwest National Laboratory

${ }^{4}$ Idaho National Laboratory
} 



\section{CONTENTS}

CONTENTS. .iii

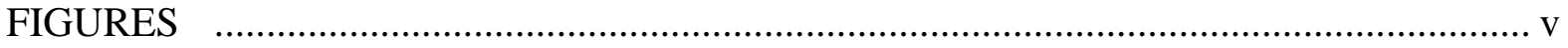

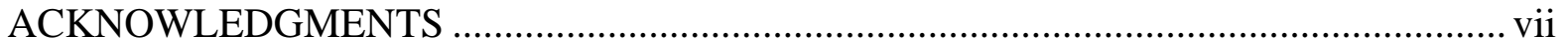

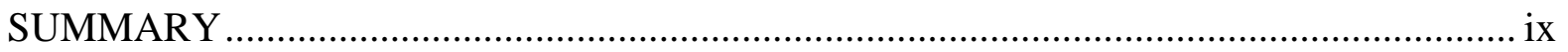

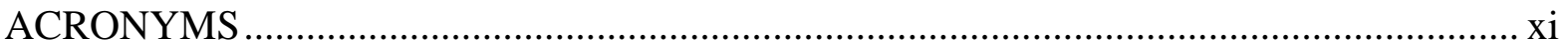

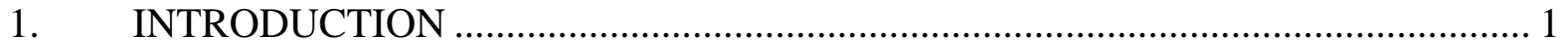

1.1 Hydropower in the United States........................................................... 1

1.2 The Department of Energy’s Hydropower Program.......................................... 1

1.2.1 Mission, Goals, and Activities .............................................................. 3

1.2.2 Program Management......................................................................... 4

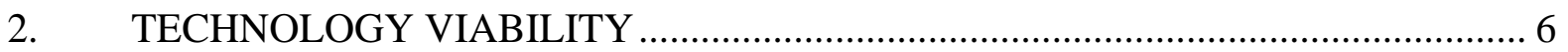

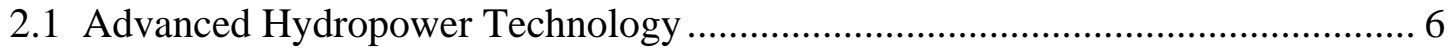

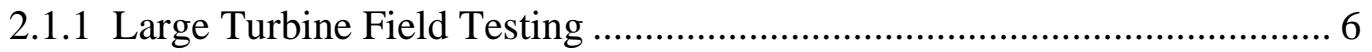

2.1.2 Water Use Optimization ............................................................... 11

2.1.3 Improved Mitigation Practices................................................................ 15

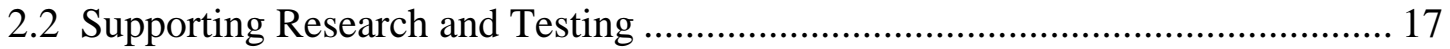

2.2.1 Environmental Performance Testing Methods .................................... 17

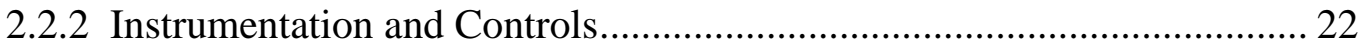

2.2.3 Computational and Physical Modeling .................................................. 25

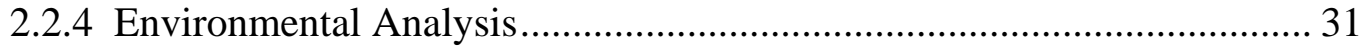

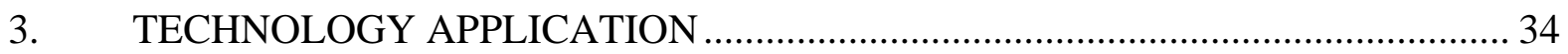

3.1 Systems Integration and Technology Acceptance .......................................... 34

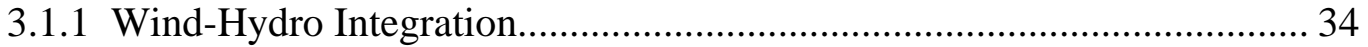

3.1.2 National Hydropower Collaborative................................................. 41

3.1.3 Integration and Communication ..................................................... 43

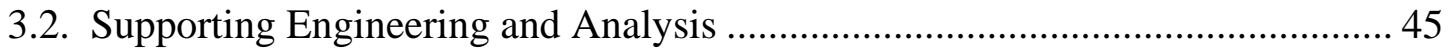

3.2.1 Valuation Methods and Assessments.................................................... 45

3.2.2 Characterization of Innovative Technology ......................................... 46

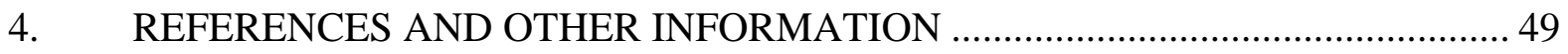

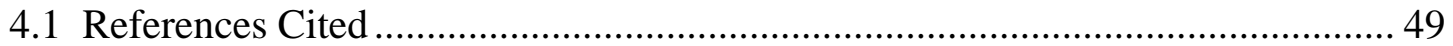

4.2 Other Publications and Presentations................................................................ 52 



\section{FIGURES}

Page

Figure 1- 1. Historical variability of annual hydropower generation from conventional plants in the U.S

Figure 1- 2. Organization of activities in the U.S. Department of Energy Hydropower

Program

Figure 2- 1. Comparison of the conventional (left/blue) and new (right/orange) MGR turbines at Wanapum Dam on the Columbia River, Washington.

Figure 2- 2. New aerating runner installed in Unit 3 at the Osage Project, Missouri.

Figure 2- 3. Observational 1:25-scale physical model of the Ice Harbor turbine at the U.S.

Army Engineering Research and Development Center, Vicksburg, MS.

Figure 2- 4. Examples of the five main types of surface flow outlets for juvenile salmonids.

Figure 2- 5. Observation tank and hi-speed camera used to record C-start behavior in turbinepassed fish at the Wanapum Dam, Washington.

Figure 2- 6. A comparison of juvenile Chinook salmon cortisol levels after passing through the old Kaplan turbine (Unit 9) or the new MGR turbine (Unit 8) at Wanapum Dam.

Figure 2- 7 Damage to the eye was easily identifiable with the dye, even though quite invisible under normal fish injury evaluation conditions.

Figure 2- 8. Turbine passage rate of change vs. nadir for Ice Harbor, John Day, and Bonneville II Test Turbines

Figure 2- 9. Illustration of different zones used for detailed Sensor Fish data analysis

Figure 2- 10. Comparison of probabilities of severe events recorded by sensor fish in different regions of the existing (unit 9) and new MGR turbines unit (unit 8) at Wanapum Dam.

Figure 2- 11. Snapshots of computed instantaneous flow at the operation point II: (upper left) streamwise velocity contours and swirling velocity vectors at a plane just downstream of the inlet; (upper right) streamwise velocity contours and cross-velocity vectors at the outlet; and vorticity and velocity vectors and vorticity contours at the vertical center (x-y) plane. 


\section{FIGURES (cont'd)}

Page

Figure 2- 12. Snapshots of VSF at two different instants in time (operation point II). Ten different colors of VSF are used to mark the different 10 release times at the inlet plane

Figure 3- 1. A conceptual view of integrating wind and hydropower facilities within a transmission balancing area.

Figure 3- 2. One-hour generation changes of a $100 \mathrm{MW}$ wind farm located in one area versus spread out geographically.

Figure 3- 3. Hourly generation changes of Grant County's request to their generators including load, sales and purchases, and 0,12 (actual), 63.7, and $150 \mathrm{MW}$

of wind energy.

Figure 3- 4. Examples of hydrokinetic and ocean energy conversion technologies considered at the DOE sponsored workshop

Figure 3- 5. Power class distribution of feasible potential projects and their associated total hydropower potential with low power projects further divided by low power technology classes.

Figure 3- 6. Virtual Hydropower Prospector Internet GIS application a) hydrologic region selector and b) application desktop. 


\section{ACKNOWLEDGMENTS}

The authors of this Biennial Report acknowledge the contributions of numerous other researchers who have been involved in DOE Hydropower Program activities: Marshall Adams, Mark

Bevelhimer, Yetta Jager, Jim Loar, Gail Morris, Kitty McCracken, Mike Ryon and Brennan Smith (Oak Ridge National Laboratory), Brooks Fost (Oak Ridge Institute for Science and Education), Fotis Sotiropoulos and Joongcheol Paik, (The University of Minnesota, St. Anthony Falls Laboratory); Zhiqun Deng, Gene Ploskey, Marshall Richmond, John Serkowski, William Perkins, Cynthia Rakowski, Russ Moursund, Tim Hanrahan, Gary Johnson, and Kenneth Ham (Pacific Northwest National Laboratory) and Brian Parsons (National Renewable Energy Laboratory). The support of Stan Calvert, Peter Goldman and Jim Ahlgrimm of the U.S. Department of Energy Office of Wind and Hydropower Technologies is greatly appreciated. 



\section{SUMMARY}

The U.S. Department of Energy (DOE) Hydropower Program is part of the Office of Wind and Hydropower Technologies, Office of Energy Efficiency and Renewable Energy. The Program's mission is to conduct research and development $(R \& D)$ that will increase the technical, societal, and environmental benefits of hydropower. The Department's Hydropower Program activities are conducted by its national laboratories: Idaho National Laboratory (INL) [formerly Idaho National Engineering and Environmental Laboratory], Oak Ridge National Laboratory (ORNL), Pacific Northwest National Laboratory (PNNL), and National Renewable Energy Laboratory (NREL), and by a number of industry, university, and federal research facilities. Programmatically, DOE Hydropower Program R\&D activities are conducted in two areas: Technology Viability and Technology Application. The Technology Viability area has two components: (1) Advanced Hydropower Technology (Large Turbine Field Testing, Water Use Optimization, and Improved Mitigation Practices) and (2) Supporting Research and Testing (Environmental Performance Testing Methods, Computational and Physical Modeling, Instrumentation and Controls, and Environmental Analysis). The Technology Application area also has two components: (1) Systems Integration and Technology Acceptance (Hydro/Wind Integration, National Hydropower Collaborative, and Integration and Communications) and (2) Supporting Engineering and Analysis (Valuation Methods and Assessments and Characterization of Innovative Technology). This report describes the progress of the R\&D conducted in FY 2005-2006 under all four program areas. Major accomplishments include the following:

- Conducted field testing of a Retrofit Aeration System to increase the dissolved oxygen content of water discharged from the turbines of the Osage Project in Missouri.

- Contributed to the installation and field testing of an advanced, minimum gap runner turbine at the Wanapum Dam project in Washington.

- Completed a state-of-the-science review of hydropower optimization methods and published reports on alternative operating strategies and opportunities for spill reduction.

- Carried out feasibility studies of new environmental performance measurements of the new MGR turbine at Wanapum Dam, including measurement of behavioral responses, biomarkers, bioindex testing, and the use of dyes to assess external injuries.

- Evaluated the benefits of mitigation measures for instream flow releases and the value of surface flow outlets for downstream fish passage.

- Refined turbulence flow measurement techniques, the computational modeling of unsteady flows, and models of blade strike of fish.

- Published numerous technical reports, proceedings papers, and peer-reviewed literature, most of which are available on the DOE Hydropower website.

- Further developed and tested the sensor fish measuring device at hydropower plants in the Columbia River. Data from the sensor fish are coupled with a computational model to yield a more detailed assessment of hydraulic environments in and around dams.

- Published reports related to the Virtual Hydropower Prospector and the assessment of water energy resources in the U.S. for low head/low power hydroelectric plants.

- Convened a workshop to consider the environmental and technical issues associated with new hydrokinetic and wave energy technologies.

- Laboratory and DOE staff participated in numerous workshops, conferences, coordination meetings, planning meetings, implementation meetings, and reviews to transfer the results of DOE-sponsored research to end-users. 



\section{ACRONYMS}

AHTS

ADYN

ADV

APA

AWEA

BPA

CFD

COE

DO

DOE

DOF

EIA

EPA

EPACT

EPI

EPRI

ERDC

ExCo

FERC

FISH

GCPUD

GFO

GIS

GW

IEA

INEEL

INL

$\mathrm{kW}$

$\mathrm{kWh}$

LIHI

MASS2

MGR

MMS

MTE

MW

MWa

NOAA

NREL

NRTO

NWCC

OCS

ORNL

OCS

PBL

PUD

PNNL
Advanced Hydropower Turbine System

simulating hydrodynamics model

acoustic Doppler velocimeters

Arizona Power Authority

American Wind Energy Association

Bonneville Power Administration

computational fluid dynamics

U.S. Army Corps of Engineers

dissolved oxygen

U. S. Department of Energy

degree(s) of freedom

Energy Information Administration

Environmental Protection Agency

U.S. Energy Policy Act of 2005

environmental performance index

Electric Power Research Institute

Engineer Research and Development Center

Executive Committee

Federal Energy Regulatory Commission

fish growth model

Public Utility District No. 2 of Grant County, WA, or

Grant County Public Utility District

Golden Field Office

geographic information system

gigawatt or $10^{9}$ watts

International Energy Agency

Idaho National Engineering and Environmental Laboratory

Idaho National Laboratory

kilowatt or $10^{3}$ watts

kilowatt hours

Low Impact Hydropower Institute

Modular Aquatic Simulation System 2-D

minimum gap runner

Minerals Management Service

multiple turbine effect

megawatt or $10^{6}$ watts

annual mean power in megawatts

National Oceanic and Atmospheric Administration

National Renewable Energy Laboratory

Near Real-Time Optimizer

National Wind Coordinating Committee

Outer Continental Shelf

Oak Ridge National Laboratory

Outer Continental Shelf

Power Business Line

public utility district

Pacific Northwest National Laboratory 


\section{ACRONYMS (cont'd)}

$\begin{array}{ll}\text { PW } & \text { petawatt or } 10^{5} \text { watts } \\ \text { R\&D } & \text { research and development } \\ \text { RAS } & \text { retrofit aeration system } \\ \text { RMS4 } & \text { TVA modeling system tools } \\ \text { RPS } & \text { representatives } \\ \text { RQUAL } & \text { water quality model } \\ \text { ROR } & \text { run of river } \\ \text { SBIR } & \text { Small Business Innovation Research } \\ \text { SIMPAS } & \text { Simulated Passage model } \\ \text { SFO } & \text { surface flow outlets } \\ \text { STAR-CD } & \text { CFD model } \\ \text { SIMPAS } & \text { Simulated Passage model } \\ \text { STTR } & \text { Small Business Technology Transfer } \\ \text { TBL } & \text { Transmission Business Line } \\ \text { TDG } & \text { Total Dissolved Gas } \\ \text { TMS } & \text { Turbulence Measurement System } \\ \text { TSP } & \text { Turbine Survival Program } \\ \text { TVA } & \text { Tennessee Valley Authority } \\ \text { TW } & \text { tetrawatt or 10 }{ }^{12} \text { watts } \\ \text { USFWS } & \text { U.S. Fish and Wildlife Service } \\ \text { USGS } & \text { U.S. Geological Survey } \\ \text { Voith Siemens } & \text { Voith Siemens -Hydro Power Generation } \\ \text { VSF } & \text { Virtual Sensor Fish } \\ \text { WAPA } & \text { Western Area Power Administration } \\ & \end{array}$




\section{DOE Hydropower Program Biennial Report for FY 2005-2006}

\section{INTRODUCTION}

This report describes the research and development activities supported by the U.S. Department of Energy's Office of Wind and Hydropower Technologies during the last two fiscal years of the Program, October 1, 2004 through September 30, 2006.

\subsection{Hydropower in the United States}

Hydropower is one of the nation's most important renewable energy resources; it generates about $10 \%$ of the country's electricity and produces more than $75 \%$ of the electricity generated from renewable sources (Energy Information Administration [EIA] 2003a). The technology for producing hydroelectricity from falling water has existed for more than a century. It has significant advantages over other energy sources: it is a reliable, domestic, renewable resource with large undeveloped potential, and it produces essentially none of the atmospheric emissions that are of growing concern, such as nitrogen and sulfur oxides and greenhouse gases. Hydropower projects can offer substantial nonpower benefits as well, including water supply, flood control, navigation, and recreation. Hydropower poses unique challenges in energy development, however, because its great benefits can be offset by environmental impacts. The environmental issues that most frequently confront the hydropower industry are blockage of upstream fish passage, fish injury and mortality from downstream passage through turbines, and reduced quality and quantity of water released below dams and diversions.

The total installed capacity of conventional hydropower in the United States is about 80,000 MW (DOE-EIA 2006). Annual generation is highly variable (Figure 1-1); the historical peak in hydropower production occurred in 1997, when 356 billion kWh were generated. However, in 2001, annual generation had dropped to 140 billion $\mathrm{kWh}$ less than that the 1997 peak. The hydropower industry in the U.S. is divided between federal (i.e., Corps of Engineers, Bureau of Reclamation, and Tennessee Valley Authority (TVA)] and nonfederal projects. There are about 180 federal hydropower projects. There are more than 2,000 nonfederal projects, which are regulated by the Federal Energy Regulatory Commission (FERC). Although there are substantial undeveloped resources in the United States (e.g., Section 4.2 below), hydropower's share of the nation's energy generation is predicted to decline through 2020 to about 6\%, due to a combination of environmental issues, regulatory complexity and pressures, and changes in energy economics. DOE's Energy Information Administration (EIA) predicts that only $560 \mathrm{MW}$ of conventional hydropower capacity will be developed by 2025 (DOE-EIA 2003b).

\subsection{The Department of Energy's Hydropower Program}

The U.S. Department of Energy (DOE) initiated the Hydropower Program in 1976 to support research and development to improve operation and development of hydropower facilities in the United States. Over the years, the program has supported research and development for low power hydropower projects, research on environmental issues and mitigation practices, development of advanced and environmentally friendly hydropower turbines, and hydropower resource assessments. 
The Hydropower Program maintains close working relationships with private industry, national hydropower organizations, regulatory agencies, and other federal agencies: U.S. Army Corps of Engineers, Bonneville Power Administration, Tennessee Valley Authority, U.S. Bureau of Reclamation, U.S. Geological Survey, and National Oceanic and Atmospheric Administration (NOAA) Fisheries. These relationships allow DOE to better understand the needs of the hydropower industry, complement research being conducted by others, and leverage research and development funds through cooperative and cost-sharing agreements.

The program's contributions are summarized in regular annual and biennial reports. A description of the DOE Wind and Hydropower Technologies Program can be found on the Internet at http://www.eere.energy.gov/windandhydro/. Annual and topical research reports are available on the DOE Hydropower Program Website: http://hydropower.inel.gov/.

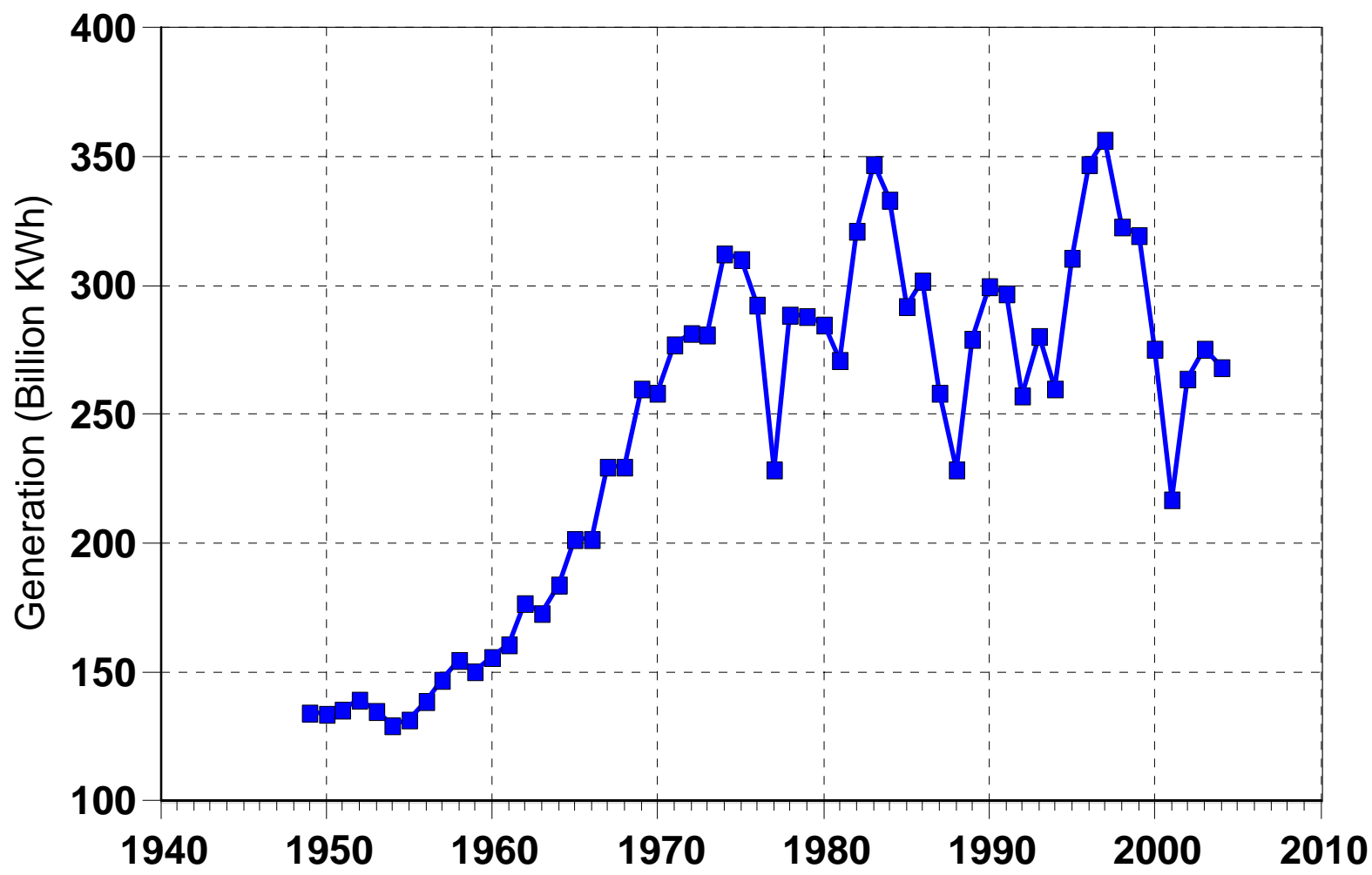

Figure 1- 1. Historical variability of annual hydropower generation from conventional plants in the U.S. (Source: DOE-EIA, 2006) 


\subsubsection{Mission, Goals, and Activities}

The program mission is to conduct research and development $(R \& D)$ that will increase the technical, societal, and environmental benefits of hydropower and advance cost-competitive technologies that enable development of new and incremental hydropower capacity, adding diversity and stability to the nation's energy supply.

The Hydropower Program has two parallel goals:

- To develop and demonstrate new technologies that will enable $10 \%$ growth in hydropower generation at existing plants, with enhanced environmental performance

- To conduct analyses and studies that will enable undeveloped hydropower capacity to be harnessed without constructing new dams or causing unacceptable environmental damage.

The activities of the Hydropower Program are organized under two technical activities, Technology Viability and Technology Application (Figure 1-2). Each of the two categories has two research areas (a total of four project research areas), each having several project areas and numerous projects. The various activities that were sponsored by the program over the past two years are described in Sections 2 and 3 of this report. The relevant planning documents for this period are the Multi-Year Technical Plan for Hydropower (DOE 2003) and the Annual Operating Plan for FY 2005 (DOE 2005). Both the President's budget request and Congressional Appropriations for FY 2005 called for a completion of DOE's Hydropower Program by the end of FY 2006. The Department's FY 2006 budget was $\$ 500,000$, down significantly from the FY 2005 budget of $\$ 4.9 \mathrm{M}$. Because of the transition into a completion mode in FY 2005, some planned projects were either cancelled or shortened, as explained in the sections that follow. 


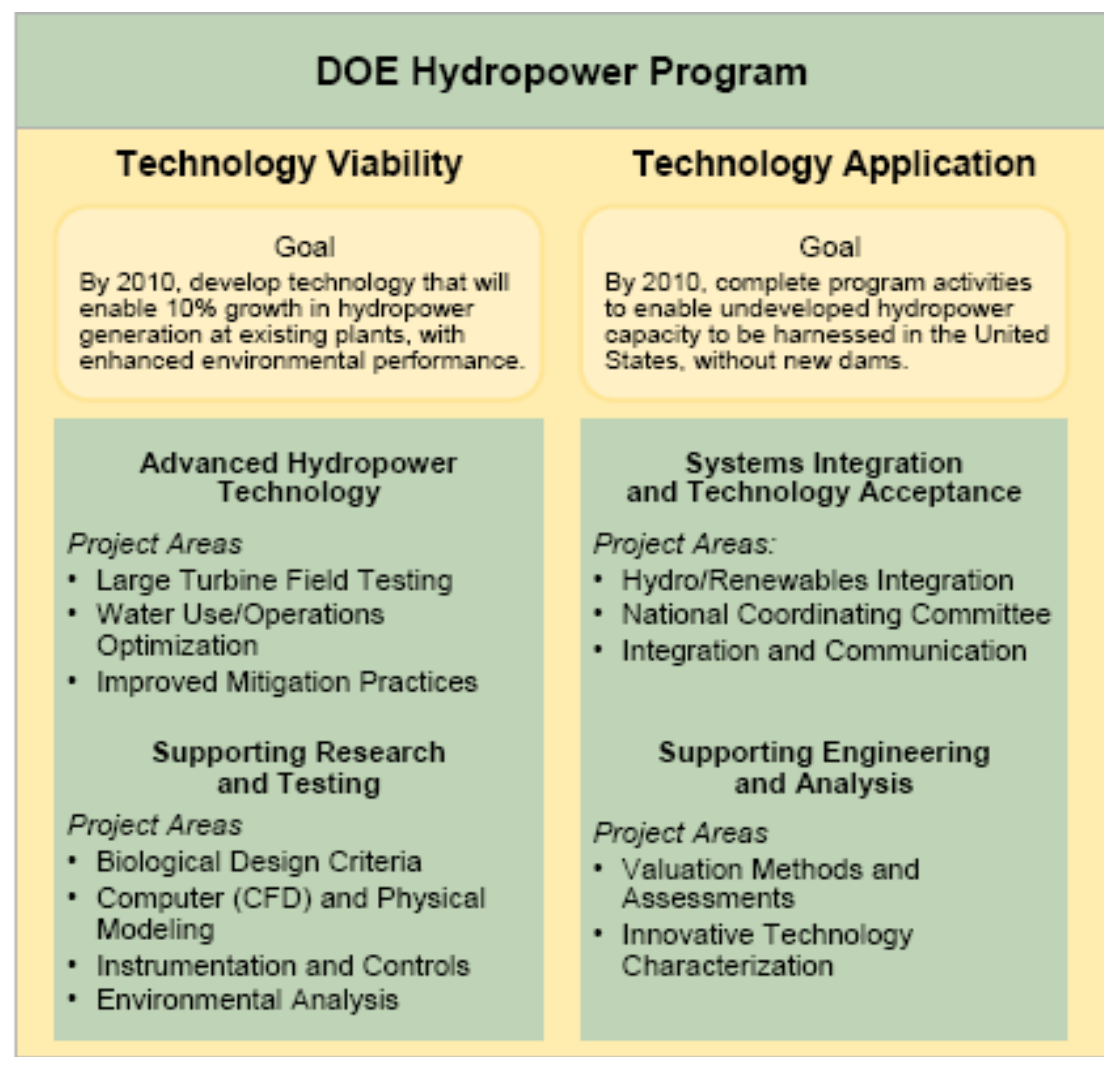

Figure 1- 2. Organization of activities in the U.S. Department of Energy Hydropower Program.

\subsubsection{Program Management}

The Office of Wind and Hydropower Technologies (DOE-HQ) is responsible for planning and organizing the DOE Hydropower Program. Its principal functions are program and policy development, budget formulation and justification, and overall program guidance and direction. DOE-HQ has the authority and responsibility for technical project direction and for contracting the research and development activities that support the program. The DOE Golden Field Office (DOE-GFO) is responsible for the administration of DOE contracts and agreements that support the Hydropower Program.

A concerted effort is made to coordinate the DOE R\&D with that of other federal agencies and industry, including both private and public entities involved with hydropower development. An open peer-review process involving industry and environmental resource agencies ensures that stakeholders are involved and that high-priority research needs are being addressed. A technical committee is maintained to review progress, evaluate results, and ensure coordination with related R\&D activities of other agencies and industry. This committee consists of experts from the hydropower industry and state and federal agencies. In addition, reviews of specialists who are not members of the technical committee are obtained when appropriate. Active coordination yields situational awareness, avoids duplication of research, and creates synergy among related research efforts. 
DOE national laboratories with experience in hydropower provide technical support to the program: Idaho National Laboratory (INL), Oak Ridge National Laboratory (ORNL), Pacific Northwest National Laboratory (PNNL), and National Renewable Energy Laboratory (NREL). INL contributes engineering and program management. ORNL contributes environmental studies, hydraulic engineering, and computational modeling. PNNL contributes biological and related studies (taking advantage of their experience and facilities for conducting tests on fish). And NREL contributes studies in the integration of hydropower with other renewables. A combination of industry, universities, and federal facilities conduct research activities for the Hydropower Program. Where federal facilities have the equipment and personnel to reduce the overall cost to DOE, they are used for conducting R\&D. 


\section{TECHNOLOGY VIABILITY}

The advanced hydropower R\&D supported under Technology Viability is intended to develop new, cost-effective technologies that will enhance environmental performance and achieve greater energy efficiencies. The following subjects are addressed:

- Testing new turbine technology, analyzing test results, and reporting the test results and conclusions

- Identifying new technology efficiencies, effectiveness of water use, and opportunities for optimal plant operations

- Providing basic data and developing computer models that help define conditions inside an operational turbine

- Correlating plant operations with environmental and ecological conditions in the vicinity of hydro projects.

\subsection{Advanced Hydropower Technology}

The activities supported in FY 2005-06 under Advanced Hydropower Technology are:

- $\quad$ Large Turbine Field Testing (Section 2.1.1)

- Water Use/Operations Optimization (Section 2.1.2)

- Improved Mitigation Practices (Section 2.1.3).

\subsubsection{Large Turbine Field Testing}

The Large Turbine Testing projects involve construction, installation, and evaluation of the operational performance of new turbine designs in full-scale settings. Performance measures of interest include energy efficiency (compared with older machine efficiencies), compatibility with environmental requirements (i.e., dissolved oxygen concentrations and fish passage survival), commercial viability, and their success at balancing environmental, technical, operational, and cost considerations. The turbine testing involves designing field test protocols, performing baseline field tests on existing plant equipment and operation, installing new technology, conducting repeat field tests on the new technology equipment, and analyzing and comparing test data related to performance objectives. All of the projects in this program activity are cost-shared with industry partners or other agencies, such as the Corps of Engineers. Staff from the DOE-GC office administer financial assistance agreements that provide the DOE portion of the funding for their projects.

\subsubsection{Wanapum Dam}

Public Utility District No. 2 of Grant County, Washington (GCPUD), installed and tested a new, minimum-gap Kaplan turbine runner (MGR) built by Voith Siemens Hydro Power Generation (Voith Siemens) at Wanapum Dam on the Columbia River in 2005 (see cover photo of this report and Figure 2-1). The Wanapum Dam project is part of the 1,755-MW Priest Rapids Hydroelectric Development (FERC Project No. 2114). Wanapum Dam has 10 conventional Kaplan turbines that have been in place for over 40 years and are reaching the end of their useful life. GCPUD is in the process of replacing all 10 Kaplan turbines at the dam with advanced turbines that were developed with support from the DOE Advanced Hydropower Turbine System (AHTS) Program. The first advanced turbine was installed and tested at the Wanapum Dam in 2005. The MGR was designed to reduce mortality of salmon smolts that pass through the turbine. Increases in efficiency were also expected from this new MGR turbine compared to the older generation of machines. If fish passage survival 


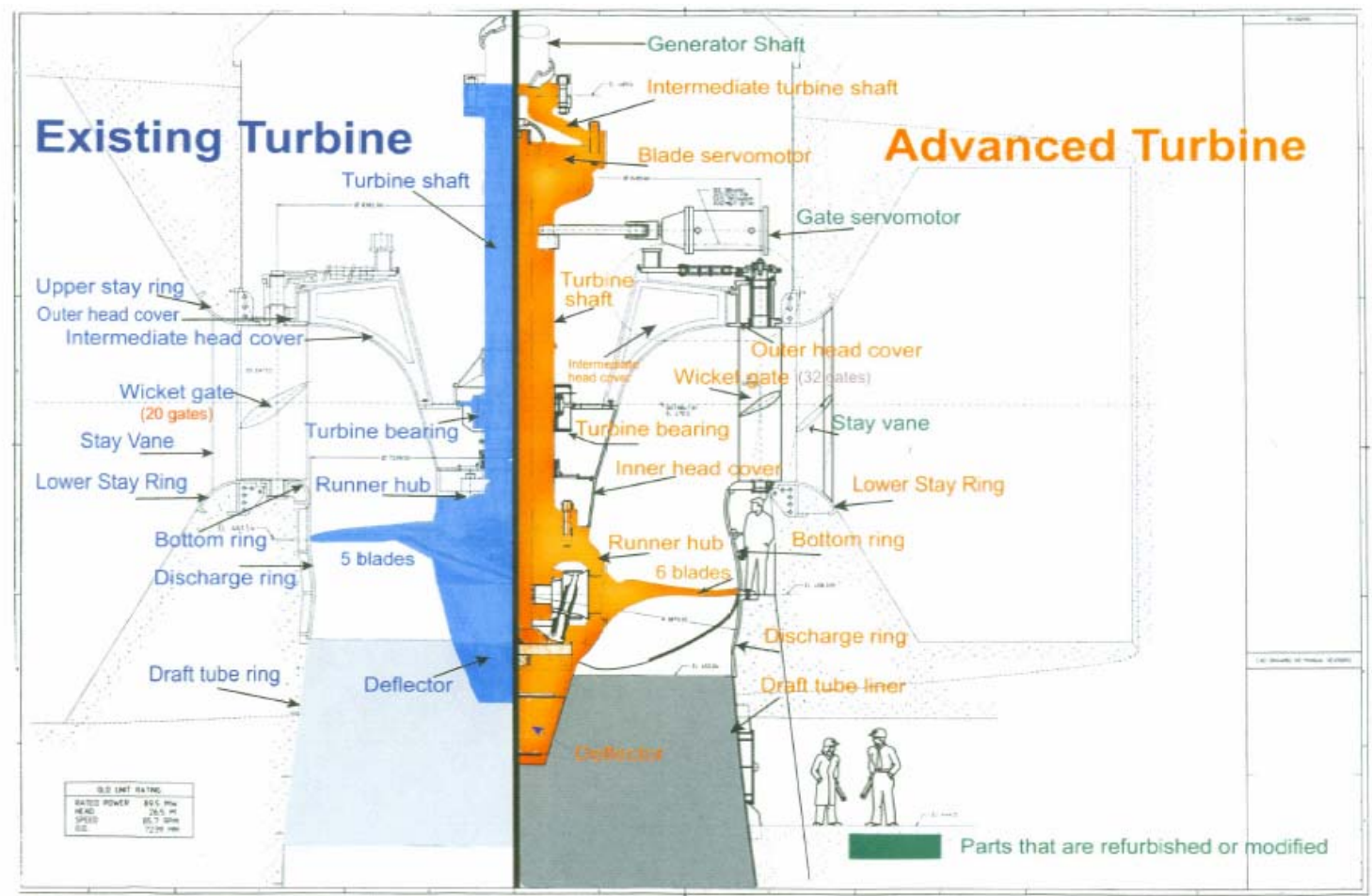

Figure 2- 1. Comparison of the conventional (left/blue) and new MGR (right/orange) turbines at Wanapum Dam on the Columbia River, Washington. (Source: Normandeau Assoc., Inc., et al. 2006)

through the advanced turbine meets decision criteria for environmental performance (fish survival through the conventional turbine is at least as good as through the existing turbine), then installation of the next nine advanced turbines would proceed over the next decade.

The engineering design of the new MGR turbine for Wanapum Dam started in January 2003 and was completed in December 2004. The manufacture, site work, and assembly phases of the project were completed in early February 2005. Extensive performance testing began on February 18, 2005, including comparison studies of the MGR, Unit 8, versus an adjacent conventional turbine, Unit 9. Originally, biological testing was planned to run through March, but because of low flow conditions in the Columbia River, fish releases continued through April 29, 2005. The initial analysis of the biological testing was completed by June 2005 with the draft report provided to the fisheries agencies and tribes for comment through July 2005. Comments were received and appropriately incorporated into the report. The revised report was provided to the Federal Energy Regulatory Commission (FERC) August 1, 2005 as was required by the FERC order authorizing the installation of the AHT (Skalski et al., 2005). A meeting to review the first-year testing results was held in July 2006, involving Grant County, its contractors and DOE staff.

The new MGR turbine was first inspected after 3,000 hours of operation and was inspected on May 19, 2005. The only item of significance noticed was cavitation frosting on the wicket gates. This "frosting" was due to a misaligned wicket gate seal. The next maintenance inspection will be at 8,000 hours of operation. 
The turbine testing at Wanapum Dam has been a major success for the DOE Program and for the hydropower industry, because it is the first full-scale demonstration of the next-generation, advanced turbines. Very high fish survival was achieved ( 97\%), and hydroelectric generation has been substantially increased (14\% more than with the existing turbine). Based on the first-year performance test of the new MGR, FERC approved the biological report and the installation of the remaining nine conventional turbines in Wanapum Dam with the MGR advanced hydroturbine. The Wanapum Dam test also illustrates how this type of prototype testing is a capital-intensive, long-term effort, with large potential benefits.

\subsubsection{Osage Project}

The Osage project is considering techniques for retrofitting cost-effective aeration into existing Francis turbines to mitigate low dissolved oxygen (DO) concentrations in tailwaters below hydropower facilities. AmerenUE owns and operates the 176-MW Osage Project (FERC Project No. 459), located at Bagnell Dam on the Osage River in Missouri. Bagnall Dam impounds the Lake of the Ozarks, a 100-foot-deep reservoir that thermally stratifies during the summer months, causing low DO water to be discharged into the Osage River below the dam. To supplement downstream DO, the turbines have been vented to the atmosphere during the low DO season. New turbines, manufactured by American Hydro Corporation, were installed in Units 3 \& 5 during the spring of 2002 (Figure. 2-2). Additional vent capacity and new nose cones were included in the new MGR turbine design. A retrofit aeration system (RAS) was installed at Bagnell Dam in 2004. The RAS was selected for testing because it was thought to be the most cost-effective way to enhance dissolved oxygen without incurring expensive civil works modifications and the purchase of expensive, self-aerating turbines.

The RAS that was tested is an attempt to further enhance the DO in the tailrace by installation of additional venting capability on Unit 6 (not upgraded with new MGR turbine) and refining the design of special nosecones which will be mounted on both Unit 3 (upgraded turbine) and Unit 6. Baseline DO testing for Units 3 \& 6 was conducted mid August, 2002. These data will be compared to further tests planned for the summer of 2003 after installation of the retrofit aeration system. During a two week outage during April, 2005, the following modifications were made to the vent system on Unit 6:

- Four new 8” vents were

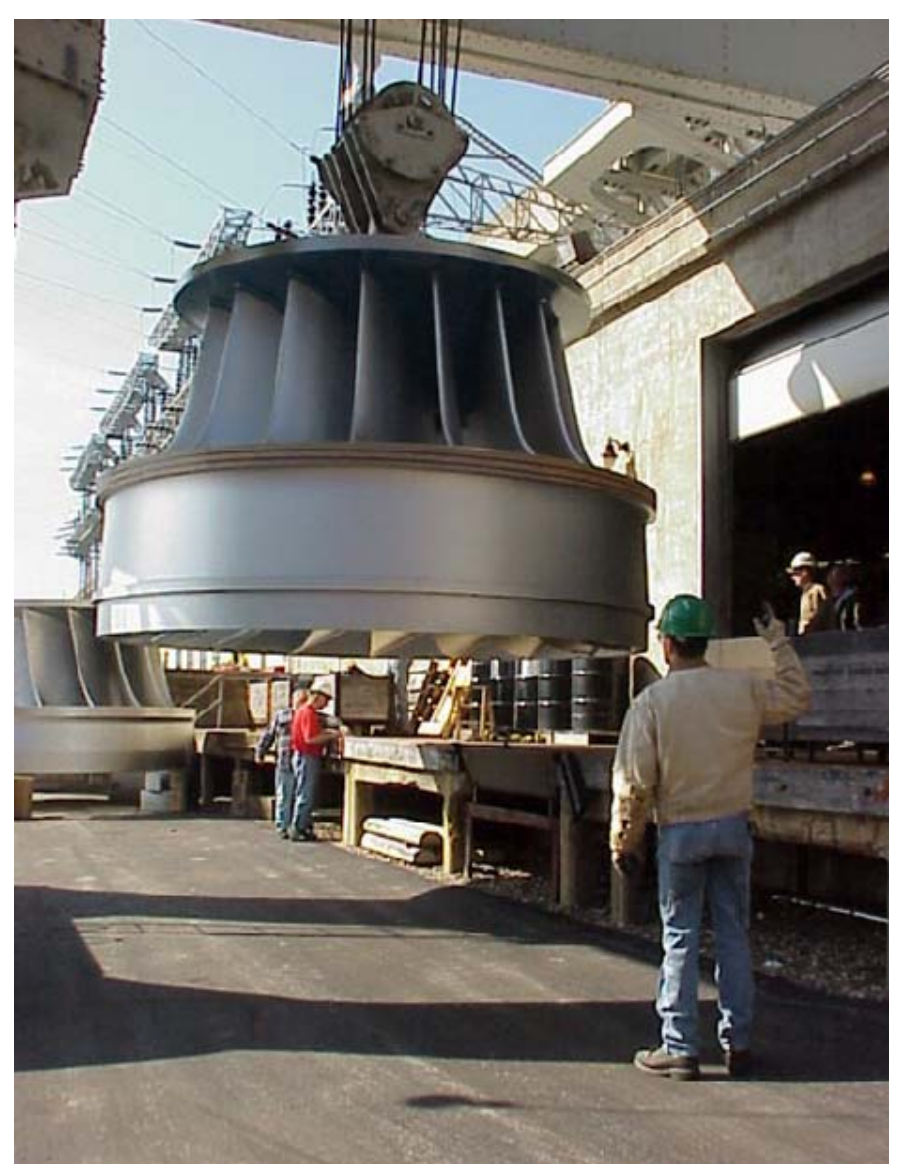
added, allowing air to pass through the bearing housing, to the top of the turbine, then out through the nose cone. 
- A 12” extension was welded onto the nosecone, thus putting the air discharge point at the center of a low pressure region. This region was identified by CFD modeling.

- The draft tube baffle, which was tested in 2004, was modified by replacing the two 8" vent pipes with a single 16 ” vent pipe.

- New air flow measuring equipment was purchased and installed in the four new vents and draft tube vent.

Testing on Unit 6 was conducted on July 26 and 27, 2005. Unit 6 was run at three different tailwater levels, providing three different heads. Turbine flow was varied from minimum, to near maximum capacity for each tailwater level. Measurements were taken in the tailrace "boil" for DO, total dissolved gas (TDG,) water temperature. Index testing was conducted to determine turbine efficiency changes from previous year's tests. Airflow and DO readings were also taken from Unit 3 in order to draw a comparison between the airflow from an upgraded turbine (new American Hydro in 2002) in Unit 3, and the modified existing turbine and retrofit aeration system (RAS) in Unit 6. The bottom plate was removed from the nosecone in Unit 3 in 2003 as a part of the RAS project. Check valves were removed from Unit 3 Vent lines in March 2005. It was believed that these might have a significant effect on air flow. The report and conclusions for the July 2005 testing were completed in 2005

Dissolved oxygen and total dissolved gas concentrations were measured in the water discharged from Units 3 and 6 at the Osage Project on July 26 and 27, 2005. Data analyses reported by AmerenUE indicated that the new MGR turbine in Unit 3 effectively aerated the water discharged from the project on the two days tested. Concentrations of dissolved oxygen in the intake water ranged from 0.15-1.94 mg/L (all values below State of Missouri water quality criteria), whereas concentrations in the discharged water ranged from $2.52-5.98 \mathrm{mg} / \mathrm{L}$. Under the various conditions tested, dissolved oxygen concentrations in the Unit 3 discharge increased by $0.70-5.80 \mathrm{mg} / \mathrm{L}$; 27 of 29 measurements indicated a dissolved oxygen increase of over $2 \mathrm{mg} / \mathrm{L}$. Dissolved oxygen concentrations in the turbine discharge were increased by more than $2 \mathrm{mg} / \mathrm{L}$ in all of the 40 measurements of Unit 6. The average increase in dissolved oxygen concentrations in the Unit 3 discharge was $3.72 \mathrm{mg} / \mathrm{L}$. Unfortunately, the aerating runner in Unit 3 also increased total dissolved gas concentrations; nitrogen supersaturation ranged from 110-140\% (22 of 29 measurements were greater than $125 \%$ saturation). The benefits of dissolved oxygen enhancement will need to be balanced against the potential adverse impacts of TDG supersaturation on fish and other aquatic organisms downstream from the project.

\subsubsection{Box Canyon}

The Box Canyon project was one of three sites that were selected by DOE for advanced turbine testing (Sale et al., 2006). Pend Oreille County PUD of Newport, Washington, proposed testing an MGR Kaplan turbine at its 72-MW Box Canyon Project (FERC Project No. 2042) on the Pend Oreille River. The specific MGR turbine to be tested was to be either a design by ALSTOM Power, Inc., or one by Voith Siemens. Both systems are designed to pass resident fish such as bull trout which is a local ESA-listed fish species. The Box Canyon project start-up was delayed into FY 2006 due to its FERC relicensing proceeding. Given the completion status of the DOE Hydropower program, work at Box Canyon has been postponed indefinitely.

\subsubsection{Cooperative Studies with the Corps of Engineers}

The Corps of Engineers’ Turbine Survival Program (TSP) has been studying mechanical and operational changes that can be made to hydropower turbines to increase fish passage survival and power production benefits for more than 10 years. DOE and the Corps have been coordinating their 
research efforts over that time, to eliminate duplication of effort and reduce the funding requirements of both Agencies. In FY 2005 and FY 2006, DOE provided financial assistance to three Corps studies:

- Stay vane and wicket gate relationships

- Ice Harbor physical modeling

- Model evaluation of the performance of an advanced ALSTOM runner

The stay vane and wicket gate model studies were conducted from September 2000 through April 2003 by a subcontractor, VA Tech, funded jointly by DOE and the Corps. In FY 2005, a final report on this work was expanded to include additional draft tube analyses (Corps of Engineers, 2005a). The final report evaluated potential environmental and performance gains that can be achieved in a Kaplan turbine through non-structural modifications to stay vane and wicket gate assemblies. VA Tech and the TSP design team examined CFD models of the original stay vane wicket gate combination and three concept designs. All three designs involved slight to moderate profile changes to the basic shape of the existing stay vane. All three designs utilized multiple stay vane profiles to better match the different flow characteristics of the different sections of the stay ring. The design selected from these tests, called variant 2, estimated a 51\% reduction in local hydraulic losses through the stay vane wicket gate region with minimal structural changes to the existing stay vane. The CFD model also predicted a performance improvement from rotating the wicket gate location $1.08^{\circ}$ clockwise from existing. In order to further increase the environmental performance, the TSP design team requested that the design recommended by the CFD study, Variant 2, be modified to minimize the gap between the stay vanes and the wicket gates. The gap between the stay vane and wicket gate is a location of potentially harmful acceleration and pressure changes for fish. VA Tech created a stay vane, Variant 2A, which was the same as the optimal CFD design on the leading edge. However the trailing edge had an extension to decrease the gap flow between the stay vane and wicket gate. VA Tech performed model tests of the stay vane Variant 2A and the Original design. The existing Lower Granite unit 4 model was utilized for these performance tests. The performance testing of Variant 2A with the original wicket gate arrangement predicted a turbine efficiency improvement in the range of 0.5 to $0.7 \%$.

With Variant 2A defined and model tested, ERDC proceeded to perform environmental tests. Neutrally buoyant beads and cameras were used to determine environmental characteristics of the original stay vane wicket gate system, Variant 2, and Variant 2A. ERDC used bead impact and abrupt directional changes (shear events) in the bead path as parameters to evaluate potential fish injury events. From these tests, Variant 2A was predicted to be the option with the best potential environmental performance.

These investigations show minor modifications to the stay vane wicket gate system resulted in estimated operation efficiency increases of 0.5 to 0.7 percent for Lower Granite Kaplan turbines. Minor changes in the profile and configuration of the stay vane and wicket gate appear to result in reduced environmental impact and improved quality of flow for fish passage. The relatively low cost of the proposed modification to the stay vanes and the large environmental and hydraulic performance increases may make this a positive addition to any rehabilitation. We expect that similar gains may be found at all the Lower Snake and Columbia River projects.

Based on these investigations, this study recommends:

- A proof of concept at Lower Granite Dam to establish predicted improvements for the existing turbine and to further refine the stay vane wicket gate designs for fish passage.

- Consideration of the stay vane wicket gate systems in any future turbine rehabilitation studies. 
At the Corps' Ice Harbor Project on the lower Snake River in Washington, 50-yr-old hydropower turbines need to be replaced. DOE cost-shared some of the design studies for this turbine-upgrade project, with the intention that new fish-friendly MGR turbines will eventually be installed there. The Ice Harbor modeling study involved construction of a 1:25-scale laboratory test model of the existing Unit 2 and use of that model to estimate the performance of the full-scale turbine (Corps of Engineers, 2005b). A Froude-similar observational “test stand,” was completed (Figure 2-3). The Unit-2 turbine runner model was delivered in early 2005. Observational testing of the scale model was completed later in 2005. Eventually, model results will be compared to observed fish survival in the field, after new MGR turbines are selected and installed. This project includes conducting baseline field biological studies at the Ice Harbor Dam, constructing a new hydraulic test stand and constructing/testing a turbine model in the new test stand to evaluate improvements in fish passage effectiveness for new turbine designs. If tests of new designs are judged favorable, turbine runners of the new design will be considered for installation at Ice Harbor Units 1, 2 , and 3 . The final report of the results of these tests will not be distributed until FY 2007.

ALSTOM Power is one of the large, international manufacturing companies that are currently designing advanced turbines promising enhanced environmental performance. Both DOE and the Corps are interested in the performance of ALSTOM's new runners relative to existing designs, so a joint, cost-shared study was initiated at the ERDC test facilities. ALSTOM provided a scale model of its fish-friendly MGR turbine runner, and it was installed in the Lower Granite physical test stand for evaluation. Estimates of biological performance (i.e.,

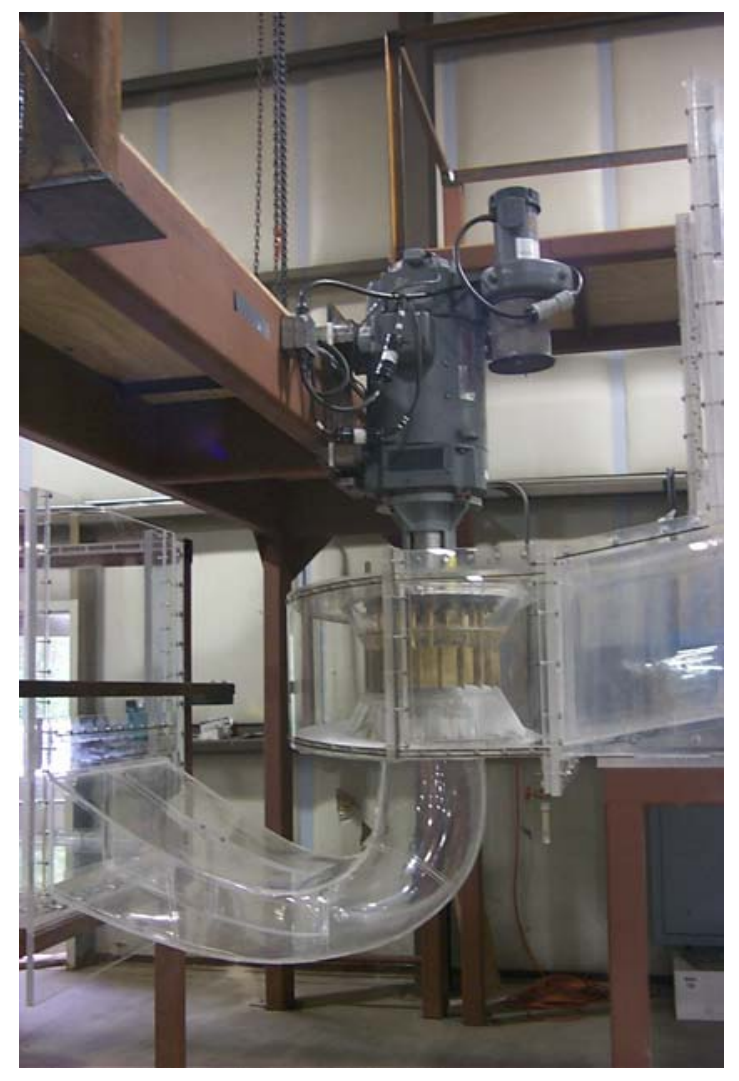

Figure 2- 3. Observational 1:25-scale physical model of the Ice Harbor turbine at the U.S. Army Engineering Research ability to pass fish safely) were made by observing neutrally buoyant beads passing through the turbine runner using high-speed video. Velocity distribution in the draft tube was also being measured. The results from the ALSTOM runner tests were compared to test results from a standard Kaplan runner conducted in the same test stand. Each runner was observed at three different flow rates, two of which were comparable to flow conditions at which biological testing was performed in the field at the Lower Granite project in 1995. The testing was completed in fall 2005, and a final report was delivered to DOE in late 2006. Lessons learned from this should be applicable to most new Kaplan turbine designs.

\subsubsection{Water Use Optimization}

Hydropower generation can be increased at a given plant by optimizing a number of different aspects of plant operations, including the settings of individual units, the coordination of multiple unit operations, and release patterns from multiple reservoirs. Based on the experience of federal agencies such as the Tennessee Valley Authority and on strategic planning workshops with the hydropower industry, it is clear that substantial operational improvements can be made in hydropower systems, 
given new investments in R\&D and technology transfer. These potential improvements can lead to increases to hydro plant factors without adverse environmental impacts; they can be achieved by analyzing how current hydropower plant operations might be modified to reduce impacts to aquatic ecosystems, while optimizing the use of water at hydropower sites and limiting effects on economic plant operations and other multipurpose project objectives. Potential energy increases of 5-10\% applied across the installed base of hydropower projects are possible - such new renewable energy would be especially desirable if it also offered environmental improvement. The need to improve the scientific basis for decisions concerning water management at hydropower dams and reservoirs is becoming increasingly acute as competition over limited water resources escalates across the U.S.

DOE's activities on Water Use Optimization in 2005 and 2006 focused on clarification and further development of research topics identified at the 2004 Water Use Optimization Workshop in Hood River. Three studies were supported to further define the subject of water use optimization relative to hydropower:

- A state-of-the art review of technologies available for hydropower optimization

- A case study analysis of how operations might be improved on the Snake River

- A report to define the opportunities for spill reduction in the Columbia Rive

\subsubsection{Hydropower Optimization}

At the Hood River workshop in 2004, the top three priorities for new research were (1) metrics and benchmarking of hydro optimization, (2) valuing the non-power costs and benefits of hydro resources and integrating those values into optimization practices, and (3) integrated modeling of hydropower production, water quality, temperature, sediment transport, and biological resources. To develop a compendium of theory and practice related to hydropower optimization, ORNL researchers reviewed optimization literature from multiple disciplines, including water resources engineering, power systems engineering, ecology, and operations research. That effort is summarized in a forthcoming report on the state of the art in hydropower resources optimization (Smith, Sale et al. Jager, 2006). With few exceptions, objectives in reported optimization schemes address three major themes: (1) energy production, energy revenue, or energy profit (i.e. revenue less operating and maintenance costs), (2) satisfying water demands (e.g. flood control, navigation, and water supply), and (3) environmental components (e.g. water temperature, water quality, fish population, biotic assemblages, biomass, and sediment accumulation).

In general, both theoretical and practical optimization schemes reported in literature focus on a single objective, incorporating the remaining objective as simplistic models or fixed constraints or disregard them completely. For example, schemes that focus on water supply, irrigation, and flood risk reduction usually oversimplify important efficiency relationships and accumulated maintenance costs inherent in hydro unit operations, and ignore the economic and security benefits of hydro ancillary services in evolving power markets. Energy optimization schemes emphasizing generation efficiency, maintenance costs, and power system reliability incorporate environmental themes as fixed constraints on flows and reservoir elevations, which precludes consideration of the tradeoffs that would identify globally optimal water release schedules.

This single-theme focus is necessary to advance the state of the art in specific disciplines, but research targeted on more holistic optimization schemes has not kept pace. Future research must address the challenges of integrating energy, water, and ecological models. A major challenge is differences in hierarchy and scale among energy, water, and ecological systems. Compared to hydropower energy objectives, environmental, water supply, and flood control objectives entail very long time scales (multiple years) over which benefits are realized. Ecosystem hierarchies may differ in time and space from the physical and control hierarchies of hydropower facilities, and validating 
ecological models over these differing scales will be another challenge. Given these contrasts, advances in holistic optimization will require new strategies, and even new model formulations, that communicate environmental, hydraulic, and energy optimality information across the gradients of temporal and spatial scales separating individual model components. In addition to identifying globally optimal strategies for operation of water resource systems over operational and strategic time horizons, such efforts could contribute significantly to integrated analyses of climate change on water resource systems.

There are substantial opportunities for research, development, and demonstration to improve the compatibility of information transferred across scales just within the narrow scope of energy optimization. Hydropower system operators typically decompose large-scale energy optimization problems into manageable components. Hydro release schedules for a series of projects are produced by a hierarchy of models and data streams with long-term (weekly or monthly allocations over a year), mid-term (daily allocations over a week or month), short term (hourly over a 24-hour period), and real-time horizons (seconds to minutes for regulation services). Within this hierarchy, modules must aggregate and disaggregate optimality measures in time and space to identify globally optimal schedules. In particular, there are opportunities to define and implement best-practices for periodically or continuously measuring and incorporating unit-specific turbine and generator efficiency data into energy optimization schemes.

The top ranking of hydropower optimization benchmarks and metrics at the Hood River workshop indicates their pivotal and inciting role in the research, development, and implementation of holistic hydropower optimization. They will enable decision-makers to quantify the potential for gains in energy, water, and environmental benefits-a precursor to increasing investment in improved optimization capabilities. Yet experience suggests that the development of performance metrics for energy, water, and environment that respond to optimization variables and operational controls in hydropower systems is an iterative process. Considerable resources will be required in the early stages of holistic optimization efforts to develop and connect benchmarks, metrics, and models that do not yet exist, with significant benefits accruing in the latter phases of development.

\subsubsection{Alternative Operating Strategies}

This project evaluated the restoration potential of mainstem habitats for Snake River Chinook salmon (Oncorhynchus tshawytscha) fall-run Evolutionary Significant Unit, listed as Threatened under the Endangered Species Act. Research activities were conducted in conjunction with the Bonneville Power Administration (BPA) Project 2003-038-00, Evaluate the restoration potential of Snake River fall Chinook salmon spawning habitat. The studies address two research questions: "Are there sections not currently used by spawning fall Chinook salmon within the impounded lower Snake River that possess the physical characteristics for potentially suitable fall Chinook spawning habitat?" and "Can hydrosystem operations affecting these sections be adjusted such that the sections closely resemble the physical characteristics of current fall Chinook salmon spawning areas in similar physical settings?” Efforts are focused at two study sites: 1) the Ice Harbor Dam tailrace downstream to the Columbia River confluence, and 2) the Lower Granite Dam tailrace. Previous studies indicated that these two areas have the highest potential for restoring Snake River fall Chinook salmon spawning habitat.

The study sites are being evaluated under existing structural configurations at the dams (i.e., without partial removal of a dam structure), and alternative operational scenarios (e.g., varying forebay/tailwater elevations). The areas studied represent tailwater habitat (i.e., riverine segments 
extending from a dam downstream to the backwater influence from the next dam downstream). The reference site for tailwater habitats is the section extending downstream from the Wanapum Dam tailrace on the Columbia River.

In FY 2005-2006, we quantified physical characteristics that define suitable fall Chinook salmon spawning habitat at Wanapum Dam tailwater reference site. Spawning habitat suitability was ranked within the project area using suitability indices. Predictions of spawning habitat suitability for the entire project area have been made by comparing characteristics of channel morphology and hydraulics to suitability criteria from redds in the Wanapum Dam tailrace.

We also quantified the physical characteristics that define suitable fall Chinook salmon spawning habitat at Ice Harbor Dam and Lower Granite Dam tailwater sites. Depth-averaged hydraulic characteristics downstream of Ice Harbor and Lower Granite Dams were simulated using the hydrodynamic and water quality model MASS2 (Modular Aquatic Simulation System 2-D). A continuous three-dimensional, raster-based bathymetric data set was required to develop the computational mesh used by the MASS2 hydrodynamic model and to describe the physical habitat characteristics for each reach in the study. A new hydrographic survey was conducted at the tailraces of Ice Harbor and Lower Granite dams to supplement existing bathymetric data that were used in previous hydrodynamic models of these reaches. Alternative hydrosystem operations strategies were quantified by simulating the discharge for three different water year types (dry, normal, wet), three different exceedence discharges $(10 \%, 50 \%, 90 \%)$, and two different downstream forebay elevations (normal and minimum operating pool elevations). Using the habitat suitability indices from the Wanapum Dam tailrace reference site, potential fall Chinook salmon spawning habitat at the study sites has been quantified for all of the discharge scenarios. Potential habitat changes will be summarized as a function of discharge, and comparing the channel morphology and hydraulic characteristics between the study sites and the reference sites.

This project will result in a final report on the location and spatial extent of potential restoration areas, and recommendations to the region for adjusting hydrosystem operations to improve Snake River fall Chinook spawning habitat, including alternative flow scenarios by water-year type.

\subsubsection{Opportunities for Spill Reduction}

This report indicates that reduction of managed spill at hydropower dams can speed implementation of technologies for fish protection and achieve economic goals (Coutant and Mann, 2006). Spill of water over spillways is managed in the Columbia River basin to assist downstreammigrating juvenile salmon, and is generally believed to be the most similar to natural migration pathways, and the most benign and effective passage route; other routes include turbines, intake screens with bypasses, and surface bypasses. However, this belief may be misguided, because spill is becoming recognized as a departure from natural conditions, with deep intakes below normal migration depths, and likely causing physical damages from severe shear on spillways, high turbulence in tail waters, and collisions with baffle blocks that lead to disorientation and predation. Some spillways induce mortalities comparable to turbines. Spill is expensive in lost generation, and controversial. Fish-passage research is leading to more fish-friendly turbines, screens and bypasses that are more effective and less damaging, and surface bypasses that offer passage of more fish per unit water volume than does spill (leaving more water for generation). Analyses by independent economists demonstrated that goals of increased fish survival over the long term and net gain to the economy can be obtained by selectively reducing spill and diverting some of the income from added power generation to research, development, and installation of fish-passage technologies. Such a plan 
would selectively reduce spill when and where least damaging to fish, increase electricity generation using the water not spilled and use innovative financing to direct monetary gains to improving fish passage.

\subsubsection{Improved Mitigation Practices}

Requirements for environmental protection, mitigation, and enhancement at hydropower projects remain one of the most controversial and expensive issues confronting the industry. Within the limitations of available funding, DOE has been studying ways to improve environmental mitigation practices throughout the history of the Hydropower Program. In FY 2005-FY 2006 period, we supported mitigation studies on instream flow requirements and on fish passage issues.

\subsubsection{Mitigation Effectiveness for Instream Flows}

Reduced flow and extreme daily fluctuations in flow have been recognized for many years as consequences of hydropower production which have the potential to negatively impact fish communities below hydropower dams. Common mitigation to address these concerns includes minimum instream flow requirements and changes in mode of operation. In 2005 we completed an analysis of the environmental benefits and economic costs of flow modification, including the effects of mitigation on river flow dynamics, hydropower generation, and biological response (Bevelhimer and Jager, 2006). The types of mitigation to which this report applies includes change in mode of operation (e.g., from peaking to run-of-river, ROR), minimum flow requirements, ramping rates, flushing flows, flow continuation, attraction flows, outmigration flows, and channel maintenance flows. The report discusses methods for evaluating the effects of instream flow alterations on river flow dynamics and compares alternative data analysis approaches for addressing issues of short-term fluctuations in flow and the occurrence of high and low flow events.

In our analysis of the effects of flow mitigation on power generation, we found that license modifications tended to have a small, negative effect on annual generation that was, in most cases, insignificant compared to the effects of year-to-year variation in flow. The change to run-of-river operation often resulted decrease in flow released, and presumably power generation, during peak demand. For example, we found that ROR operations resulted in a redistribution of flows such that the discrepancy in mean flows from weekends to weekdays was greatly reduced, that is, flow normally saved for weekday peak hours was released during the weekend. However, in projects below peaking storage projects, there was no decrease, or an increase in peaking flows.

To evaluate environmental benefits, we performed a comprehensive literature search for biological monitoring studies designed with the intent of evaluating the biological response following various forms of flow mitigation. Studies were considered sufficient for inclusion if they included data from at least one year prior to flow improvement and one year after, two or more years of data immediately following flow improvement (with the assumption that any biological response would not likely happen immediately and would progress for a few or perhaps many years after flow alteration), or at least two years from the affected site and two years from a control site. Our search turned up 25 hydropower projects with studies that met our criteria. Fourteen of the projects had enough data that we were able to subjectively conclude that a biological response to the flow enhancement had occurred and that the response was positive in all cases. Data for the remaining projects did not suggest a probable biological response either because there were no consistent trends, the data were inadequate, or other factors made it difficult to relate changes to flow enhancement. The lack of sufficient data is still a limiting factor in evaluating mitigation effects, as it was in 1990 when we did our first mitigation studies (Sale et al. 1991). 
Five case studies are used to demonstrate how benefits and costs of flow mitigation can be quantified and evaluated. A direct comparison of costs and benefits, however, is not easy as there is no common currency by which each can be expressed. All five of the projects experienced an increase in minimum flow requirements as a result of relicensing, and one project also experienced a change in operation from peaking to ROR. We detected significant reduction in yearly power generation for two projects and a significant reduction in peak hour generation for the project which changed to ROR. Environmental benefits were demonstrated in four of five cases and are expected for the fifth as more years of data are collected. The best available evidence suggests that flow enhancement generally results in a positive biological response. In addition, this benefit can be achieved with little impact on annual generation in many cases, although there seems to be some reduction in generation during peak hours of electricity demand. We recommend that future studies on instream flow mitigation address:

- Sign of statistically defensible long-term monitoring programs for detecting environmental benefits;

- Identify flow management options that produce the desired mitigation benefits while minimizing the effects on generation loss;

- Develop adaptive management strategies with clear objectives, reasonable data requirements, and clear decision points.

\subsubsection{Fish Passage Effectiveness}

Fish passage effectiveness has long been a concern of hydropower operators and regulators. In FY 2005 and FY 2006 we completed the review of surface flow outlet technology as a promising approach to safely and economically pass juvenile salmonids at hydropower dams.

We reviewed results of research conducted by engineers and biologists over the past 50 years related to development of surface flow outlets (SFOs) for juvenile salmonids that migrate downstream past hydropower dams. An SFO is a non-turbine, water-efficient passage route with an overflow structure through which flow and fish pass over a dam. Our review covered 69 SFOs in Europe and North America. We identified five main types of SFOs - low-flow bypass/sluices, high-flow sluices, forebay collectors, powerhouse retrofits, and surface spills (Figure 2-4). Most low-flow bypass/sluices are sited in Europe and on the east coast of North America, where mean annual project discharge and hydropower production for the dams we reviewed were $95 \mathrm{~m}^{3} / \mathrm{s}$ and $15 \mathrm{MW}$, respectively. The other four SFO types are found at dams on the west coast of North America with $2184 \mathrm{~m}^{3} / \mathrm{s}$ mean annual discharge and $788 \mathrm{MW}$ mean output. A conceptual framework based on fish behavior and hydraulics for different regions of a hydropower project was developed to evaluate SFO performance. For all SFO types, fish collection efficiency averaged 54\%, with an average effectiveness ratio of 17:1 (fish to inflow). If appropriately designed, surface flow outlet technology can meet the goal of concurrent anadromous fish protection and hydropower generation. 


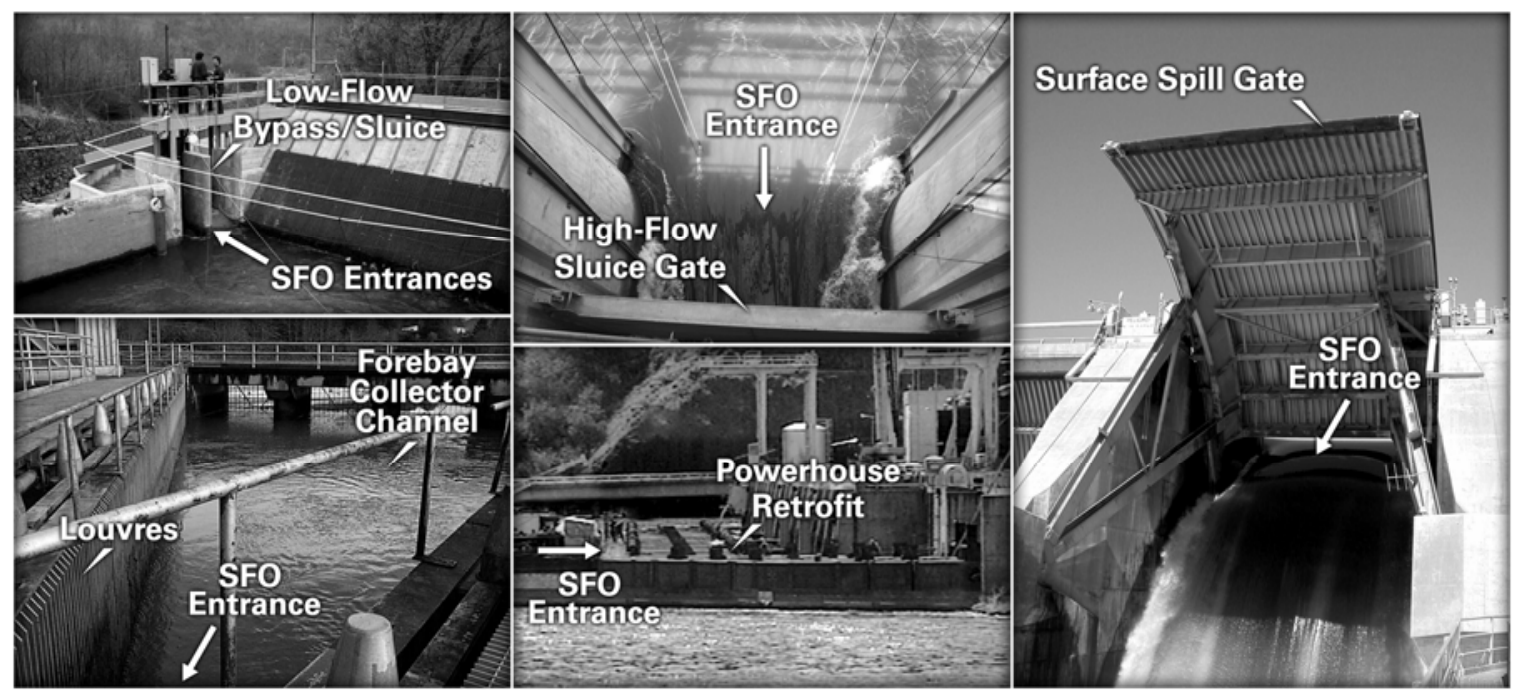

Figure 2- 4. Examples of the five main types of surface flow outlets for juvenile salmonids. Low-flow bypass (upper left; courtesy of M. Larinier); high-flow sluice (upper middle); forebay collector (lower left); powerhouse retrofit (lower middle); and surface spill (right).

\subsection{Supporting Research and Testing}

The dual concerns of the Hydropower Program (i.e., providing energy and protecting the environment), and especially the relatively new focus on improving environmental performance, require the development of new scientific understanding and new performance measurement tools. The Supporting Research and Testing activities carried out under Technology Viability are designed to yield products that will enhance the design and testing of advanced hydropower systems. Generally, we use a unique, multi-faceted research approach that employs a combination of controlled laboratory experiments, computational and physical modeling, and field observation and testing. The multiple approaches are necessary because no single method is sufficient to understand the complex hydraulic environment inside turbines from the perspective that fish experience. Our multidisciplinary studies to improve environmental performance are substantially different from the traditional engineering methods that were used to design most conventional hydropower systems. The activities conducted under Supporting Research and Testing include:

- Performance Testing Methods;

- Computational and Physical Modeling;

- Instrumentation and Controls; and

- Environmental Analysis.

\subsubsection{Environmental Performance Testing Methods}

As advanced turbines are developed and tested in full-scale settings, new tools need to be developed to measure the performance of these machines, particularly with respect to environmental performance. For example, with the exception of the balloon-tag methods that estimate fish survival rates, there are very few standard methods for measuring "fish-friendliness" in the field. This research area is related to earlier efforts to establish biological design criteria (biocriteria) for new MGR turbines. 
Projects sponsored in FY 2005-06 were designed to take advantage of the concentrated monitoring program that took place at the Wanapum Dam project. The DOE-supported studies in this program area were designed to test the feasibility of new evaluation methods.

In 2005, GCPUD replaced one of the 10 conventional Kaplan turbines at Wanapum Dam with an advanced turbine that was developed with support from the U.S. Department of Energy's Advanced Hydropower Turbine System Program (Section 2.1.1.1). Compared to a conventional Kaplan turbine, the advanced minimum gap runner (MGR) turbine is predicted to have lower values for several potential fish injury mechanisms, and therefore was expected to improve turbine-passage fish survival. Fish survival tests of the MGR turbine were carried out by GCPUD between February and April 2005. A total of 8,960 tagged juvenile summer Chinook salmon were used to quantify the differences in direct mortality associated with turbine passage for the MGR and conventional turbines - this was the largest such study of fish survival in turbine passage ever attempted. In addition to dofunding studies conducted by GCPUD, DOE supported the following research at the Wanapum Dam:

- Behavioral response of turbine-passed fish

- Biomarkers

- Injury Assessment with Dye Studies

\subsubsection{Behavioral Response of Turbine-Passed Fish}

Indirect mortality of turbine-passed fish (e.g., increased predation among uninjured but disoriented fish) is a major unresolved problem at hydropower projects in general, especially at the Columbia River dams, such as Wanapum Dam. A subsample of the fish that passed through the Wanapum Dam turbines or were introduced directly downstream from the dams as controls were examined for changes in behavior. We measured various attributes of C-start (burst) swimming performance typically used by prey fish to escape capture. Uninjured fish were retrieved from the tailwaters and rapidly transferred to the turbine deck, where their C-start behavior was recorded with a high-speed camera for later analysis (Figure 2-5). Behavior was recorded at 1, 5, and 15 minutes after return to the turbine deck to assess whether behavior changes are temporary. Aspects of C-start (escape) behavior that were compared among control and turbine-passed fish (and between the old and new MGR turbines) were presence/absence of the C-start, time to onset of the reaction, duration of the reaction, and strength of the reaction. The C-start assay was used to test the hypothesis that the advanced turbine induces less sublethal stress (that might lead to increased predation mortality) than the conventional turbine.

Relatively few significant differences were detected in overall C-start behavior or its components that could be attributed to turbine passage conditions (Cada et al. 2006). In most cases, the behaviors of turbine-passed fish were not different from their respective tailrace-passed controls. Similarly, there were few test conditions in which we were able to distinguish between the conventional Kaplan turbine and the new MGR turbine on the basis of changes in the escape behavior of uninjured fish. These results are consistent with the findings of the coincident direct mortality studies, which found a high post-passage fish survival for both turbines (> 94 percent) and no difference overall between the two turbines. 


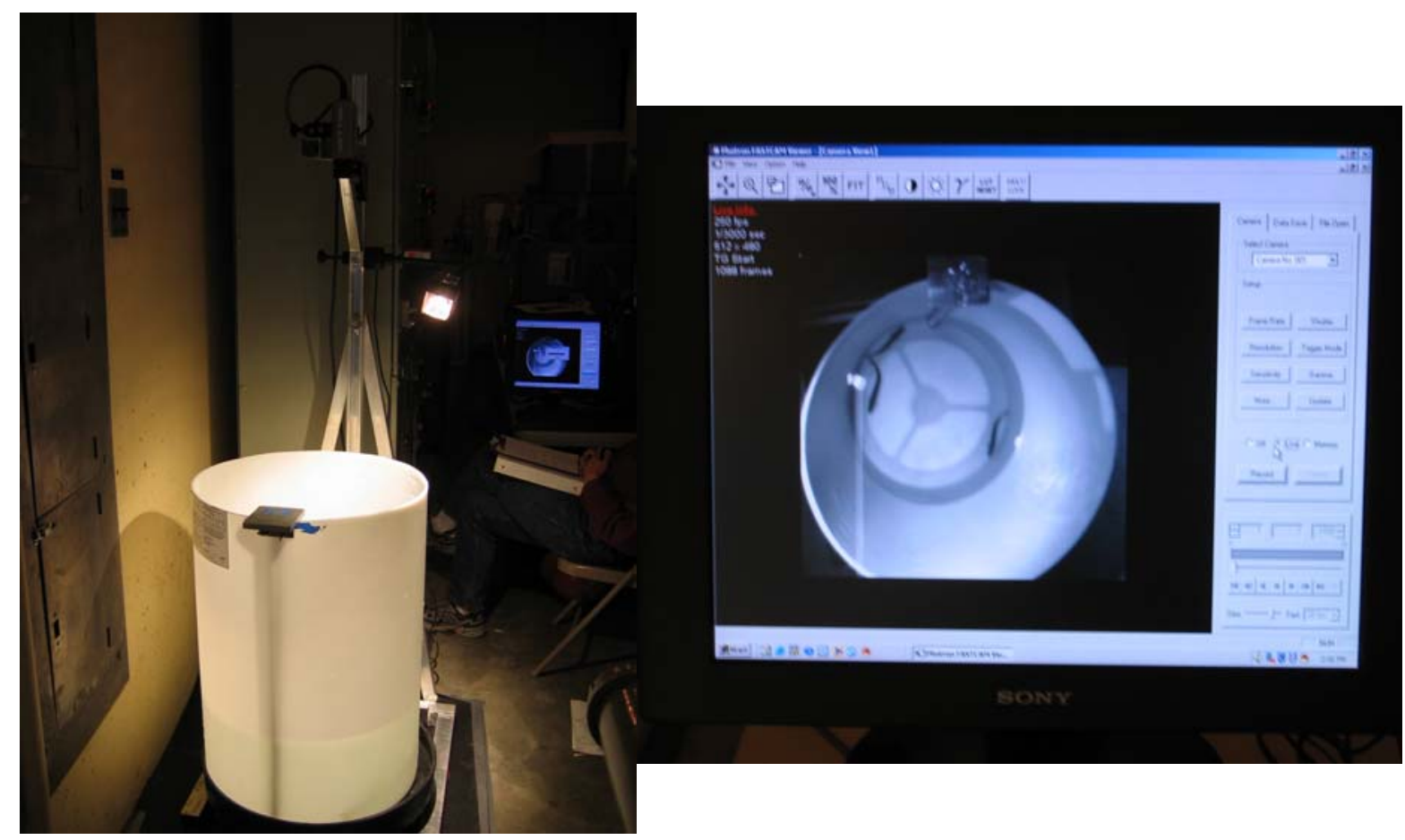

Figure 2- 5. Observation tank and hi-speed camera used to record C-start behavior in turbine-passed fish at the Wanapum Dam, Washington.

\subsubsection{Biomarkers}

Biomarkers are biochemical measures of an organism's physiological response to stresses. We investigated the feasibility of using biomarkers to detect nonlethal fish response as they pass through turbines by adding additional sampling to the balloon-tag studies at Wanapum Dam. The spring 2005 fish survival testing at Wanapum Dam also afforded us the opportunity to test multiple physiological parameters as indicators of the stress experienced by fish during turbine passage. For example, elevated serum cortisol levels are often indicative of stress in fish. We collected blood serum and gill tissue samples from turbine-passed and control fish in order to measure the concentrations of cortisol and stress-indicating proteins. At the beginning of the test, juvenile Chinook salmon were anesthetized, balloon-tagged, weighed, and measured. After tagging, fish were placed into pipes that released them into the turbine intake at a depth of $30 \mathrm{ft}$. Fish passed through the turbine and into the tailwaters. Boats patrolling the tailrace area quickly netted the fish and returned them to the deck area of the dam, where they were placed in tanks and held for 48 hrs prior to evaluation. After other investigators had evaluated the fish for injury, we collected blood and tissue from a subset (eight) of eight treatment groups (four flows - 17, 15, 11, and $9 \mathrm{kcfs}$ and two turbines - the Unit 8 advanced MGR and Unit 9 conventional Kaplan). Control groups also tested included 1) fish released into the tailrace rather than through a turbine, then collected and held for $48 \mathrm{hr}$, 2) fish released into a turbine and processed immediately after capture, and 3) fish sampled directly from the pre-test holding tank, without tagging and anesthesia.

Blood serum was later analyzed for cortisol, and gill tissue samples were submitted for stress protein induction. The stress protein analysis is not yet completed. The cortisol results show that stress levels were significantly $(\mathrm{P}<0.10)$ reduced in fish passing through the new MGR turbine 
compared to the old turbine at 15 and $9 \mathrm{kcfs}$ (Figure 2-6). No differences were found between turbines at 17 and $11 \mathrm{kcfs}$. Fish released into the tailrace rather than through turbine had higher cortisol levels than those passed through either turbine at three of the four flows tested. Controls sampled immediately after

turbine passage rather than $48 \mathrm{hr}$ later exhibited cortisol levels twice that of fish that were held $48 \mathrm{hr}$. Lower cortisol levels after $48 \mathrm{hr}$ of holding suggests that the holding period allowed for some stress recovery. These data suggest that in terms of serum cortisol concentrations, the new MGR turbine design causes no more stress than the conventional turbine design.

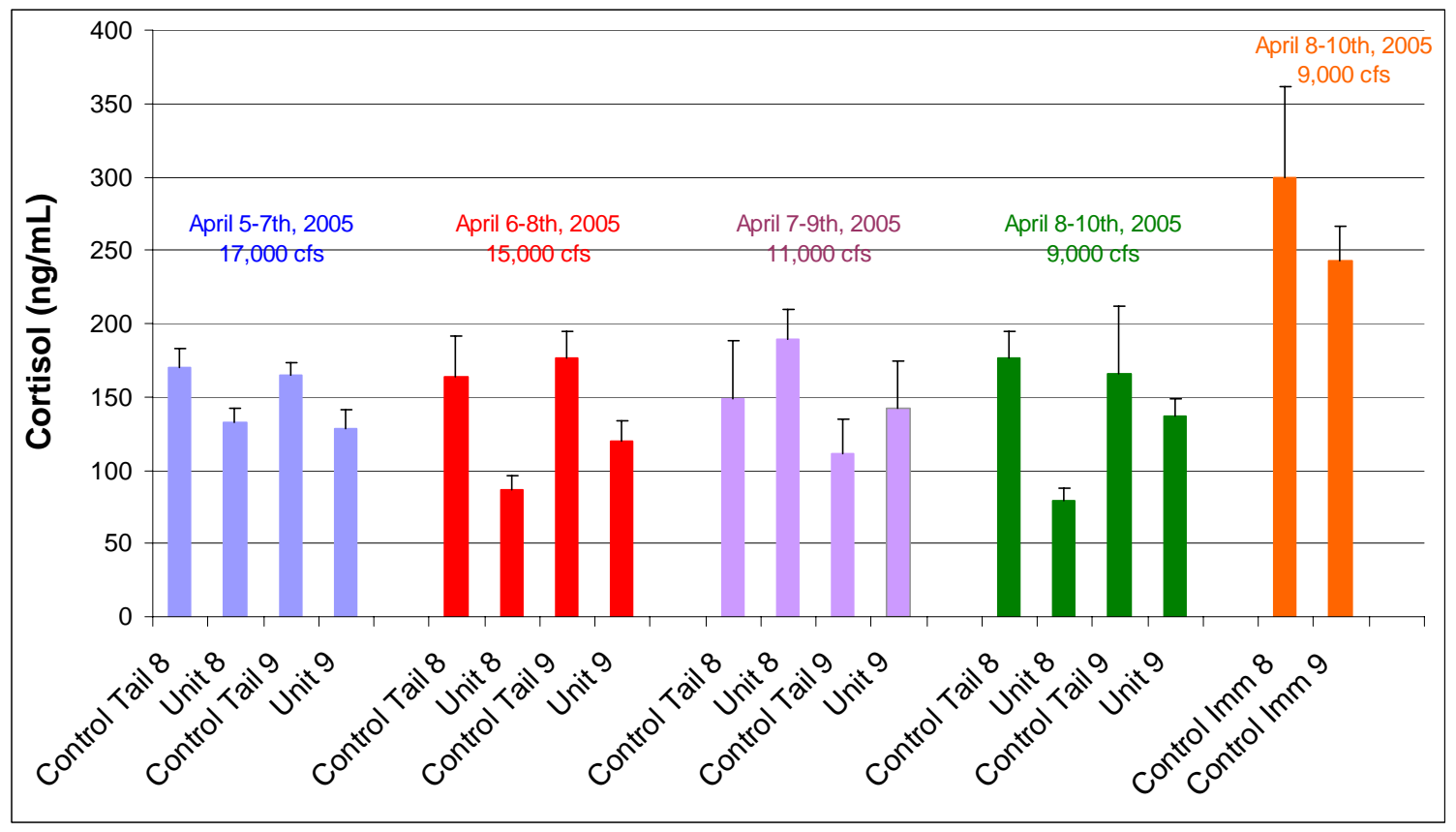

Figure 2- 6. A comparison of juvenile Chinook salmon cortisol levels after passing through the old Kaplan turbine (Unit 9) or the new MGR turbine (Unit 8) at Wanapum Dam. Colors represent different days of blood cortisol sampling, with the release date being 2 days prior to sampling. Two different controls were sampled: tagged, released to tailwater, and sampled after 48 hrs (control tail); and tagged, released into turbine, sampled immediately (control imm).

\subsubsection{Biolndex Testing}

Bio-indexing of hydro turbines is an important means to optimize passage conditions for fish by identifying operations that minimize the probability of injury. Cost-effective implementation of bio-indexing requires the use of tools such as numerical and physical turbine models to generate hypotheses for turbine operations that can be tested at prototype scales using live fish. The objectives of this project were 1) to investigate the use of mathematical and physical models to identify the operating range of best biological performance (i.e., lowest risk of injury) for fish passing through hydro-turbines and 2) to design field tests using live fish to validate the proposed operating ranges.

In 2005 and 2006, we developed numerical deterministic and stochastic blade strike models for a 1:25-scale physical turbine model built by the U.S. Army Corps of Engineers for the original design 
turbine at McNary Dam and for prototype-scale original design and replacement minimum gap runner (MGR) turbines at Bonneville Dam's first powerhouse. The stochastic model was implemented by randomizing the input variables such as discharge, fish length, and orientation using the Monte Carlo method. The performance of the numerical blade-strike models was then evaluated by comparing predictions of fish mortality resulting from strike by turbine runner blades with 1) predictions of blade strike made observing neutrally buoyant beads passing through the 1:25-scale McNary Dam physical turbine model and 2) observations of fish injury made using live fish at Bonneville Dam.

We concluded that the numerical blade strike models are valuable and cost-effective tools for assessing the biological performance of large Kaplan hydro turbines as it relates to blade strike. In addition, we found that fish orientation at the time of entry into the plane of the leading edges of turbine runner blades is one of the most significant factors and uncertainties in blade-strike modeling. Based on our results, we recommend the use of stochastic blade-strike models that consider the aspect of fish approaching the leading edges of a turbine runner's blades. Randomization of fish aspect appears to provide a more comparable prediction with experimental results and should be the preferred method for prediction of blade strike and injury probability for juvenile salmon and steelhead using numerical blade-strike models. Future models of blade strike should incorporate three-dimensional computational fluid dynamics simulations of the turbulent flow environment that are coupled with computing the motion of fish-sized objects interacting with the turbine system components.

\subsubsection{Injury Assessment with Dye Studies}

A novel technique for the detection and quantification of external fish injury has been developed at PNNL. This detection method is a more sensitive and objective measure of external fish injury than the unaided eye. From initial laboratory experiments through recent field deployment, this methodology has demonstrated the detection and quantification of injuries that are otherwise not visible and/or not readily visible. The procedure involved exposing fish to a non-toxic dye then exposing them to filtered ultraviolet light, revealing scrapes, cuts, abrasions, descaling, or puncture wounds. These fish are then digitally photographed for image processing and archival. The photographs are examined using image analysis techniques that quantify images using exactly the same algorithms and criteria for each fish. This computerized image processing and analysis reduces the variability of the results and increases the statistical power to detect differences.

The biological testing of the new MGR turbine unit at Wanapum Dam in coordination with GCPUD provided the deployment context for this study. The balloon tag test procedure underway allowed fish to be recovered and examined immediately after exposure to turbine passage in a statistically arranged treatment design. This injury assessment replicated a small portion of the overall fish survival study design to test the technique under field conditions in 2005.

Images obtained from fish released into both the conventional Kaplan (Unit 9) and advanced turbine (Unit 8) documented several types of injuries occurring during turbine passage that were not clearly detectable with the naked eye. Injury sites were detected on the head region (including the eye, isthmus, and operculum) and other body regions of turbine-passed fish. We found that injuries to the eye were both consistent and easily quantified. Two examples of those eye injuries are shown in Figure 2-7. The results showed an interaction of factors with trends such as an increased frequency of eye injuries at lower discharge and in unit 9. This study successfully demonstrated the feasibility of the dye injury assessment technique as a new tool in fish passage research with the potential to increase the statistical sensitivity of current direct fish survival methods. 

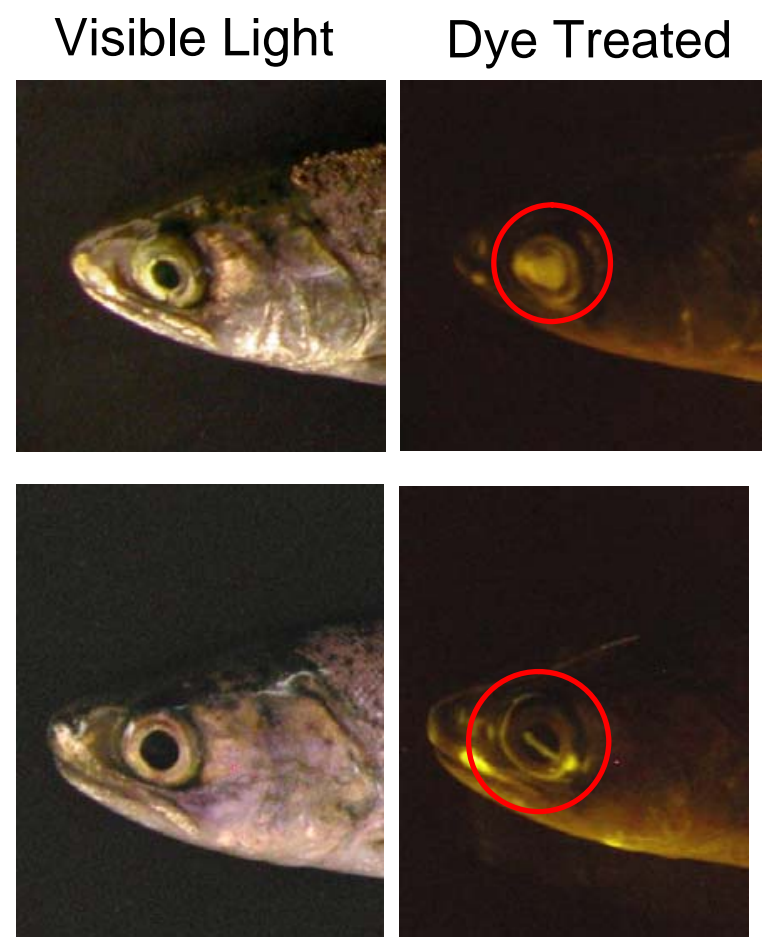

Figure 2-7. Damage to the eye was easily identifiable with the dye, even though quite invisible under normal fish injury evaluation conditions.

Photograph as seen by the naked eye under visible white light (left), and following dye exposure (right).

\subsubsection{Instrumentation and Controls}

The intent of this project area is to develop new technologies to measure physical conditions inside turbines and new methods to predict both the physical conditions inside an operating turbine and the biological effects of those conditions. These technologies and methods will increase understanding of conditions affecting fish inside turbines and provide knowledge of needed design modifications that will reduce adverse effects on the fish passing through turbines.

\subsubsection{Sensor Fish Development}

In 2005, angle rate-of-change sensors were added to the sensor fish to provide complete 6 degree of freedom (6DOF) motion measurements. Several other modifications were made to the sensor to decrease the time and handling required to download data, to increase the digital sampling rate by an order of magnitude, increase data storage capacity, add flexibility in programming data acquisition parameters, and improve battery performance. All of these changes were made without significant changes to the mass, shape, or volume of the sensor.

The new 6 DOF sensor fish device was first used to help assess the biological performance of a newly installed turbine at Wanapum Dam located on the Columbia River in Washington State. The study required over 1,000 sensor fish device releases into conventional design and advanced MGR design turbines. 
Several hundred sensor fish device releases have been made into original design turbines at Ice Harbor, John Day, and Bonneville II dams located on the mainstem Columbia River. Releases were made in the plane of the downstream intake gate slot at elevations identified using 1:25 scale physical models of the turbines. Acquired acceleration, angular rate-of-change, and absolute pressure data were analyzed. Figure 2- 8 is a scattergram of data obtained by analysis of pressure time history data. The nadir (lowest measured pressure, plotted on the abscissa) occurs during passage of the sensor through the turbine runner.

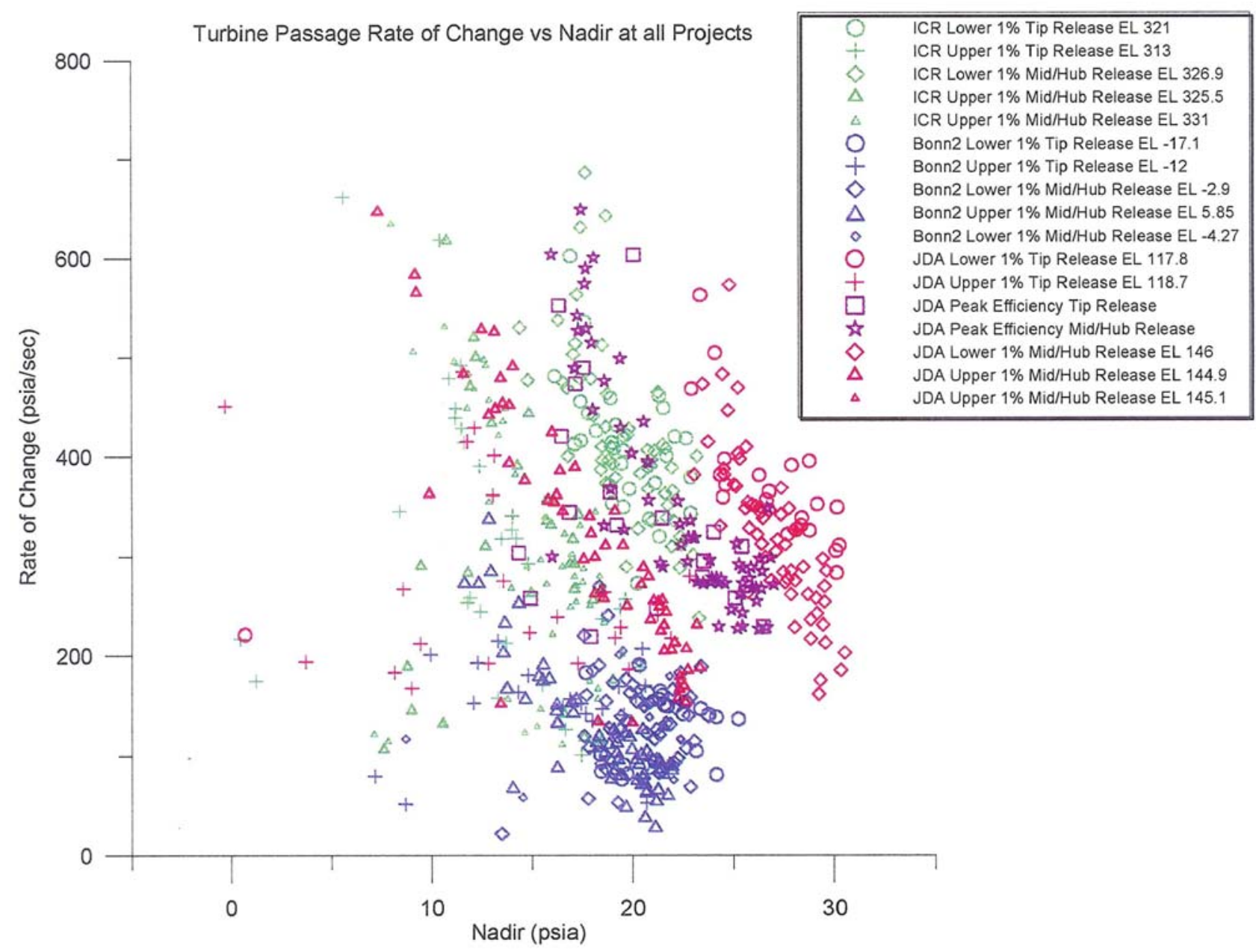

Figure 2- 8. Turbine Passage Rate of Change vs. Nadir for Ice Harbor, John Day, and Bonneville II Test Turbines. ICR = Ice Harbor; Bonn 2 = Bonneville II; JDA = John Day. 
Collectively, this new information has caused us to reconsider variables that should be considered when the effects of pressure changes on fish during turbine passage are studied. While direct mechanical injury rates have been shown to be similar for turbine passed fish at these projects, total turbine passage survivals have been found to be much less for John Day and Ice Harbor than for Bonneville II. The data we acquired using sensor fish show that the nadirs and pressure rates-ofchange for Bonneville are different than those for the other two projects. In particular, the higher nadirs and lower pressure rates-of-change occurring in Bonneville II turbines may provide safer passage conditions than the lower nadirs and higher pressure rates-of-change observed at Ice Harbor and John Day dams.

The new sensor has also been used in a number of studies to assess fish passage conditions through tainter gate controlled and overflow weir spillbays. In addition to new information to estimate the exposure of fish to mechanical strike, collision on structure, shear, and severe turbulence, sensor fish device data is providing new insight to the exposure to pressure fish experience during turbine passage.

\subsubsection{Turbulence Measurement with Acoustic Doppler Velocimeters}

Flow in the draft-tubes of turbines is dominated by large-scale, unsteady vortices induced by residual swirl at the exit of the turbine runner, pressure gradients associated with the strong curvature of draft-tube walls, and the interaction of the flow with splitter plates and piers within the draft tube. Vortices affect hydroelectric unit efficiency and operation and may influence delayed mortality or predation of turbine-passed fish. To date, most of the turbine research has been aimed at understanding flow fluctuations in zones of the turbines that are upstream of the draft-tube. Few data exist that would document the structure of unsteady flow in draft tubes and tailraces. Ongoing efforts within the DOE Hydropower Program to develop CFD models of unsteady flow in hydroturbines will require full-scale measurements of draft tube turbulence for validation.

The turbulence measurement system (TMS) was designed and built in 2002 by TVA, with funding from DOE; it includes standard acoustic-Doppler velocimeters (ADV) with modified signal processing and synchronization schemes for measurement of high-speed (greater than 10 feet per second) flows encountered in draft tubes. The TMS was field tested with mixed results in June 2002 in a draft tube at TVA's Melton Hill Hydro Project. Refinements were made to the system in 2003 and 2004 to extend the range of the TMS to capture rapid high-speed fluctuations of velocity (those that contribute significantly to Reynolds shear stresses). The enhanced TMS was deployed in the streamlined flows of TVA turbine intakes (Smith and Sale, 2006), but field test scheduling constraints have thus far precluded full-scale retesting of the enhanced TMS in draft tubes. Additional laboratory flume work will be completed in 2006 by TVA and ORNL which will improve the real-time data analysis capabilities of the TMS and quantify the noise levels of TMS velocity data in axisymmetric jets with and without swirling flow. Plans to return to full-scale draft tube testing, either at TVA's Melton Hill Project or in the draft tube of the new MGR unit at Wanapum Dam, have been postponed. 


\subsubsection{Computational and Physical Modeling}

Computational and physical models of hydropower turbines are valuable tools for estimating performance metrics that are difficult to measure directly. The high-energy, chaotic hydraulic environment inside turbines is especially challenging for direct measurements. Computational fluid dynamics (CFD) modeling is a rapidly expanding area that holds great potential for improving turbine designs. The DOE program supported a number of different modeling studies that provide valuable information that cannot be obtained by other methods, including:

- Blade-strike modeling,

- Integrated analysis of sensor fish data

- Biomechanics CFD

- Unsteady CFD and Virtual Sensor Fish

\subsubsection{Modeling Blade Strike of Fish}

This study applied both deterministic and stochastic blade-strike models to the original and advanced design turbines at Wanapum Dam (Deng et al. 2006). The modeled probabilities were then compared to the results of Sensor Fish releases (Carlson et al. 2006) and to estimates of injury/mortality of juvenile fish by Normandeau et al. (2006) that were tested under the same operational parameters.

For both turbine units, there was higher variability in the experimental results between different release locations or discharges than in the numerical results. This observation is consistent with the findings of our previous study in a 1:25 scaled physical model (Deng et al 2005) that the rate of severe contact of neutrally buoyant particles had higher variability between test conditions than the modeled results. Injury rates by the deterministic model were higher than the experimental rates of visible injury or mechanical injury, but injury rates predicted by the stochastic model were similar to the rates of visible injury. That there was better agreement between experimental data and stochastic model results is due to the fact that the stochastic blade-strike model considers the aspect of fish as they approach the leading edges of a turbine runner's blades. Although the new MGR turbine design had slightly higher modeled injury rates that the original turbine, there was no statistically significant difference in blade-strike injury probabilities between the two turbines. Thus, our modeled results were consistent with results of the field experiments involving Sensor Fish and juvenile salmonids.

\subsubsection{Integrated Analysis of Sensor Fish Data}

Computational fluid dynamics and particle tracking were used to improve the evaluation of the probable path of the sensor fish through the Wanapum Dam turbine system and then to perform an extended analysis of the response of the sensor fish to strike, pressure, and turbulence for different regions within the turbine system.

PNNL collaborated with GCPUD and Voith-Siemens on CFD applications for the Wanapum Dam. The CFD model (STAR-CD) solved the unsteady Reynolds-averaged Navier-Stokes equations together with the k-epsilon turbulence model. The computational domains included the complete intake, stay vanes, wicket gates, blades, and draft tube. The so-called arbitrary sliding interface technique was used to simulate the motion of the blades and capture the interaction between the wicket gate wakes and blades (rotor-stator interaction). The unsteady simulations were computationally intensive and were carried out on a Silicon Graphics Altix parallel computer using 
36 processors. The unsteady CFD model output was archived for later use by a Lagrangian particle tracking code that was used to simulate the trajectories of particles that were neutrally buoyant and had a mass equivalent to the sensor fish.

As part of the integrated analysis, Sensor Fish pressure and acceleration measurements were analyzed to identify characteristic signatures for particular passage event. These signatures are very helpful in identifying the occurrence and location of severe events, such as strikes. Readily identifiable are the time of passage from the injection pipe exit into the turbine intake, passage through the turbine stay vane-wicket gate cascade, the time upstream of the runner, passage through the runner, the runner wake, and passage through the draft tube. These distinctive "signature" events were used together with the Wanapum Dam CFD results to estimate the probable location and time of collision or shear exposure events. Collision and shear levels have been divided into three severity classes: severe (greater than 95 g), medium (between 95 and 50 g), and slight (between 50 and 20g). The sensor fish data and CFD data have also been used to identify passage zones within the turbine. These zones are the intake (from release to just upstream of the stay vanes), stay vane and wicket gate, runner, and draft tube (Figure 2-9). The data were analyzed to determine the number and severity of collision and shear events within each region and for each combination of test conditions (discharge, release pipe elevation, and release intake bay). Figure 2-10 shows the probability of severe events for each region within the turbine.

The combined use of sensor fish, CFD, and particle tracking has provided a more detailed and complete picture of fish passage conditions within a turbine. The project has made a significant step forward in the development of computational tools and supporting field data that can be used by manufacturers to design fish-friendly turbines. 


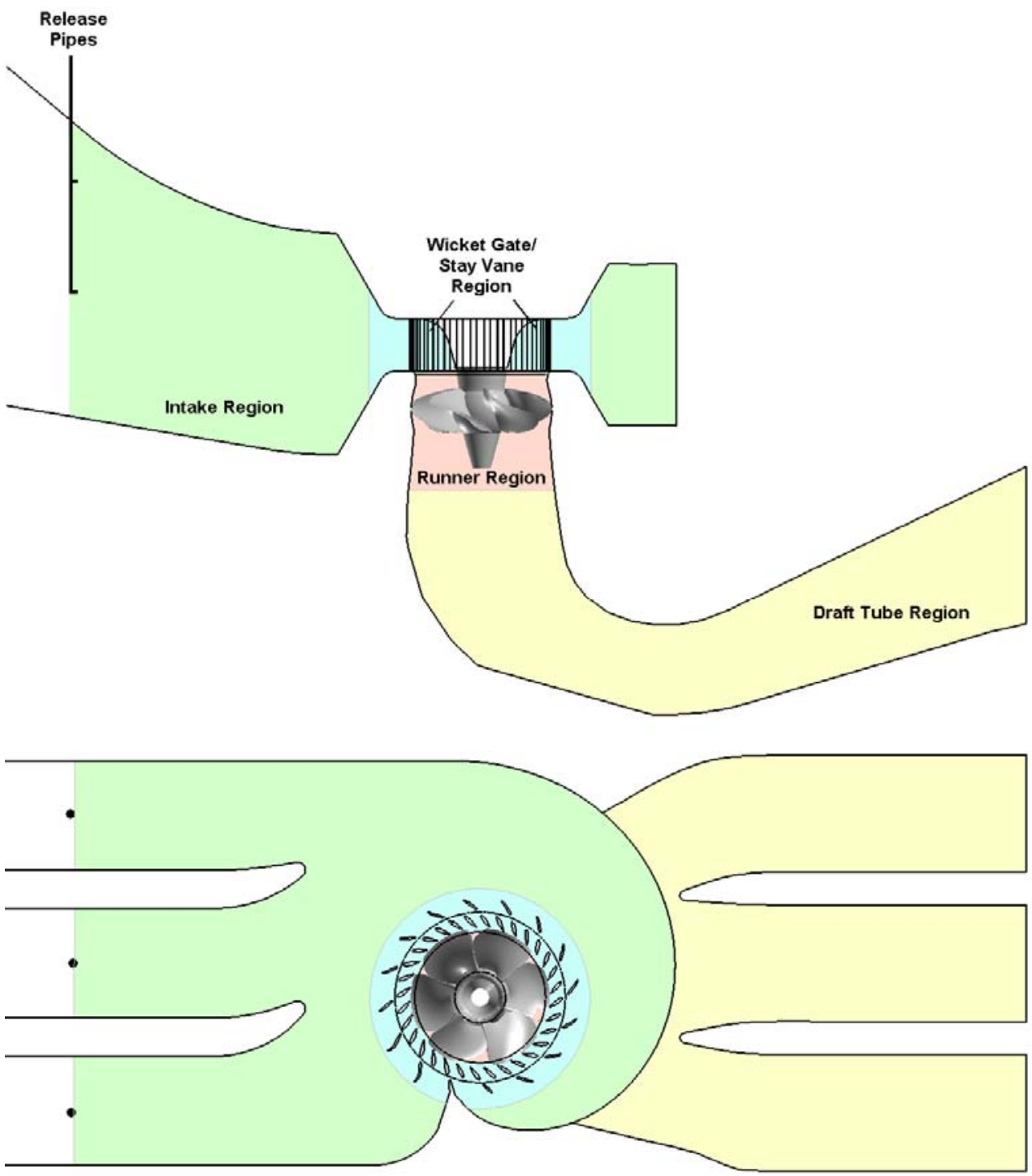

Figure 2- 9. Illustration of different zones used for detailed Sensor Fish data analysis 


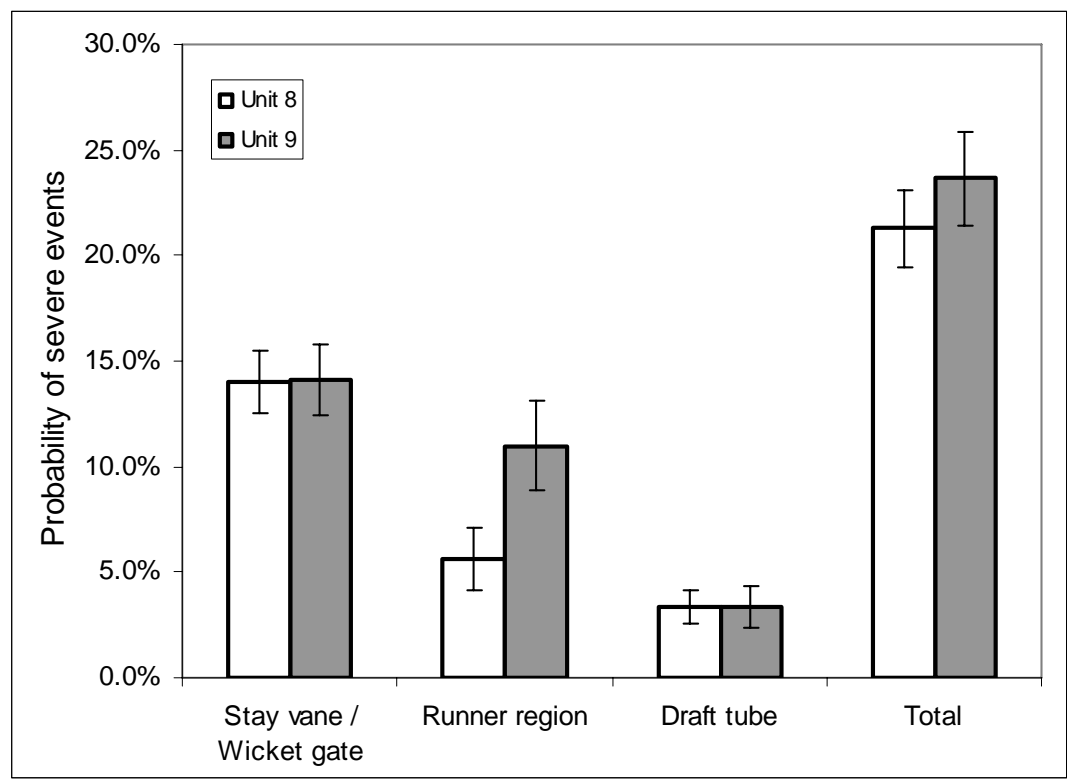

Figure 2- 10. Comparison of probabilities of severe events recorded by sensor fish in different regions of the existing (unit 9) and new MGR turbines (unit 8) at Wanapum Dam. No severe events occurred in the intake region.

\subsubsection{BioMechanics CFD}

Studies conducted at PNNL (Neitzel et al. 2004) have shown that fish can be directly injured or killed by exposure to shear and turbulence and that temporary disability, such as stunning, increases indirect mortality by predation. These experiments related fish injuries to the fluid environment in a general manner; missing are detailed measurements of the bending and torsion of the parts of the fish body, total force acting on the fish, and how these are related to the observed injuries. Detailed measurements and computations are necessary to gain an improved understanding of the biomechanics of injury mechanisms and injury thresholds.

During FY 2005 we continued with the development and application an inertial particle tracker code for objects with six-degrees-of-freedom (6DOF) or three-degrees-of-freedom where the flow field is supplied by results from an external computational fluid dynamics (CFD) simulation. The 6DOF particle tracker has several features that are key for applications to biological response in hydropower systems. These include collisions with moving or stationary meshes and boundaries (with variable coefficient of restitution), tracking on unstructured or structured CFD grids, stochastic motion using a sub-grid scale turbulence scheme, and the ability for each particle to record its exposure history to variables (pressure, etc) and events (shear, collisions, etc) in the simulated turbine environment. Enhancements in FY 2005 included incorporating sensor fish specific drag, lift, and pitching moment data (from wind tunnel tests), accounting for turbulence using an eddy interaction model, and increased computational efficiency. In addition to turbines, the particle tracker has also been applied to spillways (in conjunction with sensor fish) to look at collisions with deflectors and in forebays to aid in site selection for fish guidance structures. 
In FY 2005, experiments were conducted using hatchery fall Chinook salmon and the 6DOF sensor fish device in order to establish correlation metrics between sensor fish measurements and live fish injuries during exposure to turbulent shear flows. Two representative exposure scenarios were investigated. In the fast-fish-to-slow-water scenario, test fish were carried by the fast-moving water of a submerged turbulent jet and exposed into the standing water of a flume. In the slow-fish-to-fastwater, test fish were exposed into turbulent jet from the standing water via an introduction tube which was placed just outside the edge of the jet. Motion-tracking analysis was performed on high-speed, high-resolution digital videos of all the releases with water jet velocities ranging from 3 to $22.9 \mathrm{~m} / \mathrm{s}$. Quantile regression was used to develop correlation between live fish accelerations and sensor fish measurements, then binomial logistic regression was used to relate the probability of specific biological responses to sensor fish measurements.

The project has developed a set of tools that provide a link between laboratory experiments of fish injuries, field survival studies, numerical modeling, and support the development of biological design criteria for improving passage and survival of downstream migrating juvenile salmon and steelhead.

\subsubsection{Unsteady Computational Fluid Dynamics Modeling}

Unsteady CFD work for FY 2005-2006 started at Georgia Tech continued at the St. Anthony Falls Laboratory (SAFL) of the University of Minnesota. The objective of the work was twofold:

- to apply the advanced, coherent-structure resolving, turbulent flow solver developed in FY 2004 and FY 2005 to simulate unsteady flow in the modified draft tube of Wanapum Unit 8, downstream of the the new fish-friendly minimum gap runner, at two operating conditions and

- to demonstrate a novel stochastic CFD framework for calculating environmental performance indexes (EPIs) of hydraulic turbines. Specifically, EPIs for the modified Wanapum Unit 8 draft tube were computed using the Virtual Sensor fish (VSF) model.

Unsteady turbulent flow in the Wanapum Unit 8 draft-tube was calculated at two operating conditions: 1) a discharge of 11,000cfs, corresponding to a bulk Reynolds number of $1.0 \times 10^{6}$, and 2) a discharge of $17,000 \mathrm{cfs}$, corresponding to a Reynolds number of $1.65 \times 10^{6}$. The detached-eddy simulation turbulence modeling approach employed for both cases used a computational domain discretized with 2.1 million grid nodes allocated to multiple overset chimera grids. The details of the numerical method and turbulence modeling approach can be found in Paik et al. (2005).

Unlike earlier simulations, which employed steady inflow conditions at the draft-tube entrance, the most recent simulations benefited from a new approach developed by SAFL researchers for implementing unsteady inflow conditions. The new approach accounts for the effect of the rotating turbine blades in approximate manner, in that the results of steady RANS simulations for the runner flow, provided to SAFL by Voith/Siemens Hydro Inc., were post-processed to transform the velocity field at the exit of the runner from the rotating frame of reference to the inertial frame of reference. Thus, in the inertial frame of reference, the imposed inflow conditions at the draft-tube entrance rotate at the angular velocity of the runner. The calculated flow fields were found to be dominated by complex coherent flow structures. The model is able to reproduce a precessing rope vortex below the runner hub that forms and breaks down periodically. It also reproduces other important structural features of prototype draft tube flows, including three-dimensional flow separation zones, zones of flow reversal, and vortex shedding along the inner radius of the draft tube elbow (e.g., Figure 2-11; Paik and Sotiropoulos, 2005). 


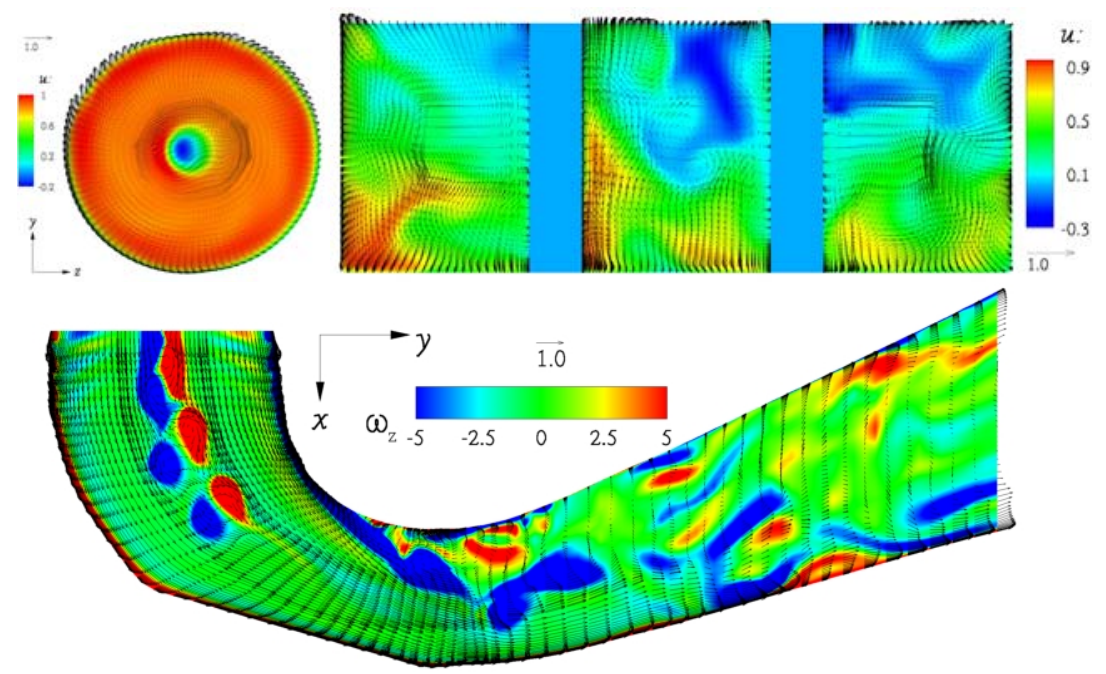

Figure 2- 11. Snapshots of computed instantaneous flow at the operation point II: (upper left) streamwise velocity contours and swirling velocity vectors at a plane just downstream of the inlet; (upper right) streamwise velocity contours and cross-velocity vectors at the outlet; and vorticity and velocity vectors and vorticity contours at the vertical center $(x-y)$ plane.

The statistical EPI approach developed in this work consists of applying the previously developed 6-degree of freedom VSF model for a large ensemble of virtual sensors released from a uniformly distributed set of initial release points at the draft-tube entrance. VSF are continuously released from each release location and their trajectories are calculated simultaneously with the solution of the flow equations. Lagrangian statistics, or integrated measures of VSF kinematics and dynamics along their trajectories through the fluctuating flow field, can thus be calculated and mapped back to the initial release locations. These maps can be used to develop EPIs for each modeled operating condition and may be based on residence times in the flow path or on statistics of acceleration, shear, and other hydrodynamical forces exerted on VSF. The results reveal significant variability of the Lagragian statistics with release locations and with turbine operational condition. Further analysis of these results to quantify incidents where VSF strike the draft-tube walls has shown that collisions of VSF tend to occur primarily near the outer wall of the elbow just downstream of the inlet plane (e.g., Figure 2-12; Paik et al., 2005). 

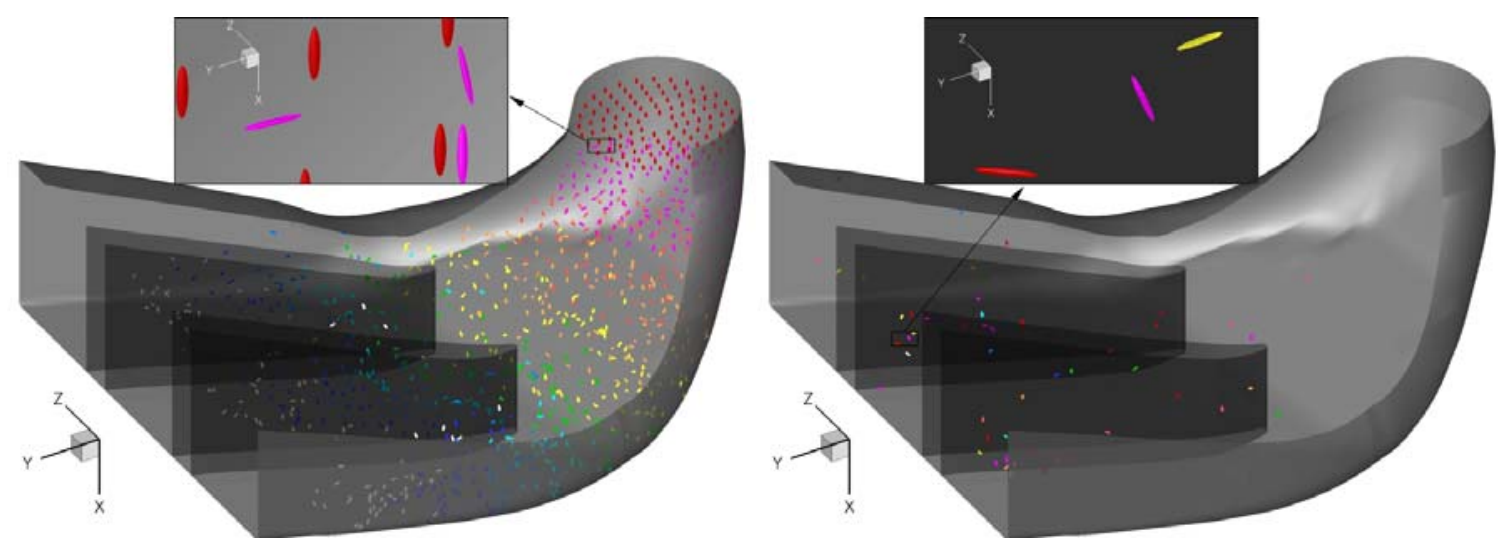

Figure 2- 12. Snapshots of VSF at two different instants in time (operation point II). Ten different colors of VSF are used to mark the different 10 release times at the inlet plane. The number of same color VSF released at each time at the inlet plane is 108.

\subsubsection{Environmental Analysis}

The Environmental Analysis activities aim to develop general approaches for estimating both the ecological impacts of hydropower operation and the beneficial effects of mitigation measures. In FY 2005-06, two projects were supported in this area: a study of the effects of multiple dams on migrating salmon, and a water quality modeling application that is related to measuring one aspect of environmental performance.

\subsubsection{Effects of Multiple Dam Passage}

Juvenile salmonids originating in the Snake River upstream of Lower Granite Dam must pass up to eight hydroelectric projects during their downstream migration to the Pacific Ocean. Fish may pass a project through a turbine or a spillbay or be screened into a bypass system that either collects fish into a barge or releases them downstream of the project. If single project passage survival estimates are applied at each passage event, then the underlying assumption is that the mortality at each project is independent of prior exposure. If individual fish approaching a project were already sub-lethally stressed, higher-than-expected mortality rates might occur upon subsequent passage events. Our hypothesis is that fish passing more than one turbine will experience a greater than expected rate of mortality. Because measuring an incremental increase in mortality would be challenging in the field, we developed an approach to first assess whether such an increment has any potential to influence a fish population. This approach identified populations at risk and will help design laboratory or field experiments to address those risks.

In our study, we used a spreadsheet model of juvenile salmonid passage and survival in the Snake and Columbia River systems to simulate passage-route histories across a range of conditions for several runs and to assess the risk of passing multiple turbines. The Simulated Passage model (SIMPAS) was developed by the National Marine Fisheries Service to simulate fish passage proportions through turbines and other routes along with route-specific survivals as calibrated by research results and regional consensus. The model was run under current system operational guidelines for some representative flow years to evaluate what conditions lead to the greatest risk of passing multiple turbines. The model was modified to simulate a hypothetical increase in mortality as 
a result of passing multiple turbines. This multiple turbine effect (MTE) was simulated at various levels, from a small increase in mortality to the extreme case of complete mortality upon passing more than one turbine.

The proportion of fish passing multiple turbines in a simulation varied due to species differences, due to distribution of flow among passage routes, and in response to management options such as the juvenile fish transportation program. Even at the most extreme levels of MTE simulated, the number of successful downstream migrant juvenile spring Chinook salmon (Oncorhynchus tshawytscha) and steelhead (O. mykiss) declined less than $8 \%$ during scenarios with transport. The number of juvenile fall Chinook salmon (O. tshawytscha) declined by $14 \%$ and $17 \%$, respectively, in low and average flow years with transport. An MTE of $59.0 \%$ in a low-flow year or $44.5 \%$ in a high-flow year was reduced the number of successful downstream migrant juvenile fall Chinook salmon arriving downstream of Bonneville Dam by 10\%. For all runs and flow years, fewer juvenile salmon were predicted to arrive downstream of Bonneville Dam for scenarios where transport was turned off.

The potential for a multiple turbine effect to have adverse impacts on populations of spring Chinook salmon and steelhead is negligible under current management guidelines. However, in spite of the management efforts to minimize turbine passage during the summer migration period, the potential for an impact to fall Chinook salmon cannot yet be ruled out. Simulations indicated that fall Chinook salmon in low and average flow years had the greatest potential for a MTE to reduce the number of juveniles arriving downstream of Bonneville dam by at least $10 \%$. Modeling also predicted that a relatively large MTE would be required to reduce the number of migrants by $10 \%$.

Because the MTE required to notably impact fall Chinook salmon is predicted to be large, a field experiment to detect whether it exists appears feasible. An experiment designed to detect impacts smaller than the threshold level could provide a statistically rigorous demonstration that the effect is too small to have an impact on the population. Conversely, the same experiment should easily detect an impact if it exceeded the threshold level.

\subsubsection{Water Quality Modeling}

Low dissolved oxygen concentrations (DO) in rivers below dams is a common environmental problem associated with hydropower projects. For example, approximately $40 \%$ of all FERC-licensed projects have requirements to monitor and/or mitigate downstream DO conditions. One area of the Hydropower Program research is the development of advanced turbines that improve downstream water quality and aquatic communities by mitigation measures that increase the concentrations of DO in water discharged from the turbine. Because most forms of mitigation for increasing DO in dam tailwaters are expensive, there is great interest in being able to predict the benefits of these modifications prior to committing to the cost of new equipment. In the case of measured water quality mitigation involving turbine replacement or modification, there is a need for methods that allow us to accurately extrapolate the benefits derived from one or two turbines with improved design to the likely benefits of replacement or modification of all turbines at a site.

The main objective of this study was to demonstrate a modeling approach that integrates the effects of flow and water quality dynamics with fish bioenergetics to predict DO mitigation effectiveness over long river segments downstream of hydropower dams (Bevelhimer and Coutant, 2006). We were particularly interested in demonstrating the incremental value of including a fish growth model as a measure of biological response. The models applied are a suite of tools (RMS4 modeling system) originally developed by the Tennessee Valley Authority for simulating hydrodynamics (ADYN model), water quality (RQUAL model), and fish growth (FISH model) as influenced by DO, temperature, and available food base. 
We parameterized a model for a 26-mile reach of the Caney Fork River (Tennessee) below Center Hill Dam to assess how improvements in DO at the dam discharge would affect water quality and fish growth throughout the river. We simulated different types of mitigation (i.e., at the turbine and in the reservoir forebay) and different levels of improvement. The model application successfully demonstrates how a modeling approach like this one can be used to assess whether a prescribed mitigation is likely to meet intended objectives from both a water quality and a biological resource perspective. These techniques can be used to assess the tradeoffs between hydropower operations, power generation, and environmental quality. 


\section{TECHNOLOGY APPLICATION}

The mission of Technology Application is to conduct research and perform analyses that identify barriers to hydropower development and to devise strategies to reduce those barriers. It addresses the following:

- Quantifying technical issues, economic costs, environmental constraints, and benefits of integrating hydropower and wind operations

- Pursuing the establishment of a national hydropower coordinating committee with members representing all stakeholder and interest groups and that will elicit input concerning program issues and inform program direction

- Providing outreach and information transfer concerning program activities and R\&D results to other agencies, industry, nongovernmental organizations, and the public

- Quantifying the varied benefits of hydropower to help the public and policymakers properly position hydropower in future competitive energy development considerations

- Evaluating unconventional turbine designs to address the undeveloped low-head/low-power potential identified in every region of the country.

A goal of Technology Application is to enable industry to begin developing the untapped lowhead/low-power potential in the United States without constructing new dams. The two research areas within Technology Application are Systems Integration and Technology Acceptance (summarized in Section 3.1) and Supporting Engineering and Analysis (summarized in Section 3.2). The two subkey activities within Technology Viability are:

- Systems Integration and Technology Acceptance; and

- Supporting Engineering and Analysis.

\subsection{Systems Integration and Technology Acceptance}

The Systems Integration and Technology Acceptance activity includes the integration of hydropower with other renewables, an activity that was started in FY 2004. With many renewable energies being intermittent in nature, hydropower represents an important stored energy asset that can enable the larger scale deployment of renewable power plants such as wind. This activity also includes program outreach activities working with hydropower stakeholders to address their issues and concerns.

\subsubsection{Wind-Hydro Integration}

Due to its decreasing and competitive costs coupled with the fact that it is a clean energy resource, wind energy capacity is likely to grow rapidly over the next two decades. As the penetration of wind energy increases, issues related to grid integration and electric system reliability become increasingly important. Hydropower resources are uniquely capable of addressing these gridintegration issues, due to the characteristics of the generators and the built-in energy storage that accompanies hydro impoundment. Because of the opportunity for synergistic operation, the Department of Energy is actively investigating the opportunity to integrate wind energy with hydropower.

Large transmission grids are typically broken into several smaller transmission "control” or "balancing” areas in which reliability requirements are met while balancing loads with generation. Within any given balancing area there may be several different types of generators, including wind and hydropower units. The average load within a balancing area typically varies in predictable daily 
and seasonal patterns, but also contains an unpredictable component due to random load variations as well as unforeseen events. In order to compensate for these variations and unforeseen events, steps are taken to ensure system reliability by having additional generation capacity on-line to provide regulation, load following and unit commitment (for the random load fluctuations) or set aside as reserves (to account for load forecast errors, unforeseen events, and unplanned outages). Together, the reliability services of regulation, load following, unit commitment and reserves are termed ancillary services. Some generators within an electrical system such as combustion turbines or hydro generators can respond quickly to load fluctuations and can be started quickly. These agile generators are the type used to provide regulation and load following on an hourly basis. The ability to provide ancillary services is of economic value to a generator above and beyond the energy produced while operating.

Introducing wind generation into a balancing area can increase the regulation and load following burden and need for reserves, due to its natural variability, and increase uncertainty in planning and unit commitment. To accurately determine the impact on the balancing area reliability and the consequential incremental increase in need for ancillary services, the wind generation must be analyzed in the context of the transmission grid, fully encumbered with all of its loads, generators, and their corresponding characteristics. Hydropower, being a responsive generation resource capable of providing ancillary services, can be partnered with wind energy to supply the incremental increase in ancillary services. However, hydropower operations may be quite constrained due to the many priorities and functions of a hydro facility which typically have a greater priority than power generation. Thus, the study of wind and hydropower generation is characterized by the following three components:

- Determination of the impact on the control area reliability and need for ancillary services of wind integration.

- Analyze the physical and economic potential for provision of the ancillary services and energy storage by the hydropower facilities.

- Ascertain the impact and potential benefits of wind integration on hydropower and hydrologic operations of the hydro facilities.

Figure 3-1 shows a conceptual view integrating wind and hydropower generation. The wind and hydropower facilities may be located anywhere within the balancing area (i.e., no need to be co-located), provided no transmission constraints exist. While the plants are essentially run independently, the integration of the resources comes within the balancing area, in serving the load and maintaining the system reliability. Thus the transmission control area is the primary context within which wind and hydropower integration is considered.

Although the goal of our wind and hydropower integration activities in FY 2003 was to identify potential sites and partners for studying integrated wind and hydropower operations, FY 2004 and 2005 activities focused on three case studies and an international collaboration through the International Energy Agency. The case studies selected represent some of the diversity found in hydro facilities and balancing areas throughout the U.S., with the hope of covering a breadth of integration issues. Each of the case studies will be described briefly below. 


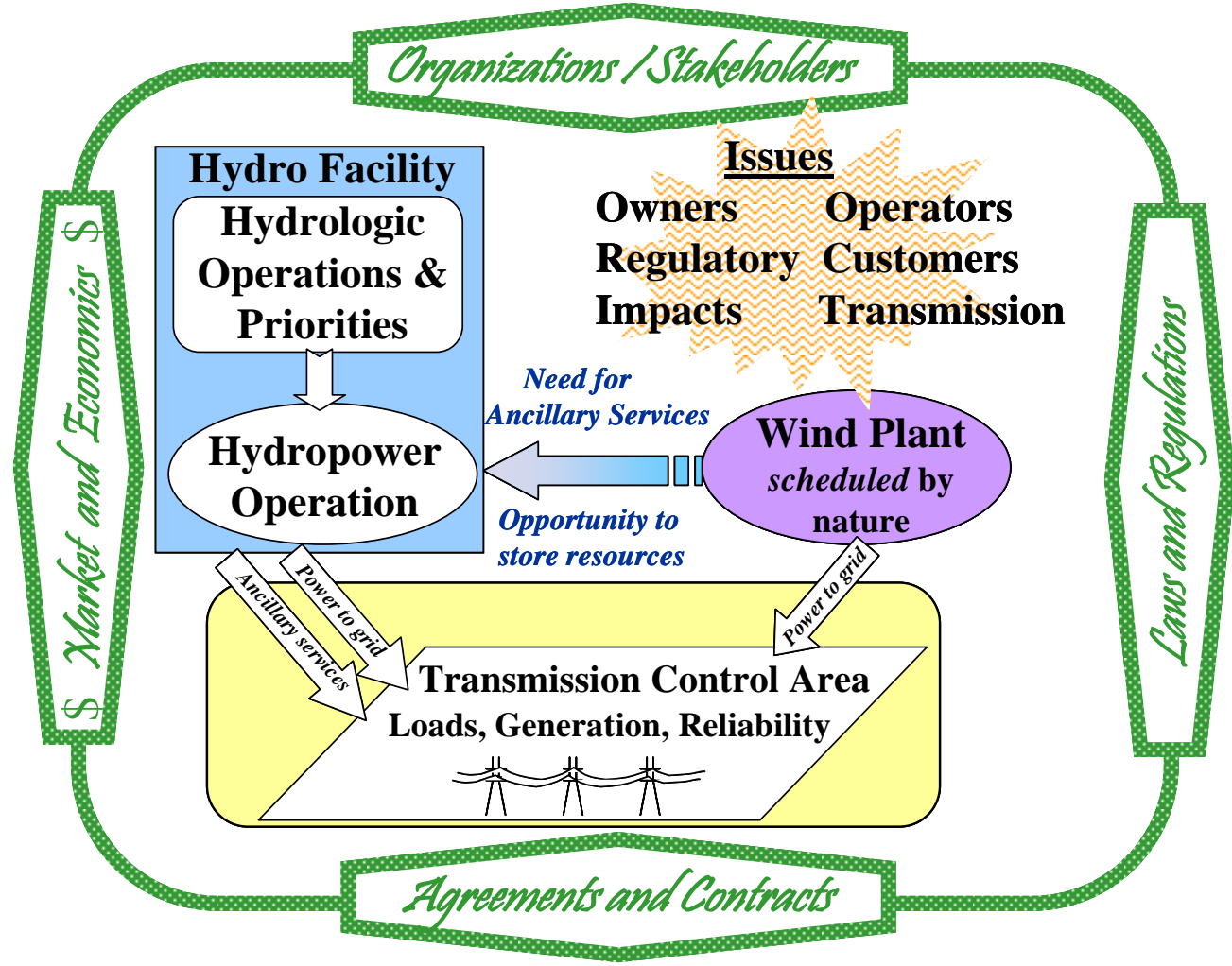

Figure 3- 1. A conceptual view of integrating wind and hydropower facilities within a transmission balancing area.

\subsubsection{Missouri River Study}

The essence of this Missouri River project is to analyze the potential for, and study the impact of, integrating wind power in the Western Area Power Administration (WAPA) control area that is supplied in part by electricity from six large hydro facilities on the Missouri River. These hydropower plants have a total nameplate capacity in excess of $2400 \mathrm{MW}$. The objectives of this project are to create a realistic wind generation scenario for North and South Dakota in wind development "zones" identified by WAPA, and to determine the incremental impacts of varying levels of wind generation on operation and scheduling in the WAPA control area, including next-day scheduling of hydro generation resources and impacts of forecast errors on operation of river system. The goal is to answer questions such as how the variability of wind generation and uncertainty of forecast fits or doesn't fit with current operational practices; and, at what point does wind become problematic for current procedures. EnerNex Corporation and Wind on the Wires are the primary investigators in this project. The project was initiated during the summer of 2004, and is expected to be completed in 2005.

An important aspect of integration wind energy on the utility grid is the nature of its variability. An example result from this project showing wind plant output variability is shown in Figure 3-2. Built from a high-resolution simulation of meteorology for historical year 2003 in WAPA defined wind development zones, this figure shows the one-hour generation changes of a $100 \mathrm{MW}$ wind farm 


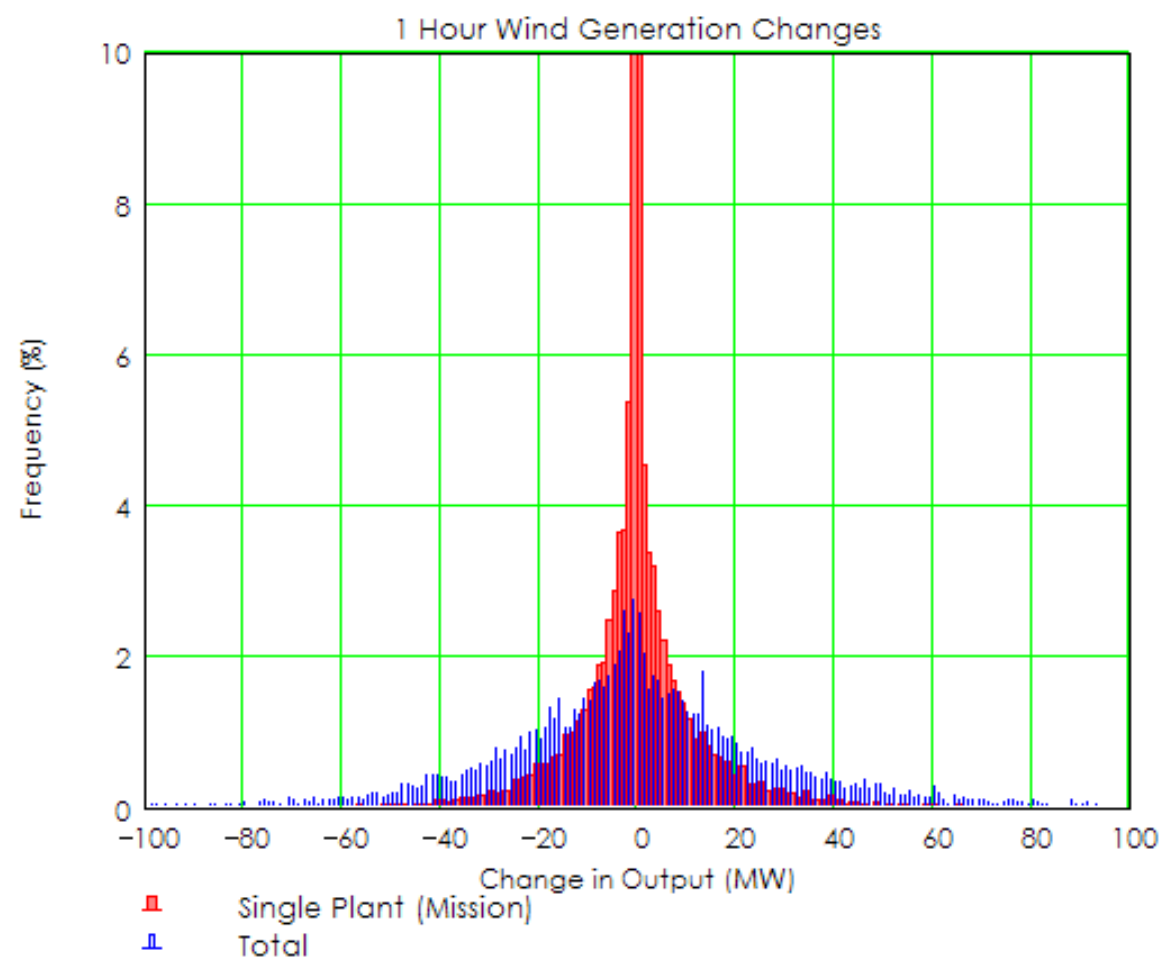

Figure 3- 2. One-hour generation changes of a $100 \mathrm{MW}$ wind farm located in one area versus spread out geographically.

either located in one area or spread out geographically. As can be seen, spreading the wind generation over a large geographic area versus installing all turbines in one location can significantly reduce the output variability, and consequently the need for ancillary services and impact on the hydro facilities providing those services. The project final report is expected in 2006.

\subsubsection{Arizona Power Authority Study}

In order to best serve its customers and the citizens of Arizona, the Arizona Power Authority (Authority) is interested and authorized to study ways to make the best use of its federal hydropower allocation and transmission rights. The potential to combine hydropower generation with renewable energy generation, in particular wind energy, offers a potential benefit to the Authority's customers and possibly to the operators of the hydropower facilities and other interconnected parties. The Authority, to generation from Hoover Dam, has an annual/monthly power allocation or entitlement and is interested in using it to allow for the integration of wind power and other renewable energy resources into its electric resource base, if economically feasible and without adverse impacts to its customers. This means that the Authority would use a portion of its Hoover allocation to provide ancillary services for the wind power, and perhaps allowing for resource storage (energy and water) in Lake Mead. Given the flexibility built into the operation of Hoover, it is very likely the hydropower facilities could support wind power integration. However, there are several important issues "surrounding" and effectively controlling whether or not this wind/hydro integration can occur 
successfully and economically. These include the laws and regulations, organizations and affected stakeholder (in particular, of the services supplied by Hoover), and existing contracts, agreements, compacts and treaties. Each of these issues needs to be considered in order to truly demonstrate the feasibility of the wind/hydro integration and the justification for proceeding further with an in-depth feasibility study.

The Authority in conjunction with Northern Arizona University and NREL are the principal investigators on this project. During FY 2004, the Authority completed a pre-feasibility study to ensure the concept of integrating wind energy with their hydro allocation was possible, and to identify the necessary activities and parties that need to be involved in a feasibility study. In FY 2005, a new project was initiated to perform a feasibility study with three foci: 1) creating partnerships and devising scenarios where actual wind developments can be used to serve APA; 2) creating a10-year backcast of wind data based upon wind modeling software and ground data; and 3) performing an integration study to learn the impacts, costs, and benefits of integrating wind with APA's hydro allocation, including hydrological impacts. Because Hoover Dam is a Bureau of Reclamation facility and the power from it is transmitted along WAPA power lines, these two organizations will be involved in the study. The pre-feasibility study demonstrated there are no major institutional or legal obstacles to the Authority integrating wind with their hydro allocation.

\subsubsection{Grant County PUD Study}

The GCPUD is interested in studying ways to expand its wind energy generation through effective integration with its hydropower operations. The District is a consumer-owned utility in a rural, predominantly agricultural region, and it owns and operates the two-dam Priest Rapids Project on the Columbia River in central Washington. Together, the Priest Rapids and Wanapum dams make up one of the nation's largest hydropower developments, with the capacity to produce approximately 2,000 megawatts of electricity. GCPUD shares the Priest Rapids Project's affordable electric power with 12 Northwest utilities that serve millions of customers, creating economic benefits throughout the Northwest. Currently, the District receives 36.5\% of the output of the Project.

In addition to its hydropower generation, the District also purchases $12 \mathrm{MW}$ (18.88\% share) of the 63.7 MW Nine Canyon Wind Project. The District integrates the wind output via a dynamic signal into the District's control area, essentially putting the output in the Priest Rapids Project's pond. The ability to combine hydropower with wind power beyond the current level offers potential benefits to the District's customers and possibly to other interconnected parties. There are two primary goals of this study: to understand the impacts and costs of GCPUD's current efforts at integrating wind and hydropower; and, to study the potential for future expansion of wind integration by the District. In addressing each of these goals, effort will be devoted to understanding the impacts of wind integration on the District's hydro operations, including identifying potential benefits, and towards determining the costs of integrating wind in with hydropower generation (e.g. ancillary service costs). GCPUD, in collaboration with Northern Arizona University and NREL, are the principal investigators on this project.

During FY 2004, the project work plan was devised, and work is commenced during FY 2005. The initial phase of the project was to gather the 2004 data for the balancing area and wind project, and devise methods to analyze the integration impacts appropriate to GCPUD's balancing and planning operations. We have submitted two abstracts were submitted that have been accepted as papers and presentations describing the results of the project: the 2006 HydroVision Conference to be held in Portland, Oregon, and the American Wind Energy Association (AWEA) WINDPOWER 2006 meeting in Pittsburgh, Pennsylvania. An important outcome found during the analysis is presented in Figure 3-3, which shows how wind impacts Grant County’s balancing area in the load 


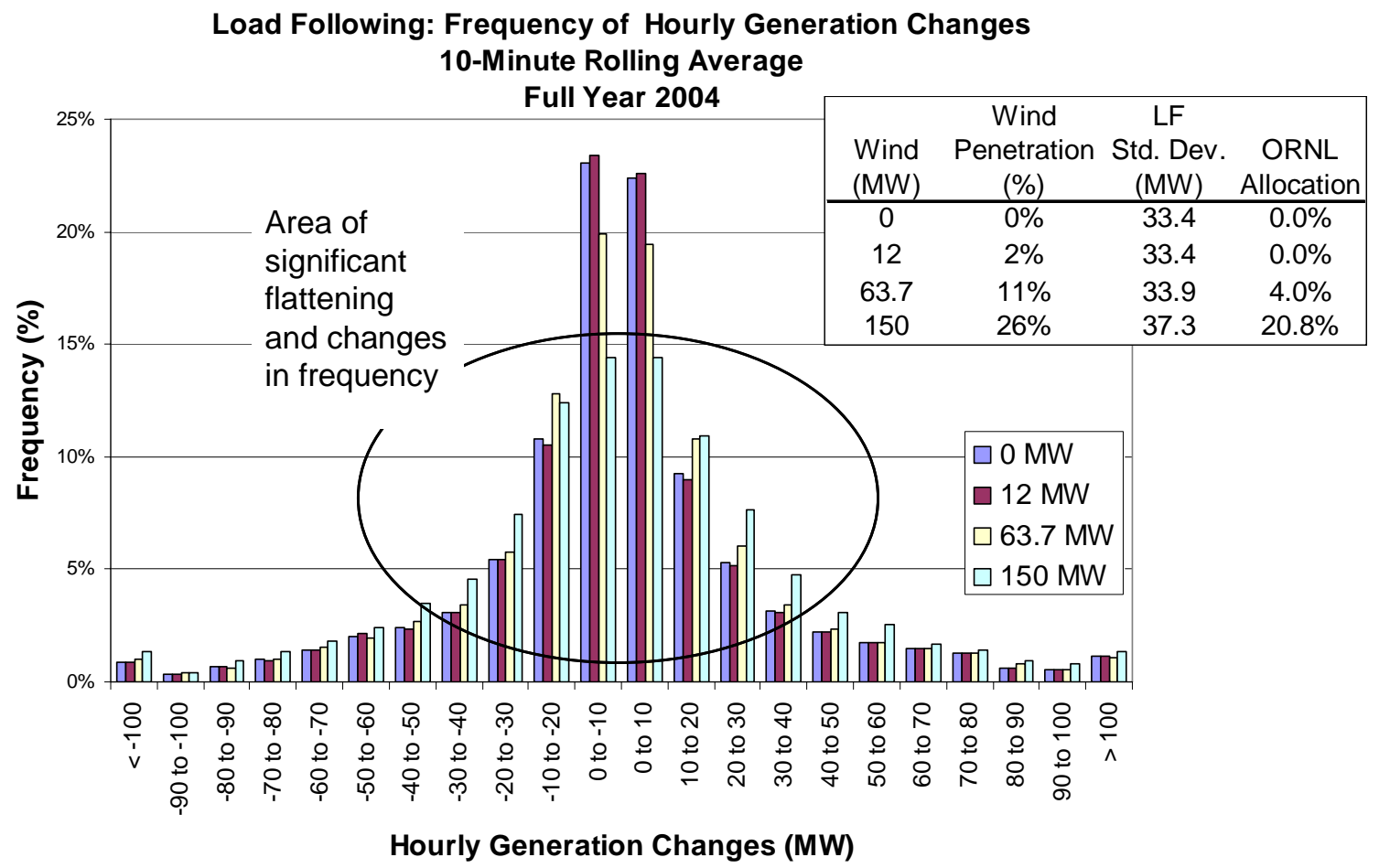

Figure 3- 3. Hourly generation changes of GCPUD's request to their generators including load, sales and purchases, and 0, 12 (actual), 63.7, and $150 \mathrm{MW}$ of wind energy.

following time scale (sub-hourly to hourly). This plot demonstrates two key results: the impact of wind on the physical generation resources is within the range of variability already handled, and 2) the changes in distribution of the hourly generation changes from lower increments (0 to $10 \mathrm{MW})$ to higher increments (10 to $40 \mathrm{MW}$ ) may be difficult for the system planners and operators to accommodate, potentially costly to manage, and must be dealt with in the planning process. Thus, the next steps in this project are to consider using wind forecasts and devising strategies for planning and costing the impact of the wind variability within the context significant hydrological constraints faced by the system operators.

\subsubsection{Bonneville Power Administration Wind Integration}

In addition to the projects mentioned above, Bonneville Power Administration (BPA) continues to address wind and hydropower integration. BPA continues to carryout research and development efforts to evaluate the costs and opportunities associated with integrating wind energy into the Federal Columbia River Power System. The result of this evaluation was two wind-hydro power related services that utilize the flexibility of the hydro system to integrate wind energy into the BPA balancing area on behalf of electrical utilities in the Pacific Northwest. One of these services, "Network Wind Integration Service," has been designed to serve the needs of public power customers with loads embedded in the BPA control area that elect to purchase all or a portion of their power from a new wind resource. The other service, "Storage and Shaping Service," has been designed to serve the needs of utilities and other entities outside of the BPA Control Area who have chosen to 
purchase the output of a new wind resource but do not want to manage the hour-to-hour variability associated with the wind output. BPA has established a goal of providing up to $450 \mathrm{MW}$ (nameplate) of wind integration services over the 2004-2011 time frame. As of 2005, subscription to these services has crested $200 \mathrm{MW}$.

BPA runs with two essentially independent arms: the Power Business Line (PBL) and the Transmission Business Line (TBL). The PBL is responsible for power system planning and the TBL is independently responsible for operating the transmission system and maintaining system reliability. At a functional level, the PBL is responsible for power system planning and operation up to the hour of generation. The TBL is in charge of generation assets within the hour, so that it can ensure transmission system reliability. This division creates some unique challenges for operating the system and in particular, for managing the variability of wind integration. With on the order of a few thousand megawatts of new wind generation potentially coming on line over the next several years, most of which will interconnect with the TBL (but not necessarily using the PBL wind integration services mentioned above), there is a significant need to understand the impact of the wind variability on systems reliability, operation and planning. In response to this challenge, BPA initiated a project in 2005 called the "BPA Wind Forecasting Network - A wind/hydro optimization RD\&D project in the Pacific Northwest." The intent of this project is to perform a two-year wind/hydro optimization RD\&D project to forecast wind each hour from real time to seven days into the future (168 hours). Important outcomes of this effort will be to:

- Improve the quality of wind generation forecasts for BPA's Hydro Optimization models Columbia Vista, NRTO;

- Improve the quality of wind generation forecasts to inform near-term marketing decisions (increasing revenue);

- Establish operating impacts of Wind Storage and Shaping \& Wind Integration Products (reducing costs); and

- Determine if wind has a capacity value (increasing revenue) and the capacity needed to support its uncertainty (reducing costs), given an accurate wind forecast

BPA is the lead organization in the project, with technical support for wind forecasting provided by the 3Tier Environmental Forecasting Group.

\subsubsection{IEA Wind-Hydro Annex}

Worldwide, hydropower facilities possess a significant amount of installed electric generating capacity. International Energy Agency (IEA) statistics indicate that within IEA member countries, there is about $450 \mathrm{GW}$ of hydropower capacity and approximately $52 \mathrm{GW}$ of wind power capacity. Of this wind generating capacity, about $80 \%$ is installed in Europe and 20\% in North America

Because of the potential for synergistic operation of wind and hydropower facilities, many countries are actively investigating the opportunity to integrate wind and hydropower systems in order to optimize their output for the benefit of the electric customer. The hope is to realize such benefits as lowering the cost of ancillary services required by wind energy, taking advantage of the built-in energy storage available at hydro facilities, the opportunity to more effectively utilize existing hydro and transmission facilities, the potential for improving hydrologic operations, and an overall energy supply portfolio that is more diverse, robust, and cleaner. To accelerate the process of realizing these benefits, the U.S. has led an effort to establish an international collaboration (or "Annex"), under the auspices of the IEA Wind Implementing Agreement. 
The primary purposes of the Annex are to conduct cooperative research concerning the generation, transmission, and economics of integrating wind and hydropower systems, and to provide a forum for information exchange. Important outcomes of the Annex are listed below:

- The identification of practical wind/hydro system configurations;

- A consistent method of studying the technical and economic feasibility of integrating wind and hydropower systems;

- The ancillary services required by wind energy and the electric system reliability impacts of incorporating various levels of wind energy into utility grids that include hydro generation;

- An understanding of the costs and benefits of and the barriers and opportunities to integrating wind and hydropower systems;

- A database of reports describing case studies and wind-hydro system analyses conducted through cooperative research of the Annex.

The Annex was approved by the IEA at the end of FY 2004 with a workplan extending through FY 2008. A Kickoff Meeting of the Annex was held in February 2005 at Hoover Dam, and the first R\&D meeting of the Annex was held in Switzerland in September 2005. Seven countries are participating: Australia, Canada, Finland, Norway, Sweden, Switzerland, and the United States. The National Renewable Energy Laboratory and Northern Arizona University are the lead organizations in the Annex.

\subsubsection{National Hydropower Collaborative}

In FY 2005, the program explored the feasibility of establishing a Hydropower Coordinating Committee, based on the successful model of the National Wind Coordinating Committee (NWCC). A consensus-based collaborative formed in 1994, NWCC identifies issues that affect the use of wind power, establishes dialogue among key stakeholders, and catalyzes appropriate activities to support the development of environmentally, economically, and politically sustainable commercial markets for wind power. NWCC members include representatives from electric utilities and support organizations, state legislatures, state utility commissions, consumer advocacy offices, wind equipment suppliers and developers, green power marketers, environmental organizations, agriculture and economic development organizations, and state and federal agencies. The budget situation in FY 2005 did not allow for full implementation of a hydropower collaborative, but we did apply the model in a limited way, by sponsoring a workshop to explore the technical issues associated with unconventional hydropower development that is beginning to emerge in the U.S. and in other countries.

Conventional hydroelectric projects, with dams and reservoirs, are used all over the world to produce renewable energy. However, the ability of conventional hydropower to meet our increasing energy demands is declining, owing to a variety of environmental concerns, including degradation of fish passage, water quality, and aquatic and terrestrial habitats. It is unlikely that many new hydropower dams will be built in the U.S., and there is increasing interest in removing some older dams in order to restore free-flowing rivers (note most of these are non-hydro dams). Nevertheless, hydropower still has a future on the domestic and international scenes because there is considerable energy associated with the motions of water that could be tapped by new, unconventional hydropower technologies. For example, Hall et al. (2004) estimated that as much as 3,400 MW of electricity could be exploited in U.S. rivers by small, unconventional systems such as free-flow (damless) turbines. The resource potential of estuaries and ocean waters is much greater; Bedard (2005) has estimated that the annual average incident wave energy at a $60 \mathrm{~m}$ depth off the U.S. coastline is $2.1 \mathrm{PWh}$ per year, or more than half of the net generation of electricity in the United States from all sources in 2004 (DOE-EIA, 2006). 
The technologies that would extract electricity from free-flowing streams, estuaries, and oceans have not been widely tested; indeed, many are little more than ideas from the drawing board (Figure 3-4). Consequently, the DOE Wind and Hydropower Technologies Program convened a workshop in October, 2005 to ascertain the technical and environmental issues associated with hydrokinetic and wave energy conversion devices. Fifty four representatives from private business, government (regulatory and resource agencies), and non-governmental organizations met for three days and shared ideas for ways to promote environmentally sound development of these technologies. Specific goals of the workshop were to (1) identify the varieties of hydrokinetic energy and wave energy conversion devices, their stages of development, and the projected costs to bring them to market; (2) identify where these technologies can best operate; (3) identify the potential environmental issues associated with these technologies and possible mitigation measures; and (4) develop a list of research needs and/or practical solutions to address unresolved environmental issues. Workshop proceedings were issued that included detailed summaries of the presentations made, the subsequent discussions, and conclusions of the workshop participants about needed environmental research. The proceedings of the workshop are available at: http://hydropower.inl.gov/hydrokinetic_wave/.

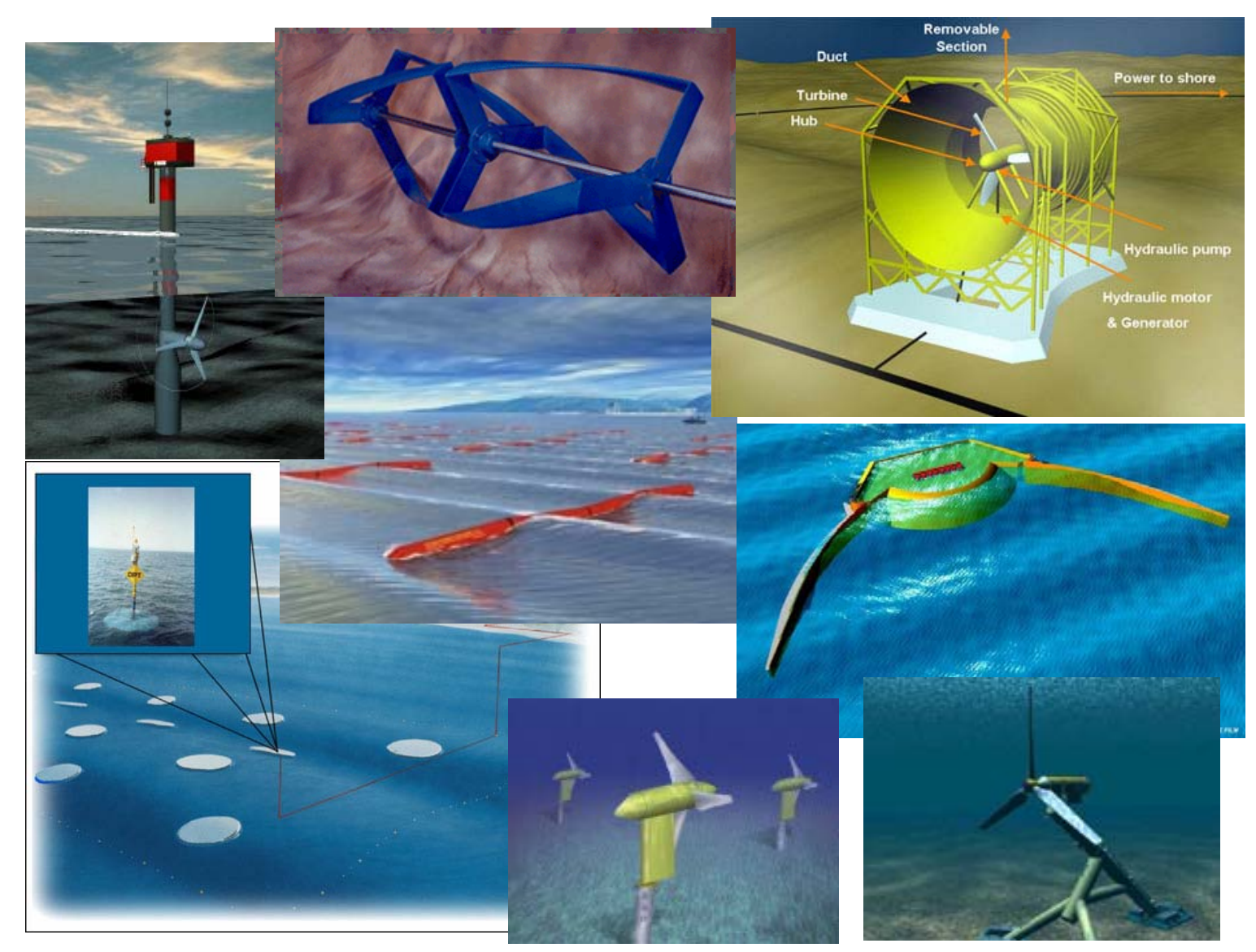

Figure 3- 4. Examples of hydrokinetic and ocean energy conversion technologies considered at the DOE-sponsored workshop (Source: Savitt Schwartz, 2005) 


\subsubsection{Integration and Communication}

The transfer of new information to the hydropower community has always been an important component of the DOE Hydropower Program. This transfer is carried out in the following ways:

- Conference planning and participation - DOE and Laboratory staff participate in or serve on organizing committees for numerous annual meetings of industry groups. Program personnel are regularly involved in preparing and delivering papers, or serving as members of technical panels.

- Proposal Review - DOE receives unsolicited proposals throughout the year for R\&D ideas and for developmental support of unconventional turbine technology. Program staff review these proposals and provide comments or other advice.

- Web site maintenance and development - The program maintains a web site for public access to hydropower facts and for access to numerous hydropower program reports and papers.

- Ad hoc outreach support is provided by program staff and includes responses to questions from individuals and groups, monitoring of the trade journals for the latest industry developments, and development of reports that are made available to the public.

Each of the three national labs provides supporting tasks for this external component of the program. Included in this project are conducting engineering analyses, monitoring and reporting on project progress, preparing and issuing program planning documents and technical reports / papers, developing program and project management plans, providing technical oversight of DOE contracts, preparing solicitations for proposals, and reviewing and evaluating proposals. Also included are program reviews, workshops, conferences, technology transfer activities, and response to public inquiries.

\subsubsection{Planning Documents and Program Reviews}

The most recent program review, planning, and implementation meetings for Hydropower were conducted in February 2004, March 2004, and September 2004, respectively. The Annual Operating Plan that was prepared for the FY 2005-2006 period is the Hydropower Program FY 2005-06 Closeout Plan (DOE, 2005), Review, planning, and implementation meetings that had been planned for 2005 and later were cancelled due to the intent to close the program.

\subsubsection{Interagency and Stakeholder Coordination}

During this time period, the Hydropower staff supported and participated in the following technical and interagency organizations and meetings: U.S. Army Corps of Engineers Turbine Working Group, United States Society on Dams, Low Impact Hydropower Institute, COE Anadromous Fish Evaluation Program, NOAA Fisheries' Watershed Ecology and Salmon Recovery Program, Independent Scientific Advisory Board for the Northwest Power Planning Council, International Energy Agency's Small Hydropower Annex meeting, Foundation for Water and Energy Education Annual Planning Meeting, and the Electric Power Research Institute's Annual Water and Ecosystems Group Meeting. Invited briefings were also delivered at several industry meetings.

ORNL staff served as liaison between the DOE Hydropower Program and the Low Impact Hydropower Institute (LIHI) as a way to track emerging trends in certifying green hydropower projects. The list of hydropower projects certified by LIHI as "Low Impact” continued to grow. These projects include both small and large facilities, indicating that there is not a direct relation between project size and environmental impact. 


\subsubsection{Conferences and Workshops}

Staff from DOE, INL, ORNL, and PNNL participated with and served on the organizing committees for several annual meetings, including the National Hydropower Association's Annual Conference in Washington, DC, and the biennial Waterpower and HydroVision conferences. Other conferences and workshops that we send representatives to include the Northwest Salmon Recovery Workshop, Ecologically Sustainable Water Management Workshop, POWER-GEN Renewable Energy Conference, North American Wildlife and Natural Resources conference, American Fisheries Society Conference, Fourth World Fisheries Congress, 2004 World Water and Environmental Resources Congress, 5th International Symposium on Ecohydraulics Conference, World Renewable Energy Congress, and the Universities Council on Water Resources. DOE-supported staff served on advisory committees, organization committees, or as session chairs for these conferences.

At HydroVision 2006, DOE co-sponsored a pre-conference symposium on Optimizing Dam Operations for Fish and for Power with the Corps of Engineers Northwestern Division. This was a technology transfer opportunity for HydroVision participants to learn about latest research and development coming from DOE and the Corps on monitoring turbine performance, design considerations related to structural and operational modifications, and associated environmental effects.

The collaborative workshop described in Section 3.1.2 above is another example of the outreach activities supported by the Hydropower Program. There has also been an increased management emphasis at DOE concerning international participation of the Hydropower Program in the International Energy Agency (IEA) Hydropower Agreement activities. This includes participation in the Executive Committee (ExCo) of the Agreement, the Small Hydro Annex, and the Wind-Hydro Integration Annex (Section 3.1.1.5).

\subsubsection{Communications and Web Site}

The program maintains an official Hydropower Web site (http://hydropower.inl.gov). This site will be maintained through the end of FY 2006, after which the site will be accessible but static. Reports on the Program's significant new research results will be added through the end of September 2006, including the new DOE reports cited in this Annual Report (Section 4). Other papers that program staff published in professional and trade journals over the past year are also available on the Web site where possible. The latest statistics on user access to the site indicate steady interest and access by users worldwide.

\subsubsection{Grants and Review of Proposals}

The Office of Energy Efficiency and Renewable Energy expanded and diversified its request for $R \& D$ proposals for advances in energy efficiency and renewable energy technologies through the Department of Energy's FY 2004 Small Business Innovation Research (SBIR) and Small Business Technology Transfer (STTR). One of the solicitations included concepts for low-head hydropower systems. This grant solicitation is for development and implementation of innovative, cost effective, and environmentally acceptable concepts for low-head hydropower energy systems for the production of electricity. The INEEL provided technical support in evaluating the proposals received in response to the SBIR/STTR Low Head Hydropower Systems Solicitation. One project was selected under this solicitation. 
DOE received several unsolicited proposals throughout the year, including research and development ideas for unconventional turbine technology. National laboratory staff and DOE conducted technical reviews of these proposals and responded with comments to the proposers. The proposers were also advised of current and planned solicitations, so that they could participate in this process.

\subsection{Supporting Engineering and Analysis}

The Supporting Engineering and Analysis subkey activity provides a number of necessary functions to support industry and the program and to further Hydropower energy technology deployment and application. The efforts under this subkey activity will help reach the Technology Application goal of the Hydropower Program.

\subsubsection{Valuation Methods and Assessments}

This project area is intended to support studies to better understand the developed and undeveloped hydropower resources in the U.S. Budget limitations precluded extensive effort here, other than an internal review of data standards and extant information sources, in the event that funding comes available for building a consolidated data base that can be used for evaluating trends in the national hydropower industry (both federal and nonfederal projects included).

ORNL and INL staff also participated in an interagency workshop on Renewable Energy Modeling in May 2005 that focused on hydropower resources. The Renewable Energy Modeling Series began in 2002 to identify ways to improve information about and modeling of environmental effects of renewable energy, in support of environmental and energy policy development and market transformation. The primary sponsors of the series are EPA, NREL, and DOE-EIA. Hydropower was selected as the workshop topic for the May 2005 because of its unique modeling challenges. The DOE Hydropower Program helped organize the May workshop and provided three of the presentations: an overview of existing hydropower resources in the U.S. (Sale, 2005), description of opportunities for incremental additions to existing systems (March, 2005), and description of opportunities for capacity increases (Hall, 2005). Overall, the workshop was a successful exchange of unique information on hydropower (see: http://www.epa.gov/cleanenergy/renew/renew_series7.htm). The workshop conclusions were:

- Large increases in new capacity have not taken place in recent years, despite significant growth in the past - and tremendous available resource potential in the United States;

- New capacity has tremendous regulatory/processes to overcome that are not reflected purely by using costs in the model. Moreover, the process is lengthy and risky. Ignoring these real "costs" will result in over-projections by models that only use normal cost measures;

- Increased utilization and efficiency could be a significant source of new energy, and should be considered as improvements in capacity factors in modeling efforts;

- Increased capacity at existing sites through e.g., adding and/or replacing turbines could also be a significant source of new capacity - because costs and regulatory hurdles may be much lower than new builds. This should also be considered to be modeled;

- Some participants wanted to see hydropower treated in an "equal" manner to other renewables (e.g., State RPS and Federal Tax Credits;

- When considering longer-term projections, such as to 2030, new wave, tidal, and in-stream technologies need to be accounted for and/or included; and

- The National Energy Modeling System’s Conventional Hydropower Submodule needs additional review and checking, both by EIA and by external reviewers. 


\subsubsection{Characterization of Innovative Technology}

The Small Hydropower Resource Assessment and Technology Development Project (formerly called the Low Power Hydropower Resource Assessment and Technology Development Project) completed a feasibility assessment of approximately 500,000 water energy resource sites in the United States (Hall et al. 2006). The water energy resource sites were stream reaches averaging 2 miles in length and having gross power potentials greater than $10 \mathrm{KW}$. The gross power potential of these sites was estimated in the basic resource assessment the project performed during 2003-2004. This work was published by Hall et al. (2004).

The objectives of the feasibility assessment were to identify feasible potential project sites and to estimate their hydropower potential using a damless small hydropower development model with associated development criteria. The feasibility criteria included site availability and accessibility, plus load or transmission proximity Application of the feasibility criteria resulted in the identification of approximately 130,000 feasible potential project sites. The total gross power potential of these sites was approximately 100,000 MWa (annual mean power).

The damless small hydropower development model incorporated a submerged diversion weir or a power channel consisting of a secondary branch of a stream or a constructed channel. Diverted water is carried by a penstock running parallel to the stream, passes through the powerhouse, and is returned to the stream. The associated development criteria included:

- A penstock no longer than a majority of small hydropower plants in the same hydrologic region those actual length was determined by an optimization algorithm that minimized length while maximizing working hydraulic head

- The lesser of half the stream flow rate or sufficient flow rate to produce $30 \mathrm{MWa}$ using the working hydraulic head.

The methodology for determining penstock length was developed after the results of a pilot study of the Pacific Northwest hydrologic region for which development penstock length was fixed at 1,000 $\mathrm{ft}$ was found to be overly restrictive based on the existing small hydroelectric plant population. The use of water flow rates of half the stream flow or less is also restrictive resulting in an automatic $50 \%$ reduction in power potential, but was considered consistent with the damless development model having minimal environmental impact.

Preliminary results of the feasibility assessment were presented at a meeting of the project Technical Advisory Committee held in conjunction with the Waterpower XIV Conference in Austin, TX in July 2005. The results of the feasibility assessment are reported in Feasibility Assessment of the Water Energy Resources of the United States for New Low Power and Small Hydro Classes of Hydroelectric Plants, DOE-ID-11263, January 2006. The bottom line results of the study are shown in Figure 3-5. Application of development criteria to the nearly 130,000 feasible potential project sites results in an estimated total developable power potential (as opposed to gross power potential based on the elevation difference between the upstream and downstream ends of the reach and the full reach flow rate) of nearly 30,000 MWa. Figure 3-5 shows distributions of the feasible potential project sites and their associated developable hydropower potential based on power classes and low power technology classes. (The small hydro power class is between 1 and 30 MWa and the low power class is less than $1 \mathrm{MWa}$ with the low power conventional technology class having hydraulic heads greater or equal to than $8 \mathrm{ft}$, the low power unconventional technology class having hydraulic heads less than $8 \mathrm{ft}$, and microhydro having power potentials less than $100 \mathrm{~kW}$.) 
The feasibility assessment report presents results for the nation, compares developable power potential amongst the states, and shows the spatial distribution of the feasible project sites on a map. Appendix A of the report describes federal land use and environmentally sensitive zones in which hydropower development is unlikely. Appendix B presents feasibility results for each of the 50 states.

As a means of making the results of the basic resource assessment and feasibility assessment publicly available, the project expanded a pilot version of a geographic information system (GIS) application for the Pacific Northwest that was CD based to a version accessible on the Internet that displays results for the entire country. The application named the Virtual Hydropower Prospector accessible at http://hydropower.inl.gov/prospector/ was launched on the Internet in July 2005. An upgraded version that included the results of the feasibility assessment was launched in November 2005. The application displays the over 500,000 water energy resource sites and the nearly 130,000 feasible potential project sites on maps of the 20 U.S. hydrologic regions. The objective of the developing the application was not only to display these sites and provide attribute information about

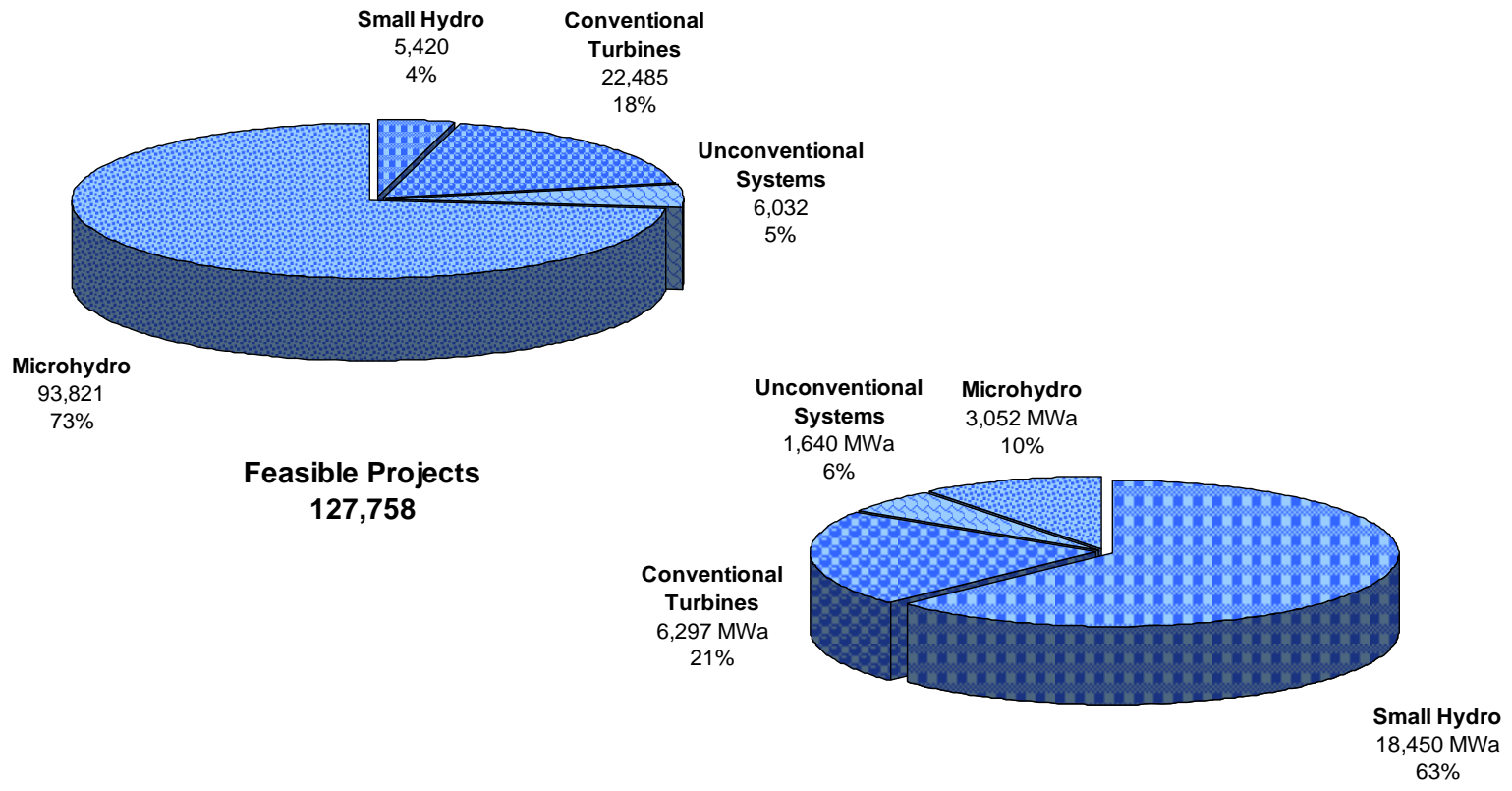

Feasible Project Hydropower Potential 29,438 MWa

Figure 3- 5. Power class distribution of feasible potential projects and their associated total hydropower potential with low power projects further divided by low power technology classes. 
them, but also to display context features that would allow stakeholders to perform their own customized site evaluations. To this end, the application displays context features including:

- Topography

- Hydrography

- Power infrastructure including all power plants, transmission lines, and substations

- Transportation infrastructure including roads and railroads

- Areas and places including cities, populated areas, and governmental boundaries

- Land use including development exclusion zones and land controlled by seven federal agencies.

The application provides attribute information for the features that are displayed using identify, proximity, or query tools. The custom maps the user produces are printable or can be saved as a file for inclusion in a document or presentation slide. The data resulting from use of the information tools can be copied and pasted into a spreadsheet for further analysis.

The region selector used to display a particular map on the application desktop and the application desktop itself are shown in Figure 3-6. The application comes with a complete user's guide (Hall et al. 2005).

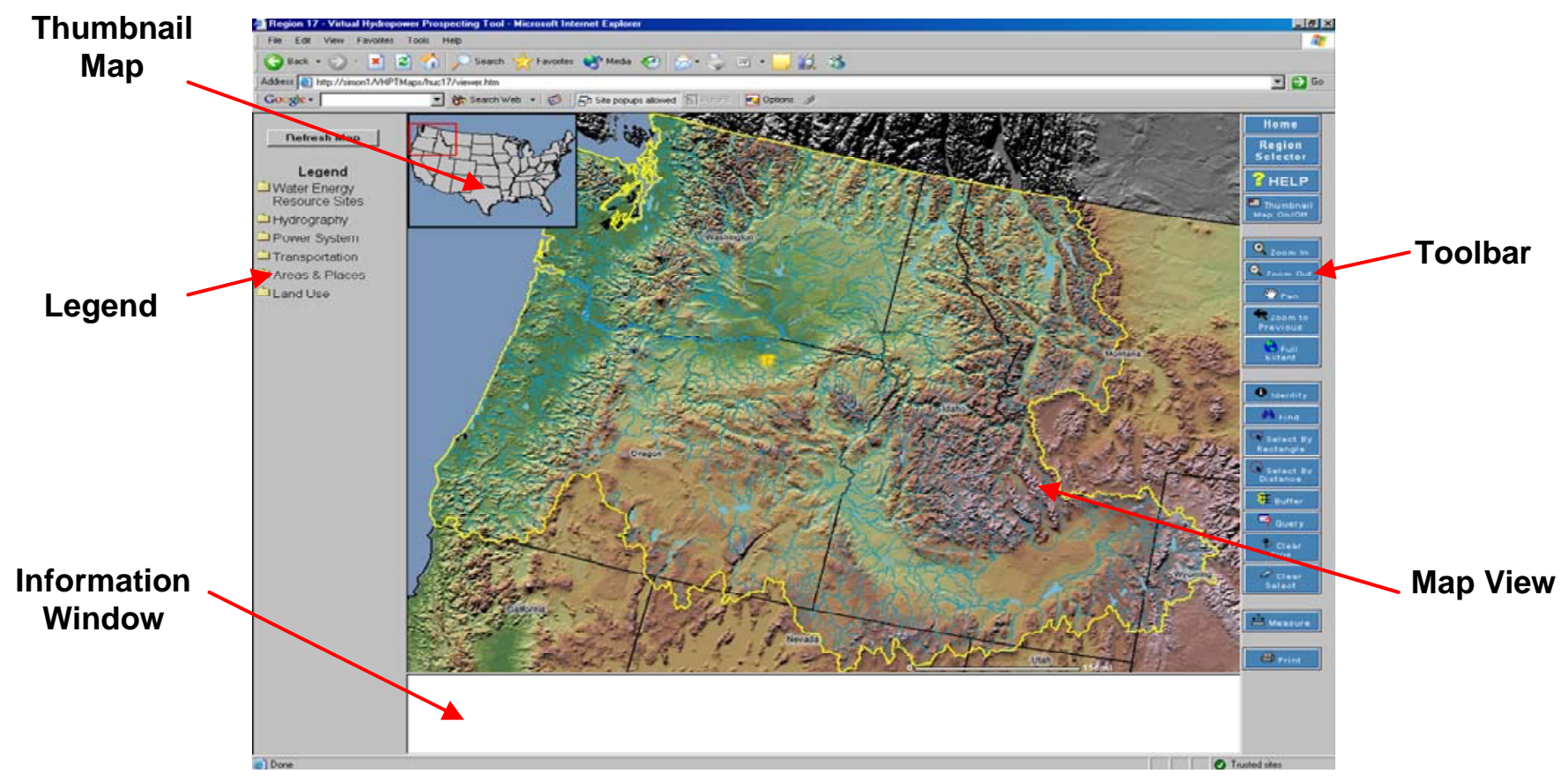

Figure 3- 6. Virtual Hydropower Prospector Internet GIS application a) hydrologic region selector and $b$ ) application desktop. 


\section{REFERENCES AND OTHER INFORMATION}

Most of the DOE-sponsored publications cited in this report are available electronically. References that can be accessed and downloaded from the DOE Hydropower web site are indicated by an asterisk. For electronic access to those references, see: http://hydropower.inl.gov.

\subsection{References Cited}

Bedard, R. 2005. Electric Power Research Institute (EPRI)'s Ocean Energy Research Program. Pages 77-79. In: Proceedings of the Hydrokinetic and Wave Energy Technologies Technical and Environmental Issues Workshop. U.S. Department of Energy, Washington, DC.

*Bevelhimer, M.S., and C.C. Coutant. 2006. Assessment of dissolved oxygen mitigation at hydropower dams using an integrated hydrodynamic/water quality/fish growth model. ORNL/TM-2005/188. Oak Ridge National Laboratory, Oak Ridge, TN.

*Bevelhimer, M.S., and H.I. Jager. 2006. Mitigation effectiveness of instream flow requirements at hydropower dams. ORNL/TM-2006/89. Oak Ridge National Laboratory, Oak Ridge, TN.

*Cada, G.F., M.J. Sale, and D.D. Dauble. 2004. Hydropower, Environmental Impact of. Encyclopedia of Energy, Volume 3, p. 291-300. Academic Press/Elsevier Science, San Diego, CA.

*Cada, G.F., J.G. Smith, and J. Busey. 2005. Use of pressure sensitive film to quantify sources of injury to fish. North American Journal of Fisheries Management 25(2):57-66.

*Cada, G.F., M.G. Ryon, C.A. Luckett, and J.G. Smith. 2006. The effects of turbine passage on C-start behavior of salmon at the Wanapum Dam, Washington. ORNL/TM-2006/88. Oak Ridge National Laboratory, Oak Ridge, TN.

*Cada, G.F., J.M. Loar, L. Garrison, R.K. Fisher, and D. Neitzel. 2006. Efforts to reduce mortality to hydroelectric turbine-passed fish: Locating and quantifying damaging shear stresses. Environmental Management 37(6):898-906.

*Cada, G.F., J. Ahlgrimm, M. Bahleda, T. Bigford, S. Damiani-Straakas, D. Hall, R. Moursund, and M. J. Sale In Review. The Potential Impacts of Hydrokinetic and Wave Energy Conversion Technologies on Aquatic Resources. Submitted to Fisheries.

Carlson T.J., J.P. Duncan, M.C. Richmond, J.A. Serkowski, and Z. Deng. 2006. Characterization of Spillway Passage Conditions at Lower Monumental Dam, Snake River, Washington, 2005. PNWD-3662, Battelle, Pacific Northwest Division, Richland, WA.

*Corps of Engineers (U.S. Army Corps of Engineers). 2005a. Stay vane and wicket gate relationship study. Report prepared by the U.S. Army Corps of Engineers Portland District, Hydroelectric Design Center, Portland, OR. January 19, 2005. 
*Corps of Engineers (U.S. Army Corps of Engineers). 2005b. Ice Harbor 1:25-scale turbine model construction and calibration report. Final report prepared for the Department of Energy. U.S. Army Corps of Engineers' Engineering Research and Development Center and the Northwestern Division Turbine Survival Program, Vicksburg, MS. July 2005.

*Coutant, C.C. and G.F. Cada. 2005. What's the future of instream hydro? Hydro Review XXIV(6):42-49.

*Coutant, C.C., and R. Mann. 2006. Reduced spill at hydropower dams: opportunities for more generation and increased fish protection. ORNL/TM02005/179, Oak Ridge National Laboratory, Oak Ridge, TN.

*Deng, Z., T.J. Carlson, G.R. Ploskey, M.C. Richmond. 2005. Evaluation of blade-strike models for estimating the biological performance of large Kaplan hydro turbines. PNNL-15370, prepared for the U.S. Department of Energy, Office of Energy Efficiency and Renewable Energy, Wind and Hydropower Technologies by Pacific Northwest National Laboratory, Richland, WA.

*Deng Z., G.R. Guensch, C.A. McKinstry, R.P. Mueller, D.D. Dauble, and M.C. Richmond. 2005. Evaluation of fish-injury mechanisms during exposure to turbulent shear flow. Canadian Journal of Fisheries and Aquatic Sciences 62(7):1513-1522.

*Deng Z., T.J. Carlson, G.R. Ploskey, M.C. Richmond, and D.D. Dauble. 2006. Evaluation of bladestrike models for estimating the biological performance of Kaplan turbines. PNNL-SA-48765, Pacific Northwest National Laboratory, Richland, WA (also, submitted to Ecological Modeling).

*Deng Z., T.J. Carlson, J.P. Duncan, and M.C. Richmond. 2006. The six-degree-of-freedom Sensor Fish: an autonomous device helping protect migrating salmons. PNNL-SA-48821, Pacific Northwest National Laboratory, Richland, WA. HydroReview. In Press.

*Department of Energy (DOE). 2003. Hydropower Multi-Year Technical Plan. Energy Efficiency and Renewable Energy Office, Office of Wind and Hydropower Technologies, U.S. Department of Energy, Washington, DC., October 22, 2003.

*Department of Energy (DOE). 2005. DOE Hydropower Program FY 2005-06 Closeout Plan. Energy Efficiency and Renewable Energy Office, Office of Wind and Hydropower Technologies, U.S. Department of Energy, Washington, DC., June 6, 2005.

Department of Energy, Energy Information Administration (DOE-EIA). 2006. Summary Statistics for the United States. U.S. Department of Energy, Washington, DC. http://www.eia.doe.gov/cneaf/electricity/epa/epates.html

Ferguson, J.W., R.F. Absolon, T.J. Carlson, and B.P. Sandford. 2006. Evidence of delayed mortality on juvenile Pacific salmon passing through turbines at Columbia River dams. Transactions of the American Fisheries Society. 135:139-150.

*Hall, D.G., S.J. Cherry, K.S. Reeves, R.D. Lee, G.R. Carroll, G.L. Sommers, and K.L. Verdin. 2004. Water energy resources of the United States with emphasis on low head/low power resources. DOE/ID-11111, Idaho Engineering and Environmental Laboratory, Idaho Falls, ID, April 2004. 
Hall, D.G. 2005. Hydropower capacity increase opportunities. EPA-DOE/EIA Workshop on Renewable Energy Modeling, Washington, DC, May 10, 2005. http://www.epa.gov/cleanenergy/pdf/hall may10.pdf

*Hall, D. G., S.E White, J.A. Brizzee and R.L. Lee, 2005. User’s Guide - Virtual Hydropower Prospector Version 1.1. INL/EXT-00402, Rev. 1, Idaho National Laboratory, Idaho Falls, ID, November 2005.

*Hall, D.G., K.S. Reeves, J.A. Brizzee, R.D. Lee, G.R. Carroll, and G.L. Sommers,. 2006. Feasibility assessment of the water energy resources of the United States for new low power and small hydro classes of hydroelectric plants. DOE-ID-11263, Idaho Falls, ID, January 2006.

*Ham, K.D., J.J. Anderson, J.A. Vucelick. 2005. Effects of multiple turbine passage on juvenile Snake River salmonid survival. PNNL-15450, prepared for the U.S. Department of Energy, Office of Energy Efficiency and Renewable Energy, Wind and Hydropower Technologies by Pacific Northwest National Laboratory, Richland, WA.

Johnson, G.E., and D.D. Dauble. 2006. Surface flow outlets to protect juvenile salmonids passing through hydropower dams. Reviews in Fisheries Science. In Press.

March, P. 2005. Opportunities for incremental hydropower. EPA-DOE/EIA Workshop on Renewable Energy Modeling, Washington, DC, May 10, 2005. http://www.epa.gov/cleanenergy/pdf/march_may10.pdf

*Moursund, R.A., and T.J. Carlson. 2005. In-turbine imaging technologies may provide data for fish-friendlier designs. Hydro Review.

Neitzel, D.S., D.D. Dauble, G.F. Cada, M. Richmond, G. Guensch, R. Mueller, C. Abernathy, and B. Amidan. 2004. Survival estimates for juvenile fish subjected to a laboratory-generated shear environment. Transactions of the American Fisheries Society. 122:446-453.

Normandeau Associates, Inc., J. R. Skalski, and R. L. Townsend. 2006. Performance evaluations of the new advanced hydro turbine system at Wanapum Dam, Columbia River, Washington. Final report prepared for Public Utility District No. 2 of Grant County, Ephrata, WA. April 2006.

Paik, J., and F. Sotiropoulos. 2005. Coherent structures dynamics upstream of a long rectangular block at the side of a large aspect ratio channel, Physics of Fluids, 17, 115104.

Paik, J., F. Sotiropoulos, and M.J. Sale. 2005. Numerical simulation of swirling flow in a hydroturbine draft tube using unsteady statistical turbulence models, ASCE Journal of Hydraulic Engineering, 131:441-456.

Rakowski, C.L., L.L. Ebner, M.C. Richmond. 2005. Using CFD to Study Juvenile Salmon Bypass at Bonneville. Hydro Review. March 2005. pp. 56-65.

Rakowski C.L., M.C. Richmond, J.A. Serkowski, and G.E. Johnson. 2006. Forebay Computational Fluid Dynamics Modeling for The Dalles Dam to Support Behavior Guidance System Siting Studies. PNNL-15689, Pacific Northwest National Laboratory, Richland, WA. 
*Sale, M.J., G.F. Cada, L.H. Chang, S.W. Christensen, S.F. Railsback, J.E. Frakcfort, B.N. Rienhart, and G.L. Sommers. 1991. Environmental mitigation at hydroelectric projects. Vol I. Current practices for instream flow needs, dissolved oxygen, and fish passage. DOE/ID-10360. U.S. Department of Energy, Idaho Field Office, Idaho Falls, ID.

Sale, M. J. An overview of hydropower resources in the U.S. EPA-DOE/EIA Workshop on Renewable Energy Modeling, Washington, DC, May 10, 2005. http://www.epa.gov/cleanenergy/pdf/sale_may10.pdf

*Sale, M.J., G.F. Cada, and D.D. Dauble. 2006. Historical perspective on the U.S. Department of Energy’s Hydropower Program Proceedings of HydroVision 2006, July 31-August 4, Portland, Oregon.

*Savitt Schwartz, S. (ed). 2005. Proceedings of the hydrokinetic and wave energy technologies technical and environmental issues workshop. October 26-28, 2005. U.S. Department of Energy, Washington, DC.

Skalski, J.R., R.L. Townsend, and Normandeau Assoc., Inc. 2005. Quantitative evaluation of the performance of the new advanced hydro turbine system at Wanapum Dam, Columbia River, Washington. Report prepared for Public Utility District No. 2 of Grant County, Epharta, Washington, August 16, 2005.

Smith, B.T, M.J. Sale and H.I. Jager, 2006, Optimization of Hydropower Resources

*Weiland, M.A., R.P. Mueller, T.J. Carlson, Z.D. Deng, C.A. McKinstry. 2005. Characterization of bead trajectories through the draft tube of a turbine physical model. PNNL-14879, prepared for the U.S. Department of Energy, Office of Energy Efficiency and Renewable Energy, Wind and Hydropower Technologies by Pacific Northwest National Laboratory, Richland, WA.

\subsection{Other Publications and Presentations}

Bevelhimer, M. S., and S. M. Adams. 2005. Using proteomics as a basis for assessing multiple environmental stressors. Annual Meeting of the American Fisheries Society. Anchorage, Alaska, September 11-15, 2005.

Cada. G.F. Fish passage research by the U.S. Department of Energy. USFWS/USGS Workshop on Future Fish Passage Management and Research Needs, Hadley, Massachusetts, December 7-8, 2004.

Cada, G.F. and E. Meyer. Characterizing natural streams. Hydrokinetic and Wave Energy Technologies Technical and Environmental Issues Workshop, Washington, DC, October 26-28, 2005.

Cada, G.F. Environmental performance of advanced turbines. Workshop on Advanced Turbine Research and Deployment. Albany, New York, November 15, 2005.

Cada, G.F. Developing biocriteria to ensure safe fish passage. Symposium on Optimizing Dam Operations for Fish and for Power. HydroVision 2006 Conference, Portland, Oregon, July 31, 2006. 
Carlson, T.J. 2006. Pressure investigations using sensor fish and hyperbaric testing- HydroVision 2006, Portland, OR

Deng, Z. 2006. Evaluation of blade strike models as a means to estimate the biological performance of Kaplan turbines - HydroVision 2006, Portland, OR

*Deng Z., M.C. Richmond, R.P. Mueller, J.P. Duncan, and T.J. Carlson. 2005. Laboratory study of biological response of juvenile salmon subjected to turbulent shear flows. In Proceedings of Waterpower XIV, Advancing Technology for Sustainable Energy, Austin, Texas, July 18-22, 2005, 15 pp. HCI Publications, Kansas City, MO.

Dresser, T, C. Dotson, R. Fisher, M. Graf, M.C. Richmond, C.L. Rakowski, T.J. Carlson, D. Mathur, and P. Heisey. 2005. Wanapum Dam Advanced Hydro Turbine Upgrade Project: Part 2 Evaluation of fish passage test results using computational fluid dynamics. HydroVision 2006, Portland, OR.

Hall, D.G. 2005, Virtual Hydropower Prospector - window on United States water energy resources Tools for Small Hydro Site Assessment and Design Workshop, Waterpower XIV Conference, Austin, TX, July 2005.

Hall, D.G. 2006. Virtual Hydropower Prospecting - a foundation for water energy resource planning and development, National Hydropower Association Conference, Washington, DC, April 2006.

Hall, D.G. 2006. Tools for water energy resource planning and development, Innovative Small and Medium Hydro Technologies Workshop, HydroVision Conference, Portland, OR, August 2006.

Paik, J. and F. Sotiropoulos, Coherent vortex shedding in turbulent flow past a long surface-piercing block at the side of a shallow open channel. 4th Conference on Bluff Body Wakes and VortexInduced Vibration, Santorini, Greece, June 21-24, 2005

Paik, J. and F. Sotiropoulos, Detached-eddy simulation of the horseshoe vortex system. Wither Turbulence Prediction and Control, Seoul, Korea, March 26-29, 2006

Paik, J., C. Escauriaza, and F. Sotiropoulos, Simulation of Junction Flows with Coherent Structure Resolving Turbulence Models, 2nd International Conference From Scientific Computing to Computational Engineering, Athens, Greece, July, 5-8, 2006.

Sale, M. J., Status of the DOE-EE Hydropower Program. Presentation to the Corps of Engineers, Engineering and Design Center, Vicksburg, MS, June 5, 2005.

Sale, M. J. History of the DOE-Industry Turbine Program. Invited presentation at a Workshop on Advanced Turbine Research and Development, sponsored by the National Hydropower Association and EPRI, Albany, NY, November 15, 2005.

Sale, M. J, and M. Hightower, The Energy-Water Nexus, presentation to the National Science and Technology Council, Subcommittee on Water Availability and Quality, Washington, DC, December 14, 2005.

Sale, M.J. Innovations for hydropower and other renewables: potential benefits to the Energy-Water Nexus. IN Proceedings, Increasing Freshwater Supplies, Annual Conference of the Universities Council on Water Resources, Santa Fe, NM, July 18, 2006. 
Sale, M. J., G. F. Cada, D. D. Dauble, and D. G. Hall. Historical perspective on DOE's Hydropower Program. Poster presentation at HydroVision 2006, Portland, OR, August 2, 2006.

Smith, B.T., F. Sotiropoulos, and M. J. Sale, Improving hydropower turbines with new hydraulic science. Presentation to the National Hydropower Association's Hydraulic Power Committee, Blacksburg, VA, February 14, 2006.

Smith, B.T., M.J. Sale, and F. Sotiropoulos. Improving hydraulic turbines with better science: a research agenda for hydraulic studies of turbine design and performance. Future Program Planning Workshop, CEATI Hydraulic Plant Life Interest Group, Chattanooga, TN, February 23, 2006.

Smith, B.T. and Sale, M.J. Measurement and Analysis of Unsteady Flow in Hydro Intakes and Draft Tubes. HydroVision 2006, Portland, OR, August 3, 2006. 


\subsection{Contact Information}

For more information about the DOE Hydropower Program, contact the following people:

\section{Jim Ahlgrimm, Hydropower Technology}

U.S. Department of Energy

Office of Wind and Hydropower Technologies

Energy Efficiency and Renewable Energy

1000 Independence Ave., SW

Washington DC 20585

Phone: (202) 586-9806

E-mail: jim.ahlgrimm@ee.doe.gov

\section{Michael J. Sale, ORNL Hydropower coordinator}

Oak Ridge National Laboratory

P. O. Box 2008, MS-6036

Oak Ridge, TN 37932

865-574-7305

E-mail: salemj@ornl.gov

\section{Dennis D. Dauble, PNNL Hydropower contact}

Director, Natural Resource Division

Environmental Technology Directorate

Battelle, Pacific Northwest National Laboratory

P.O. Box 999

Richland, WA 99352

Phone: (509) 376-3631

E-mail: dd.dauble@pnl.gov

\section{Douglas G. Hall, INL Hydropower contact}

Battelle Energy Alliance

P.O. Box 1625

MS 3830

Idaho Falls, ID 83415-3830

Phone: (205) 526-4311

E-mail: dgh@inel.gov 



\section{ORNL/TM-2006/97}

\section{INTERNAL DISTRIBUTION}

1. M. S. Adams

2. M. S. Bevelhimer

3. G. F. Cada

4. B. A. Fost

5. R. A. Hawsey

6. G. K. Jacobs

7. H. I. Jager

8. J. M. Loar
9. M. K. McCracken

10. G. W. Morris

11-15. M. J. Sale

16. B. T. Smith

17. ESD Library

18. ORNL Central Research Library

19. ORNL Laboratory Records CRC

\section{EXTERNAL DISTRIBUTION}

20. Thomas L. Acker, College of Engineering and Natural Resources, Northern Arizona University, 15600 S. McConnell Dr., Engr. Bldg 69, Flagstaff, AZ 86011-5600

21. Jim Ahlgrimm, EE-2B, U.S. Department of Energy, Office of Wind \& Hydropower Technologies, Room 5H/072 FORS, 1000 Independence Ave., SW, Washington, DC 20585

22. Martin Ahmann, U.S. Army Corps of Engineers, 201 North Third Avenue, Walla Walla, WA 99362-1876

23. Paul Bernhardt, Brookfield Power, 225 Greenfield Parkway, Suite 201, Liverpool, NY 13088

24. Peggy Brookshier, U.S. Department of Energy, 1955 Fremont Ave. MS-1220, Idaho Falls, ID 83401-1220

25. Stephen Brown, Grant County PUD, P.O. Box 878, Ephrata, WA 98823

26-27 Stanley Calvert, EE-2B, US Department of Energy, Office of Wind \& Hydropower Technologies, Room 5H/072 FORS, 1000 Independence Ave., SW, Washington DC 20585

28. Tom Carlson, Pacific Northwest National Laboratory, 620 S.W. 5th Avenue, Suite 810, Portland, OR 97204

29. Peter Christensen, R2 Resource Consultants, 15250 NE 95th Street, Redmond, WA 98052

30. Bill Christman, Chelan County PUD, 327 North Wenatchee Ave., P.O. Box 1231, Wenatchee, WA 98801

31. Ron Corso, Mead \& Hunt, Inc., 904 Farley Court, S.E., Vienna, VA 22180-5916

32. Dennis D. Dauble, Pacific Northwest National Laboratory, Battelle Boulevard, P.O. 999, Richland, WA 99352

33. Zhiqun Deng, Battelle, Pacific Northwest Laboratory, P.O. Box 999/K9-33, Richland, WA 99352

34. Doug Dixon, EPRI, 7905 Berkeley Drive, Gloucester Point, VA 23062

35. Steve Doret, Mill Road Engineering, 23 Mill Road, Westborough, MA 01581 
36. Laurie L. Ebner, U.S. Army Corps of Engineers, P.O. Box 2946 , Portland, OR 97208-2946

37. John W. Ferguson, National Marine Fisheries Service, Northwest Fisheries Center, 2725 Montlake Boulevard, East Seattle, WA 98112

38. Douglas Hall, Idaho National Laboratory, P.O. Box 1625, Idaho Falls, ID 83415-3830

39. Kenneth Ham, Battelle, Pacific Northwest Laboratory, P.O. Box 999/MS K6-85, Richland, WA 99352

40. Tim Hanrahan, Battelle, Pacific Northwest Laboratory, P.O. Box 999/MS K6-85, Richland, WA 99352

41. Scott Hendricks, Georgia Power Company, Environmental Laboratory, 5131 Maner Road, Smyrna, GA 30080

42. Jennifer Hill, Federal Energy Regulatory Commission, 888 First Street, N.E., Washington, DC 20426

43. Gary E. Johnson, Battelle, Pacific Northwest Laboratory, P.O. Box 999/BPO, Richland, WA 99352

44. Mike Langeslay, U.S. Army Corps of Engineers, P.O. Box 2946, Portland, OR 97208-2946

45. Charles R. Liston, Consultant, 168 Ralston Road, Bedford, KY 40006

46. Edward Meyer, National Marine Fisheries Service, 525 N.E. Oregon St., Suite 500, Portland, OR $97232-2737$

47. Cloe A. Luckett, Centre College, 600 W. Walnut Street, Danville, KY 40422

48. Lawrence B. Moore, Southern Services Company, 42 Inverness Center Parkway, Birmingham, AL 35242

49. Russ Moursund, Battelle, Pacific Northwest Laboratory, P.O. Box 999/MS K6-85, Richland, WA 99352

50. Thomas R. Murphy, Federal Hydro Projects, Bonneville Power Administration, PGF/6th Floor, P.O. Box 3621, Portland, OR 97208-3621

51. Joongcheol Paik, University of Minnesota, St. Anthony Falls Laboratory, Mississippi River at 2 Third Avenue, SE, Minneapolis, MN 55414

52. William Perkins, Battelle, Pacific Northwest Laboratory, P.O. Box 999/MS K9-36, Richland, WA 99352

53. Gene Ploskey, Battelle, Pacific Northwest Laboratory, P.O. Box 999, Richland, WA 99352

54. Cynthia Rakowski, Battelle, Pacific Northwest Laboratory, P.O. Box 999/MS K9-33, Richland, WA 99352

55. Marshall Richmond, Battelle, Pacific Northwest Laboratory, P.O. Box 999/MS K9-33, Richland, WA 99352

56. John Serkowski, Battelle, Pacific Northwest Laboratory, P.O. Box 999/MS K9-33, Richland, WA 99352

57. Fotis Sotiropoulos, University of Minnesota, St. Anthony Falls Laboratory, Mississippi River at 2 Third Avenue, SE, Minneapolis, MN 55414

58. Rod Wittinger U.S. Army Corps of Engineers, P.O. Box 2946, Portland, OR 97208-2946 


\section{A Strong Energy Portfolio for a Strong America}

Energy efficiency and clean, renewable energy will mean a stronger economy, a cleaner environment, and greater energy independence for America. By investing in technology breakthroughs today, our nation can look forward to a more resilient economy and secure future.

Far-reaching technology changes will be essential to America's energy future. Working with a wide array of state, community, industry, and university partners, the U.S. Department of Energy's Office of Energy Efficiency and Renewable Energy invests in a portfolio of energy technologies that will:

- Conserve energy in the residential, commercial, industrial, government, and transportation sectors

- Increase and diversify energy supply, with a focus on renewable domestic sources

- Upgrade our national energy infrastructure

- Facilitate the emergence of hydrogen technologies as vital new "energy carriers."

\section{The Opportunities}

Biomass Program

Using domestic, plant-derived resources to meet our fuel, power, and chemical needs

Building Technologies Program

Homes, schools, and businesses that use less energy, cost less to operate, and ultimately, generate as much power as they use

Distributed Energy \& Electric Reliability Program

A more reliable energy infrastructure and reduced need for new power plants

Federal Energy Management Program

Leading by example, saving energy and taxpayer dollars in federal facilities

FreedomCAR \& Vehicle Technologies Program

Less dependence on foreign oil, and eventual transition to an emissions-free, petroleum-free vehicle

Geothermal Technologies Program

Tapping the Earth's energy to meet our heat and power needs

Hydrogen, Fuel Cells \& Infrastructure Technologies Program

Paving the way toward a hydrogen economy and net-zero carbon energy future

Industrial Technologies Program

Boosting the productivity and competitiveness of U.S. industry through improvements in energy and environmental performance

Solar Energy Technology Program

Utilizing the sun's natural energy to generate electricity and provide water and space heating

Weatherization \& Intergovernmental Program

Accelerating the use of today's best energy-efficient and renewable technologies in homes, communities, and businesses

Wind \& Hydropower Technologies Program

Harnessing America's abundant natural resources for clean power generation

To learn more, visit www.eere.energy.gov 